\title{
From polarity in flies to hearts in mice : the wnt- frizzled cascade in cardiac wound healing
}

Citation for published version (APA):

van Gijn, M. E. (2001). From polarity in flies to hearts in mice : the wnt-frizzled cascade in cardiac wound healing. [Doctoral Thesis, Maastricht University]. Datawyse / Universitaire Pers Maastricht. https://doi.org/10.26481/dis.20010920mg

Document status and date:

Published: 01/01/2001

DOI:

10.26481/dis.20010920mg

Document Version:

Publisher's PDF, also known as Version of record

\section{Please check the document version of this publication:}

- A submitted manuscript is the version of the article upon submission and before peer-review. There can be important differences between the submitted version and the official published version of record.

People interested in the research are advised to contact the author for the final version of the publication, or visit the DOI to the publisher's website.

- The final author version and the galley proof are versions of the publication after peer review.

- The final published version features the final layout of the paper including the volume, issue and page numbers.

Link to publication

\footnotetext{
General rights rights.

- You may freely distribute the URL identifying the publication in the public portal. please follow below link for the End User Agreement:

www.umlib.nl/taverne-license

Take down policy

If you believe that this document breaches copyright please contact us at:

repository@maastrichtuniversity.nl

providing details and we will investigate your claim.
}

Copyright and moral rights for the publications made accessible in the public portal are retained by the authors and/or other copyright owners and it is a condition of accessing publications that users recognise and abide by the legal requirements associated with these

- Users may download and print one copy of any publication from the public portal for the purpose of private study or research.

- You may not further distribute the material or use it for any profit-making activity or commercial gain

If the publication is distributed under the terms of Article $25 \mathrm{fa}$ of the Dutch Copyright Act, indicated by the "Taverne" license above, 
From polarity in flies to hearts in mice 
(C) M.E. van Gijn, Maastricht 2001 ISBN $905278311 \mathrm{X}$

Printed by: Datawyse / Universitairc Pers Maastricht Cover Design by J. van Gijn-Versfelt 


\title{
FROM POLARITY IN FLIES TO HEARTS IN MICE
}

The wnt-frizzled cascade in cardiac wound healing

\author{
PROEFSCHRIFT \\ ter verkrijging van de graad van doctor \\ aan de Universiteit Mastricht, \\ op gezag van de Rector Magnificus \\ Prof.dr. A.C. Nieuwenhuij»en Kruseman, \\ volgens het besluit van het College van Decanen, \\ in het openbaar te verdedigen \\ op donderdag 20 september 2001 om 12.00 uur \\ door \\ Maria Elisabeth van Gijn \\ geboren op 21 februari 1970 te Dordrecht
}

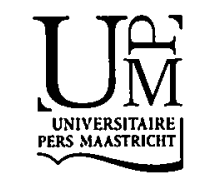




\section{Promotores}

Prof.dr. J.F.M. Smits

\section{Co-promotor}

Dr. W.M. Blankesteijn

\section{Beoordelingscommissie}

Prof.dr. M. Borgers (voorzitter)

Prof.dr. M.J.A.P. Dacmen

Prof.dr. J.C. Clevers (UMC)

Prof.dr. H.J.G.M. Crijns

Prof.dr. A.C. (iittenberger-de Groot (IUUMC)

Financial support by the Netherlands Heart Foundation for the publication of this thesis is gratefully acknowledged. 
- 


\section{List of abbreviations}

\begin{tabular}{|c|c|c|c|}
\hline $\begin{array}{l}A P C \\
B S A\end{array}$ & adcnomatous polyposis coli & MLCK & $\begin{array}{l}\text { madin darby canine kidney cell } \\
\text { linc }\end{array}$ \\
\hline $\mathrm{CHO}$ & chinese hamster ovary cell line & MoMlul,' & moloncy murinc leukemia virus \\
\hline $\cos 7$ & $\begin{array}{l}\text { african green monkey kidney cell } \\
\text { line }\end{array}$ & $\begin{array}{l}\text { NB' } \\
\text { OH }^{\circ}\end{array}$ & $\begin{array}{l}\text { nitroblue tetrazolium } \\
\text { outflow tract }\end{array}$ \\
\hline CRD & cystcin-rich domain & PBS & phosphate-buffered saline \\
\hline$D A B$ & diaminoben\%idinc & PC12 & pheochromocytoma derived \\
\hline DEP & dishevelled-egl 10-pleckstrin & & cell line \\
\hline DGS & DiGcorge syndrome & \multirow[t]{2}{*}{ PCNA } & proliferating cell nuclear \\
\hline DIG & digoxygenin & & antigen \\
\hline $\mathrm{DIX}$ & dishevelled-axin & PCR & polymerasc chain reaction \\
\hline DMEN & $\begin{array}{l}\text { dulbecco's modified eagle } \\
\text { medium }\end{array}$ & PIZ & $\begin{array}{l}\text { PSD-95/SAP90, discs- } \\
\text { large, } Z \mathrm{OO}-1\end{array}$ \\
\hline DNA & deoxyribonuclcic acid & \multirow[t]{2}{*}{ PECAMI } & platelet-cndothelial cell \\
\hline D'IT & dithiothreitol & & adhesion molcculc \\
\hline DV'L. & dishevelled & \multirow[t]{2}{*}{ P-JNK } & phosphorylated c-Jun \\
\hline EGF & cpidermal growth factor & & N-terminal kinasc \\
\hline [i] & epicardium & $\mathrm{PKC}$ & protcin kinasc C \\
\hline l:Gl: & fibroblast growth factor & $\mathrm{PP}$ & protcin phosphatase \\
\hline FRPs & frizzled related proteins & RGS & regulators of $\mathrm{G}$ protein \\
\hline $1 \%$ & frimzled & & signaling \\
\hline GAPDH & $\begin{array}{l}\text { glyceraldehyde-3phosphate } \\
\text { dehydrogenases }\end{array}$ & \multirow[t]{2}{*}{$\begin{array}{l}\mathrm{RNA} \\
\mathrm{R} \mathrm{I}^{\prime}-\mathrm{P} C \mathrm{CR}\end{array}$} & $\begin{array}{l}\text { ribonucleic acid } \\
\text { reverse transcriptase }\end{array}$ \\
\hline GSK $3-\beta$ & glycogen-synthase kinase $3-\beta$ & & polymerase chain reaction \\
\hline Gl' & granulation tissuc & R' & right ventricle \\
\hline GIP & guanosine tiphosphate & SAPK & stress activated protcin kinase \\
\hline $\mathrm{HBH},-100$ & human breast epithelial cell line & $S \wedge R P$ & secreted apoptosis related \\
\hline $\mathrm{HE}$ & hematoxylin and cosin & & protcin \\
\hline $\mathrm{HIF}^{*}$ & hypoxia-jnducible factor & SIFRP & sccreted frizoled-like protein \\
\hline $\mathrm{HI},-60$ & human leukoemic cell line & SHAM & sham operated animals \\
\hline $\mathrm{HMG}$ & high mobility group & $\mathrm{SN}$ & smooth muscle \\
\hline HPI.C & high performance liquid & $\mathrm{SP}$ & substance P' \\
\hline & chromotography & $\mathrm{TCF}$ & l'-cell factor \\
\hline HRP & horsradish peroxidase & TGI:- $\beta$ & transforming growth factor- $\beta$ \\
\hline hsleRP & human secreted frizzled related & TIN"P & tissuc inhibitors of MMIPs \\
\hline & protcin & IMIB & tetramethyl benzidinc \\
\hline HUVEC & human umbilical vein & INF & tumor necrosis factor \\
\hline $\mathrm{IGF}^{2}$ & $\begin{array}{l}\text { cndothclial cell } \\
\text { insulin-like growth factor }\end{array}$ & IUNEI. & tdt-mediated dU'P-X nick end \\
\hline JNK & c-Jun N-tcrminal kinase & U'TP & uridine triphe \\
\hline $\mathrm{I} A \mathrm{DD}$ & left anterior descending (artery) & V'Cl:S & velo-cardio-facial syndrome \\
\hline 1.EF & lymphoid cnhancing factor & Y'E & vascular cndothclium \\
\hline MI & myocardial infarction & Y'EGI' & vascular endothelial growth \\
\hline MMP & matrix metalloproteinase & & \\
\hline & & WC & wingless \\
\hline
\end{tabular}




\section{Contents}

Chapter 1

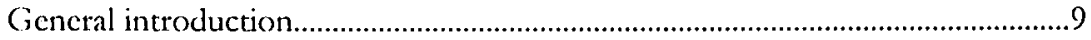

Chapter 2

lirizzled expression in the mouse heart after MI............................................ 31

Chapter 3

Frizzled 2 RN $\Lambda$ cxpression and protcin localization in intestinal epithelial cells during their migration along the villi.

Chapter 4

Frizzled 2 is transicntly expressed in ncural crest containing arcas during

development of the heart and great arteries in the mouse.

Chapter 5

Possible signal transduction pathways of frizzled 2 in myofibroblasts in the healing infarct.

Chapter 6

Overexpression of components of the wnt-frizzled cascade results in apoptotic cell death, mediated by $\beta$-catenin

Chapter 7

libroblast alignment in vitro, is there a role for frizzled?

Chapter 8

Beta-catenin, an inducer of uncontrolled cell proliferation and migration in malignancies, is localized in the cytoplasm of vascular endothelium during neovascularization after myocardial infarction.

Chapter 9

$\Lambda$ bsence of $\beta$-catenin in intercalated disks between cardiomyocytes is associated with infarct rupture in dishevelled-1 knockout mice

Chapter 10

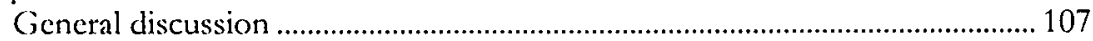

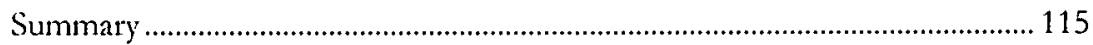

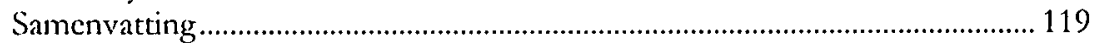

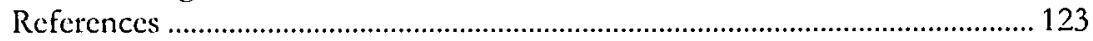

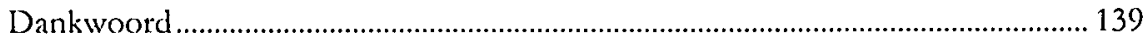

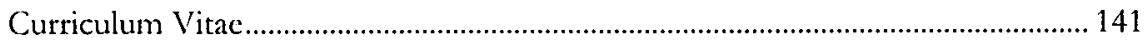



Chapter 1

\section{GENERAL INTRODUCTION}




\section{General introduction}

Myocardial infarction (MI) is one of the main causes of mortality and morbidity in Western countrics. It is the result of an interruption of the coronary blood flow, usually resulting from atherosclcrosis and thrombolic occlusion of a coronary artery. Because treatment of acute MI with anti-arrhythmic and thrombolytic agents has improved over the years, the number of people that die during the acute phase of $\mathrm{MI}$ is decreasing. Patients that have recovered from MI frequently have a reduced cardiac output. This reduction activates cardiac compensatory mechanisms. These mechanisms initially compensatc the impaired function, but often result in further deterioration of the heart leading to congestive heart failure'. Heart failure is a progressive disorder with a poor prognosis ${ }^{2}$. Because little is known about the mechanisms leading to heart failure, current therapy is aimed at relieving the symptoms rather than curing the causc.

Understanding the development of congestive heart failure following MI is important for a rational approach to thcrapy. Most studics have focused on the limitation of muscle injury and prevention of the progressive dilatation of the viable non-infarcted myocardium, that occurs in the months after MI. Less attention has been paid to the infarct area, which also contributes to the dilatation of the ventricle.

Recent studies indicate that infarct healing is a dynamic process. The granulation tissuc, which eventually matures into the scar, is a cellular, vascularized, metabolically active and contractile tissuc ${ }^{3}$. Infarce healing appears to be a well-controlled process, constituting a potential target for therapcutic interventions.

This thesis focuses on genes known to be involved in architectural control, the so-called tissuc polarity genes of the frizzled (fz) family, in the heart, with special emphasis on the healing process after MI. In this chapter, the wound healing after MI will be discussed, with focus on the architecture of the devcloping scar. Attention will be paid to the tissuc polarity gene $f \%$ and its signal transduction cascadc. liurthermorc, the role of this cascade in cardiac development and after myocardial infarction will be discussed. Finally, the aim of the present thesis will be outlined.

\section{Wound healing after MI}

The wound healing process after MI is a complex cascade of events. Cardiomyocyte nccrosis and an acute inflammatory response occur in the infarct arca. Invaded mononuclear cells differentiate into macrophages, which are responsible for removing the necrotic cells. Fibroblast-like and endothclial cells migrate into the infarct area and start to proliferatc. The fibroblast-like cells are responsible for the deposition of extraccllular matrix in the granulation tissue, whercas the endothelial cells are involved in the neovascularization to restore the blood supply to the areat. In a later phase most of the infiltrated cells disappear and additional extracellular matrix is deposited. This process is referred to as the 
Figure I. Time course of the wound healing response after myocardial infarction in rat and mice. (A) In the first hours cardiomyocytes die due to necrosis or apoptosis. (B) About 24 hours after the onset of the infarct, polymorphonuclear neutrophils infiltrate the necrotic area. (C) After $1-2$ weeks the infarct contains granulation tissue with prominent capillaries. myofibroblasts and macrophages. The necrotic debris has been largely removed and collagen has been deposited. (D) Starting at about 3 weeks after Ml, the granulation tissue matures into a scar.

maturation of the scar. Different aspects of infarce healing are depicted in fig. 1 and will be discussed below.

\subsection{Cell death}

Cardiomyocytes loss after acute MI has long been thought to result from necrosis. While this form of cell death remains the most important cause of the tissue injury after MI, recent studies have suggested that apoptosis or programmed cell death also contributes to the cell $\operatorname{loss}^{5.9}$. $A$ clear discrimination between apoptosis and necrosis can not be made. Therefore myocardial cell death after MI has been classified in three forms: necrosis or oncosis, apoptosis and a combination of apoptosis and necrosis". ". Cardiomyocyte necrosis has been thought to be an irreversible form of cell death, whereas apoptosis is thought to be reversible towards a certain point ${ }^{3-11}$.

Another reversible form of cardiomyocyte dysfunction in the borderzone of the infarce area is cardiomyocyte dedifferentiation ${ }^{2}$. Dedifferentiation, often referred to as hibcrnating myocardium, results from hypoxia duc to a chronic or repetitive underperfusion accompanied by a limited coronary flow reserve ${ }^{12}$. The precise mechanism of cardiomyocyte death and dedifferentiation after MI are beyond the scope of the present thesis and therefore will not be further discussed in this chapter. $\Lambda$ poptosis is also important in later phases of infarct healing; it is involved in the disappearance of infiltrated mono- and leukocytes, endothelial cells and the fibroblast population in the healing infarct ${ }^{13}$.

\subsection{Cell proliferation}

The loss of viable cardiomyocytes after MI results in an increased workload on the remaining cardiomyocytes. To compensate for the lost cells, the remaining cardiomyocytes undergo hypertrophy as carly as threc days after $\mathrm{MI}^{1.4}$. Although cardiomyocytes are thought to be terminally differentiated cells and therefore have lost their capability to divide, cardiomyocyte hyperplasia has also been described after $\mathrm{MI}^{15}$.

Experiments in rats and mice have shown that DN $\Lambda$ synthesis significantly increases after $\mathrm{MI}$, but less than $2 \%$ of the DNA synthesizing cells are cardiomyocytes ${ }^{16.1}$. Increased DNA synthesis was exhibited mainly by fibroblasts, whereas cndothelial cell DNA synthesis contributed approximately $30 \%$ to the 
ovcrall increase ${ }^{16}$. I'our days after infarction fibroblasts start to proliferate, transform into myofibroblasts and migrate into the infarct area. Myofibroblasts have characteristics of both fibroblasts and smooth muscle cells in that they synthesize extracellular matrix proteins but also have contractile properties. These cells have been shown to be predominantly responsible for the collagen formation at the infarct site in the rat heart ${ }^{18}$. It has been suggested that the contractile properties of myofibroblasts contribute to the wound healing process by preventing the dilatation of the infarct arca". 2". Proliferation of the endothelial cells suggests the formation of new or the remodeling of pre-existing capillarics.

\section{Architectural alterations in the infarct area}

MI leads to complex architectural alterations, involving ventricular thinning, dilatation, fibrosis and angiogenesis. Expansion of the infarcted myocardium also contributes to dilatation and thinning of the ventricle ${ }^{21}$. During the first weck, infarct expansion is characterized by stretching and slippage of cardiomyocytes and is related to degradation of the extraccllular matrix. $\Lambda$ second phase, lasting for more than 6 wecks, consists of progressive dilatation of the immature scar. Extensive infarct expansion is associated with the development of congestive heart failure, ancurysm formation and myocardial rupture ${ }^{1,22}$.

Increasing evidence indicates that interference in the healing process after infarction can alter ventricular remodeling ${ }^{23,24}$. In order to develop a proper therapy to prevent infarct thinning and dilatation it is important to understand the genes and signal transduction pathways that are involved in the architcctural control of infarce healing.

\subsection{Neovascularization}

After MI, new blood vessels penetrate the necrotic area and the surrounding ischemic tissue to restore the blood flow to the infarct arca. This ncovascularization, comprizing of both angiogenesis and arteriogenesis, is a prerequisite for the development of granulation tissuc in the infarce arca ${ }^{25}, 26$.

The exact mechanism of the neovascularization process is starting to be unraveled. Hypoxia and other, poorly defined, factors stimulate cells to produce angiogenic molecules such as vascular endothelial growth factor (VEGH), fibroblast growth factors (FGl's), transforming growth factor- $\beta$ (TGF- $\beta$ ) and others ${ }^{27}{ }^{2 x}$. VEGI and FGFs have a direct cffect on the cndothelial cells, but TGF- $\beta$ activates the inflammatory cells, which in turn control angiogencsis ${ }^{27}{ }^{28}$. The expression of hypoxia-inducible factor-1 (HIF-1), a transcriptional activator of VEGF, was detected in myocardial tissue with evidence of acute ischemia or carly infarction, suggesting a role for this transcription factor after $\mathrm{MI}^{29}$. Studics in animal models of ischemia have proven the feasibility of enhancing collateral function by delivery of angiogenic factors and the field of therapcutic angiogenesis is currently moving from preclinical investigations to clinical trials ${ }^{31}$. 


\subsection{The collagen network}

The collagen network is a major contributor to the prescrvation of the myocardial architecture and chamber geometry and plays a role in global ventricular remodeling". Scar formation is the net result of a delicate balance between collagen degradation and synthesis ${ }^{i 2}$. Collagen degradation after MI involves a family of genes encoding matrix metalloproteinases (MMPs) which mediate degradation of fibrillar collagen ${ }^{18.3}$. The expression of MMPs is upregulated during infarct healing ${ }^{33}$. The upregulation of MMP expression results in MMP production, but matrix degradation requires the latent enzymes to be activated by proteolytic cleavage. Several activation mechanisms and activators have been described, but the most important mechanism afrer $M I$ is the activation by plasmin ${ }^{3.4 .35}$. Plasmin is generated from plasminogen by plasminogen activators. Activated MMPs can be inhibited by tissue inhibitors of MMP's (TIMPs) ${ }^{33}$.

In mice, the deletion of the plasminogen ${ }^{3-1}$ or $\mathrm{uP}^{\mathrm{P}} \Lambda^{35}$ gene abolishes wound healing following MI and diminishes thinning of the infarcted wall. Furthermore, inhibition of plasminogen activators or MMPs prevents cardiac rupture ${ }^{35}$. MMP inhibition after MI also reduces the extent of left ventricular dilatation ${ }^{37}$. Intervention in the MMP cascade could therefore be promising for therapcutic applications. Care should be taken, however, as angiogenesis following MI and cardiac function are also impaired in these mice ${ }^{35}$.

\subsection{Myofibroblast alignment after MI}

A part from the extracellular matrix, myofibroblasts play another important role in the preservation of the myocardial architecture; their contractile properties likely prevent the scar from dilatation. Myofibroblasts are oricnted parallel with the force that the scar is subjected to, which is thought to be necessary to cope effectively with the strain. Based on these observations, a large number of myofibroblasts, aligned in the proper orientation, can be anticipated to contribute to the tensile strength of the scar. Little attention, however, has so far been given to the mechanisms that lead to their orientation in the tissuc.

Cell alignment or polarity in gencral means that the cytoskeleton of the cell is directed to an extracellular reference point, for example a neighbor cell. The process implicates several molecular components such as adhesion receptors, cytoskeletal linking proteins, and extracellular matrix ligands. In a previous study, we have found that during the alignment and migration process of myofibroblasts after MI, the expression of a homologue of the tissue polarity gene fz was upregulated $^{\text {is }}$. In the following part, $f z$ and its mechanism of action will be discussed.

\section{Frizzled and its cascade}

The f7 tissue polarity genes consist of a family with multiple members, encoding 7-transmembrane receptors. Their function and signal transduction cascade are far from being completely understood. Most studies have been done in Drosophila and Xenopus. The downstream elements of the wnt-fz signal transduction pathway 
have first been identified in Drosophila and have been shown to be conserved and to function in the mammalian system ${ }^{39}$, 40. The homologues of the signal transduction molecules of different species have been given different names. The abbreviations for these members for some species are given in table 1 .

The $\mathrm{fz}$ proteins, their secreted homologues, ligands and different components of the signal transduction pathway will be discussed below.

Table I. Nomenclature of Frizzled signal transduction components in different species

\begin{tabular}{|c|c|c|c|}
\hline & Drosophila & Xenopus & Mammals \\
\hline Wnt Mingless & $w g$ & xwnt & wnt \\
\hline Frizzled & fzor ofz & $x f z$ & $f \geq$ or FZD \\
\hline Dishevelled & dsh & xdsh & $d v 1$ \\
\hline Glycogen Synthase Kinase- $3 \beta$ / Zeste-white 3 & $2 \times 3$ & $x G S K-3 \beta$ & GSK-3 $\beta$ \\
\hline$\beta$-catenin/ Armadillo & Arm & $\beta$-catenin & $\beta$-catenin \\
\hline
\end{tabular}

\subsection{The frizzled genes}

The $f z$ genes are named after the Drosophila tissue polarity gene $f z$, which was the first member of the family to be isolated. Epithelial structures, such as the wing hairs and ommatidia in Drosophila, are aligned in the plane of the epithelium. This planar polarity requires the coordination of the local orientation of cells with respect to their neighbors. During the development of wing hair-polarity in Drosophila $\mathrm{fz}$ genes coordinate the alignment process ${ }^{41}$. $\mathrm{Fz}$ has two different functions; it is responsible for polarization of the cytoskeleton of the cell itself and for relaying the signal to adjacent cells ${ }^{42}$. Fzs can be found in invertebrates and vertebrates. In Drosophila four $\mathrm{fz}$ homologues have been described. The ten $\mathrm{fz}$ homologues so far identified in mammals are listed in table 2.

$\mathrm{Fz}$ proteins are receptors that have an $\mathrm{N}$-terminal extracellular cystein-rich domain, seven transmembrane spanning regions and an intracellular $\mathrm{C}$-terminal domain $^{40}$, depicted in fig. 2. The extracellular cysteinrich domain is a conserved domain of 120 amino acids containing 10 invariant cysteins, suggesting that this region contains a number of disulfide bonds ${ }^{40}$. This domain is implicated in ligand binding. In fig. 3 the phylogenetic tree of the cystein-rich domains of different fzs and secreted homologues is shown. Although $\mathrm{fz}$ proteins have seven membrane spanning regions like G-proteins, the transmembrane regions of $\mathrm{f} z$ show no primary sequence homology with G-protein coupled receptors, and they lack the most conserved motifs that are found in nearly all G-protein coupled receptors ${ }^{40}$.

FZ

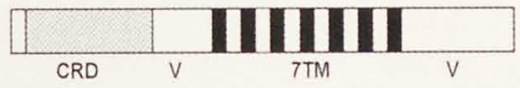

FRP

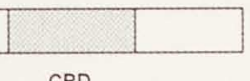

Figure 2. Schematic representation of the receptor frizzled (FZ) and the secreted frizzled related protein (FRP). CRD=cystein-rich domain, $V=$ variable domain, 7TM=seven -transmembrane domaine, (adapted from http://www.ana.ed.ac.uk/ musse/wntwindow.html). 
Table 2. Mammalian frizzled homologues and their expression pattern

\begin{tabular}{|c|c|c|c|c|}
\hline Gene (mouse) & $\begin{array}{l}\text { Human } \\
\text { orthologue }\end{array}$ & $\begin{array}{l}\text { Rat } \\
\text { orthologue }\end{array}$ & Wnt interaction & Expression pattern \\
\hline$" f z d \mid=f z l$ & $\left.F \angle D\right|^{45}$ & $R \mathrm{fz}^{46}$ & & $\begin{array}{l}\text { kidney, heart, liver, uterus and } \\
\text { ovary }^{46}\end{array}$ \\
\hline $\mathrm{f}_{\mathrm{z}} \mathrm{d} 2 \mathrm{Mfz} 2^{40}$ & $\mathrm{~F} Z \mathrm{D} 2^{47}$ & $\mathrm{Rf} z 2^{46}$ & & $\begin{array}{l}\text { brain, eye, heart, kidney, lung } \\
\text { and testis }\end{array}$ \\
\hline $\mathrm{fz} d 3=\mathrm{Mfz} 3^{40}$ & ${\mathrm{~F} Z D 3^{48}}^{48}$ & & no wg binding 49 & brain, eye, lung and testis ${ }^{40}$ \\
\hline $\mathrm{fzd} 4=\mathrm{Mfz}_{4}$ & $F Z D 4^{50}$ & & wg binding ${ }^{49}$ & $\begin{array}{l}\text { brain, eye, heart, kidney, liver. } \\
\text { lung and testis }\end{array}$ \\
\hline$f z d 5=M f z 5^{40}$ & $\mathrm{HF} \geq 5^{40}$ & & $\begin{array}{l}\text { wg and } X w n t 5 a \\
\text { binding }\end{array}$ & $\begin{array}{l}\text { eye, heart(low), kidney, liver, } \\
\text { lung, spleen (low) and testis }\end{array}$ \\
\hline$f z d 6=M f z 6^{40}$ & $F Z D 6^{52}$ & & no wg binding ${ }^{49}$ & $\begin{array}{l}\text { brain, eye, heart, kidney, lung } \\
\text { and testis }{ }^{40}\end{array}$ \\
\hline $\mathrm{fz} \mathrm{d} 7=\mathrm{Mfz}^{40}$ & $\mathrm{~F} Z \mathrm{DD}^{45}$ & & wg binding ${ }^{49,53}$ & $\begin{array}{l}\text { brain, eye, heart, kidney, liver, } \\
\text { lung and testis }{ }^{40}\end{array}$ \\
\hline$f z d 8=M f \angle 8^{40}$ & & & Wg binding ${ }^{49}$ & $\begin{array}{l}\text { not detectable in adult } \\
\text { organs }^{40}\end{array}$ \\
\hline$f z d 9=M f z 9^{40}$ & $\begin{array}{l}\text { FZD9 } \\
\text { (previously called } \\
\text { FZD3) }\end{array}$ & & & $\begin{array}{l}\text { brain, heart, skeletal muscle } \\
\text { and testis }{ }^{40}\end{array}$ \\
\hline$* \mathrm{fzd} 10=\mathrm{Mfz} 10^{55}$ & $\mathrm{~F} \angle \mathrm{D} 10^{56}$ & & & $\begin{array}{l}\text { brain, placenta, heart and } \\
\text { lungss }\end{array}$ \\
\hline
\end{tabular}

$$
\begin{aligned}
& \text { FZE3 } \\
& (=F Z D 7 ?)^{45}
\end{aligned}
$$

* The classification of the orthologues of $\mathrm{fzdl}$ and 2 has not been resolved yet (http://www.ana.ed.ac.uk/rnusse/wntwindow.html)

**very similar to Mfz2

The $\mathrm{C}$-terminal regions show little or no homology between the different fzs. The lengths of this domain can range from 25 amino acids in Mfz7 to 200 amino acids in $\mathrm{Mfz}^{40}$. The intracellular C-terminal domain is probably involved in signal transduction $^{43}$. Little is known about the amino acids involved in signal transduction but recently it has been demonstrated that a short conserved C-terminal cytoplasmatic motif (Lys-Thr-X-X-X-Trp) is important for activation of the signaling ${ }^{4}$. 


\subsection{Frizzled ligands and ligand interaction}

\section{W/n/s}

The proposed ligands for the fz receptors are wnts, a family of cystcinc-rich glycosylated proteins that bind to the extracellular domain of $\mathrm{f} z$. The wnt-family in mammals consists of at least 16 members that are involved in processes as diverse as embryonic induction, generation of cell polarity and specification of cell fatc ${ }^{57.58}$. Wnts are difficult to obtain in a soluble, biologically active form and tend to stick

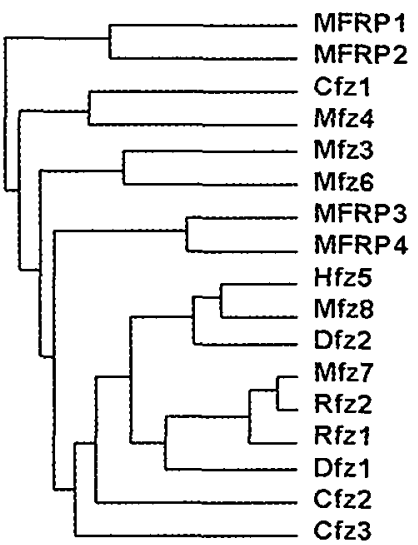

Figure 3. Phylogenetic tree of the cystein-rich domains of different frizzleds $(\mathfrak{f} z)$ and frizzled-related proteins (FRP) in different species. $M=$ mouse, $C=C$-elegans, $H=$ human, $D=$ Drosophila and $R=$ rat. to the extracellular matrix". For this reason, in most studies conditioned culture medium obtained from cells transfected with wnt cDN $\Lambda$ s has been used instead of purificd wnt protein to study the effects of wnts on cell morphology, proliferation, transformation or gene expression.

The apparent functional differences between wnts (table 3) have led to the hypothesis that wnts can be divided into two classes that might employ different signal transduction mechanisms: members of the Xwnt1 class are active in axis duplication assays in Xenopus, whereas members of the Xwnt5a class are not. Instead, overexpression of members of the Xwnt5a class affects morphogenetic movements and may antagonize members of the Xinnt1 class ${ }^{(1,1) \cdot 6.3}$. Nlso other functional parametcrs, like the capability of increasing $\beta$-catenin and to induce cell transformation, have shown that wnts can be divided into two groups (table 3 ).

\section{Wnt-Frizzled interaction}

Much remains to be lcarned about the selectivity and specificity of wnt-fz interaction. Whereas wnt- $f z$ binding specificity may underlic many wnt-class specific effects, it does not reflect the simple division of wnts into two classes. For example $f_{2} 7$ secms to be able to activate either the $\beta$-catenin or the calcium signaling pathway, depending on whether it is expressed alone or together with Xwnt8b $b^{53}$. Furthermore the inability of Xwnt5a to induce a secondary axis in Xenopus can be overcome by co-injection of Hfz.5. When expressed alone, these two components can not induce a secondary axis", which illustrates the synergism of these two components. Moreover, this demonstrates that the lack of activity of a fz or wnt protcin in activating signaling in a particular context may be due to the absence of an appropriate ligand or receptor. 
Table 3. Wht homologues and their functional differences

\begin{tabular}{|c|c|c|c|c|c|c|}
\hline $\begin{array}{l}\text { Mouse } \\
\text { gene }\end{array}$ & $\begin{array}{l}\text { Human } \\
\text { orhtologue }\end{array}$ & $\begin{array}{l}\text { Axis } \\
\text { duplication }\end{array}$ & $\begin{array}{l}\text { Increase } \\
\beta \text {-catenin }\end{array}$ & $\begin{array}{l}\text { Transformation of } \\
\text { C57 or RAC cells }\end{array}$ & $\begin{array}{l}\text { Classi- } \\
\text { fication }\end{array}$ & Null-mutants \\
\hline Wnt $\left.\right|^{64}$ & $\begin{array}{l}\text { WNTI } \\
(\text { INTI })^{64}\end{array}$ & yes $^{65}$ & yes $^{65}$ & yes ${ }^{65}$ & Xwnt I & $\begin{array}{l}\text { midbrain and } \\
\text { cerebellum defects }{ }^{66}\end{array}$ \\
\hline$w n t 2^{67}$ & $\begin{array}{l}\text { WNT2 } \\
(\text { IRP) }\end{array}$ & yes ${ }^{69}$ & yes $^{65}$ & $y_{e s}{ }^{65}$ & Xwntl & placental defects 70 \\
\hline $\begin{array}{l}\text { wnt2B/ } \\
\text { wnt } 13^{71.72}\end{array}$ & WNT $13^{73}$ & & & & & \\
\hline$w n t 3^{14}$ & WNT $3^{68}$ & & yes ${ }^{65}$ & $y_{e s}^{65.75}$ & Xwnt I & $\begin{array}{l}\text { axis formation } \\
\text { defects }^{76}\end{array}$ \\
\hline$w n t 3 A^{77}$ & WNT3A ${ }^{67}$ & yes $^{78}$ & $y_{e s}^{65}$ & $y_{e s}^{65.75}$ & Xwnt I & $\begin{array}{l}\text { absence tail bud and } \\
\text { truncated rostral to } \\
\text { the hindlimbs }\end{array}$ \\
\hline wnt $4^{79}$ & WNT4 $4^{68}$ & no $0^{6 !}$ & $n o^{65}$ & $n 0^{65.75}$ & Xwnt5a & kidney defects ${ }^{80}$ \\
\hline$w n t 5 A^{79}$ & WNT5A & no $0^{63}$ & $n o^{65}$ & no 65.75 & Xwnt5a & truncated limbs ${ }^{82}$ \\
\hline wnt $5 B^{7}$ & & & no & yes/no 65.75 & $?$ & \\
\hline wnt $6^{79}$ & WNT6 & & $n o^{65}$ & nolyes ${ }^{65.75}$ & $?$ & \\
\hline wnt7 $A^{79}$ & WNTIAA ${ }^{84}$ & & $10 w^{65}$ & yes $^{65,75}$ & Xwntl & $\begin{array}{l}\text { limp polarity } \\
\text { defects }^{85}\end{array}$ \\
\hline wnt $7 B^{79}$ & WNT7B ${ }^{68}$ & & no $0^{65}$ & yes/no 65.75 & $?$ & \\
\hline wnt8 $A^{86}$ & & $y_{e s}{ }^{87}$ & & & Xwnt I & \\
\hline wnt8B & WNT8B ${ }^{88}$ & yes $^{89}$ & & & Xwntl & \\
\hline \multicolumn{7}{|l|}{ Wnt $10 A^{90}$} \\
\hline $\begin{array}{l}\text { wnt } 10 \mathrm{~B} / \\
\text { wnt } 12^{90}\end{array}$ & WNTIOB & & & & & \\
\hline wnt $11^{92}$ & WNTII ${ }^{93}$ & yes/no ${ }^{6 i .94}$ & & yes $^{95}$ & $?$ & \\
\hline
\end{tabular}

wnt $12^{92}$

\section{WNT $14^{96}$}

wnt $15^{96}$ WNTI5\%

Wnt $16^{77}$ WNT $16^{97}$

(http://www.ana.ed.ac.uk/rnusse/wntwindow.html) 
Table 4. FRP classes, interactions and expression patterns

\begin{tabular}{|c|c|c|c|}
\hline Mouse genes & Human genes & Interacts with & Expression pattern $n^{103}$ \\
\hline $\begin{array}{l}\text { FRPI }^{102}= \\
\text { Frp I } \\
\text { SARP2 } \\
\text { FrzA }^{104}\end{array}$ & SFRPI ${ }^{106}$ & & $\begin{array}{l}\text { heart, kidney, lung, brain, aorta, otic vesicle, neural } \\
\text { crest }\end{array}$ \\
\hline $\begin{array}{l}\text { FRP2 }=102 \\
\text { SDF5 } \\
\text { SARPI }\end{array}$ & SFRP2 $2^{106}$ & $\mathrm{wg}^{102}$ & gut, eye retina, Lung, brain \\
\hline $\begin{array}{l}\text { FRP3 } 3^{102}= \\
\text { FrzB } \\
\text { Frzb| } \\
\text { Fritz }\end{array}$ & $\mathrm{FRZB}^{109}$ & $\begin{array}{l}w^{102} \\
X w_{n} 8^{54} \\
\text { wnt } 1^{100}\end{array}$ & $\begin{array}{l}\text { cartilage, anterior and posterior mesoderm, limb } \\
\text { bud, kidney, testis }\end{array}$ \\
\hline $\begin{array}{l}\text { FRP4 }={ }^{102} \\
\text { FrpAP } \\
\text { FrpHE }\end{array}$ & SFRP4 & & ovary, brain, kidney,lung, endometrium \\
\hline SARP3 $3^{104}$ & SFRP5 & & pancreas \\
\hline
\end{tabular}

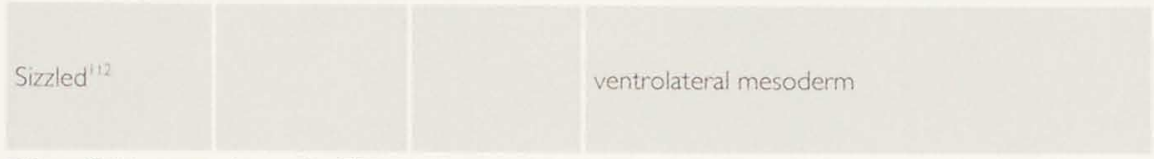

*The official nomenclature for FRPs is shown in boldface

(http://www.ana.ed.ac.uk/musse/wntwindow.html)

FRPs

Recently a family of secreted proteins containing a cystein-rich domain (CRD) similar to that of fzs has been identified in vertebrates ${ }^{54,98-102}$ (see fig. 2). Many different groups have worked with Frizzled Related Protein (FRPs) and each of them has given different names to the proteins, so the FRP nomenclature is complex: Frizbee, Fritz, SARP, SFRP, Sizzled and SDF have been used to refer to these proteins. In table 4 the different FRPs are classified.

FRPs can bind wnts directly and the CRD is necessary and sufficient for this interaction ${ }^{54,100,102}$. The proposed function for FRPs is to antagonize wnt proteins; different FRPs are able to block xwnt8 induced axis duplication in frogs ${ }^{5+, 100}$. Furthermore, wnt1-mediated accumulation of $\beta$-catenin is inhibited by Frzb1 ${ }^{108}$. Interestingly, although Frzb1 (=FRP3) can also bind to wnt5a, it does not block the activity of wnt5a in Xenopus ${ }^{108}$. 
Apart from modulating $\beta$-catenin levels some liRPs have been shown to influence the sensitivity to apoptosis ${ }^{11+4}$ "': overexpression of SARP1 (=FRP2) has been shown to make cells more resistant to apoptosis, but overexpression of SARP2 (=FRP1) has been shown to make cells more susceptible to apoprosis ${ }^{11 ! 4}$. Stimulators of apoptosis, like scrum deprivation, have been shown to induce hsl'RP (=FRPI) expression in HBI,-100 cells"'

\section{Corcieplors}

The complexity of receptor-ligand specificity may be further increased by coreceptors such as proteoglycans ${ }^{114.115}$. In analogy with $\mathrm{I}^{\circ}$ ( $\mathrm{I}^{*}$ signaling, proteoglycans may be low-affinity coreceptors for wnts, which would serve to increase the local concentration of ligand available for binding to high-affinity receptors ${ }^{15}$. Atematively, proteoglycans in the extracellular matrix may directly regulate the formation of wnt-fz complexes ${ }^{114}$. $A$ third possibility is that the ability of wnt-fz. complexes to transduce their signal may be regulated by glycosaminoglycan interactions ${ }^{11 \cdot}$.

Figure 4. Examples of proposed frizzled signal transduction pathways

\begin{tabular}{|c|c|c|c|}
\hline \multirow[t]{2}{*}{ Ligand } & wingless/wnt & wingless & $x w n t 5 a$ \\
\hline & $\downarrow$ & $\downarrow$ & $\downarrow$ \\
\hline \multirow[t]{2}{*}{ Receptor } & 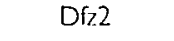 & $F_{2}$ & $r f 22$ \\
\hline & $\downarrow$ & $\downarrow$ & $\downarrow$ \\
\hline \multirow[t]{2}{*}{ Coupling molecule } & Dishevelled & Dishevelled & G-protein \\
\hline & $\downarrow$ & $\downarrow$ & $\downarrow$ \\
\hline \multirow[t]{2}{*}{ Signal transduction molecule } & Zeste-white 3 & Rho A & Inositol P3 \\
\hline & $\downarrow$ & $\downarrow$ & $\downarrow$ \\
\hline \multirow[t]{2}{*}{ Second messenger } & Armadillo & MAP kinase cascade & $\mathrm{Ca}^{i}$ release \\
\hline & $\downarrow$ & & \\
\hline Effector & DTCF & & \\
\hline Species & Drosophila & Drosophila & Zebrafish \\
\hline
\end{tabular}

\subsection{Frizzled signal transduction pathway}

Not all $f z$ homologues functionally activate the same signal transduction parhway. In fig. 4 different signal transduction pathways are shown. Even in Drosophila, the situation is complex. F $z$ and Dfz.2 are redundant receptors for the ligand. The cytoplasmic sequence of Df $z 2$ preferentially activates the Armadillo (arm)/ $\beta$-catenin pathway and the cytoplasmic sequence of $f$. preferentially activates the planar polarity cascade. Both receptors can activate either pathway but with different efficiencies ${ }^{116}$. In mammals a classification can also be made: ifz.1 and 


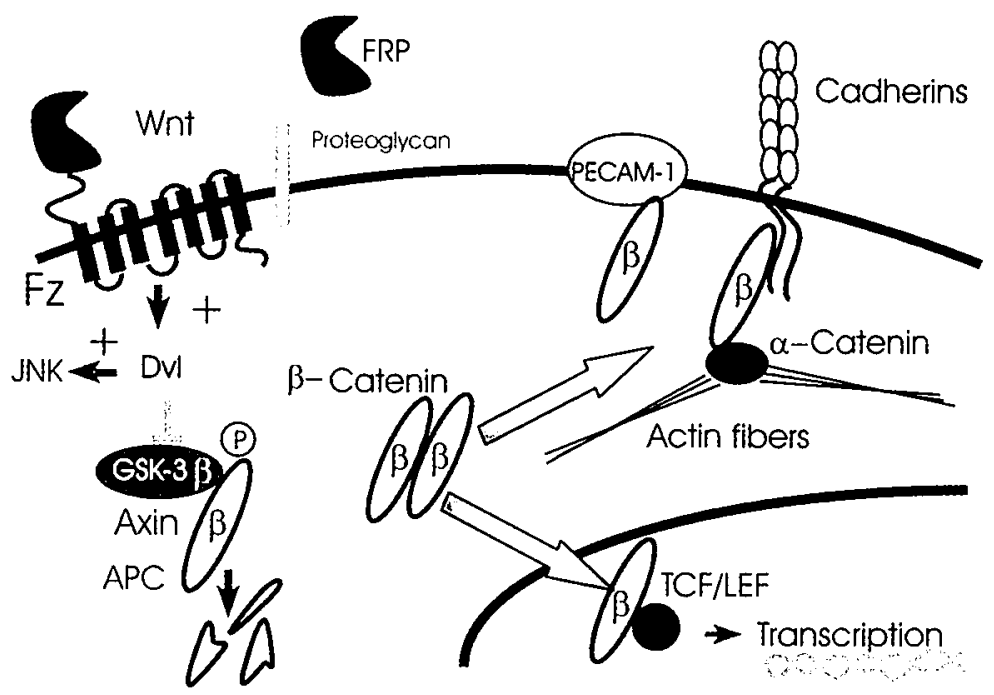

Figure 5. Schematic representation of different signal transduction pathways of frizzled receptors. Proteins form the wht family can bind to frizzled receptors. This causes an activation of the signal transduction molecule dishevelled (dvi) which in turn can activate the JNK pathway and can inhibit the enzyme GSK3- $\beta$. This enzyme is responsible for the phosphorylation of $\beta$-catenin, a protein that can act as a second messenger in this cascade. $\beta$-Catenin is phosphorylated in a complex with, among other components. Axin and adenomatous polyposis coli (APC) protein which is a first step in its degradation by the ubiquitin proteasome pathway. $\beta$-Catenin can activate transcription factors from the $T$-cell factor/lymphocyte enhancer factor (TCF/LFF) family, and can form a complex with cell adhesion molecules of the cadherin family and PECAM.

$\mathrm{mf} z 7$ activate the $\beta$-catenin pathway and $\mathrm{rf} 72, \mathrm{mf} 73, \mathrm{mf} 74$ and $\mathrm{mf} z 6$ induce protein kinase $C(P K C)$ activation and $\mathrm{Ca}^{2+}$ release ${ }^{11 ?} . \Lambda$ schematic representation of the best characterized signal transduction pathway for $f 7$ is given in fig. 5 . The different components of the signal transduction route will be bricfly described below.

\section{G-proteins}

Although serpentine receptors are generally (i-protein coupled, there is no experimental evidence of a direct interaction between $f z$ and $(i$-proteins. They lack the most conserved motifs that are found in nearly all ( 3 -protein coupled receptors ${ }^{411}$. This does, however, not exclude the involvement of (i-proteins in their signaling. In fact, there is increasing evidence that $G$-proteins are involved in wnt signaling. Rat $f z 2$ cooperates with Xenopus wnt5a to activate a G-protein dependent pathway when overexpressed in zebrafish embryos ${ }^{118}$. lurthermore, in mouse 199 teratocarcinoma cells rat f $z 1$ expression promotes differentiation into endoderm via pathways that require specific (i-proteins ${ }^{119}$. In addition, regulators of ( $)$ protein signaling (RGS) proteins inhibit embryonic responses to wnt8 in Xenopus assays, suggesting that wnt signaling operates via a (i-protein-dependent receptor or mechanism ${ }^{12 "}$. 


\section{Disbevelled}

The most upstream component of the wnt-f\% signal transduction cascade, below $f \%$ itself, is dishevelled (dvl). Three murine homologues have been described ${ }^{121 \cdot 123}$. The extensive overlap in spatial and temporal expression patterns and the high homologies suggest that these genes have mutually redundant functions. This is in accordance with the obscrvation that dvll-knockout mice do not show any structural defects and reproduce normally ${ }^{12-4}$.

The biochemical mechanism through which dvl transduces the wnt signal remains unclear, but it has been suggested that, in response to the wnt signal, dvl becomes hyperphosphorylated and translocates to the membrane, where the activated dvl transduces the signal to the next signaling molecule ${ }^{39,}{ }^{125}$. Affinity purification of a complex containing $\mathrm{dvl}$ and several associated proteins revealed the association of dvl with Cascin Kinase 2 (CK2). In virro and in vivo, CK2 efficiently phosphorylates $\mathrm{dvl}$ but the functional significance of this phosphorylation is not clear ${ }^{126}$.

\section{Dul siruclure}

Dvl encodes a ubiquitously expressed cytoplasmatic protein containing 4 domains that are highly conserved among all known homologues. $\Lambda$ t the $N$ terminus, dvl contains a Disbevelled-Axin (DIX) domain similar to a region of $A x i n$, a protein implicated in wht signaling in vertebrates ${ }^{12-}$. The central tegion contains a short

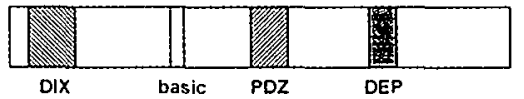

Figure 6. A schematic representation of $d v 1$ with the four conserved domains. A DIX domain similar to a region of $\mathrm{Axin}^{2 \%}$, a short basic domain with so far no described function. a PDZ domain that binds to specific C-terminal sequences of membrane proteins and/or to other PDZ domains ${ }^{179}$. The DEP domain is also found in GTPase-activating protein families" (For an explanation of the abbreviations see text) basic domain and a PSD-95/SAP90, discslarge, ZO-1 (PD\%) domain, that has been described to be a modular protein-protein interaction domain that binds to specific C-terminal sequences of membrane proteins and/or to other PD\% domains that have a role in protein-protein interactions ${ }^{12 x}$. The C-terminal region contains a dishevelled-eg/ 10-plecks/rin (DIPP) domain, which is also found in GTPaseactivating protein families, and is trought to function in (i-protcin signaling ${ }^{1 . i 1} . \Lambda$ schematic representation of the structure of dvl is given in fig. 6 .

\section{Dw signaling patbways}

Activation of dvl proteins in Drosophila can induce two signal transduction pathways; 1 . Dvl inhibits the degradation of arm/ $\beta$-catenin by inhibiting glyeogen synthase kinase $3 \beta$ (GSK-3 $\beta$ ), which will be further explained below, and 2 . Dvl is able to induce planar polarity by activating c-Jun $\mathrm{N}$-terminal kinasc (JNK) and Rho ${ }^{131.131}$. Also in mammalian cells dvl is able to activate JNK ${ }^{132}$. The DE. ${ }^{2}$ domain of dvl is essential for JNK activation, whereas for the upregulation of $\beta$-catenin all domains of dvl are necessary ${ }^{1.11,132}$. Recently, has been found that the 
small G-proteins cdc42 or Rac, which are involved in JNK activation by many stimuli, do not play a major role in dvl-mediated JNK activation ${ }^{132}$.

\section{$\beta$-Catenin}

$\beta$-Catenin is a member of the Armadillo repeat protein family ${ }^{133}$. It is present at the plasma membrane, the cytoplasm and in the nucleus ${ }^{13+136}$. The wnt pathway is an important regulator of cytoplasmatic $\beta$-catenin by controlling the $\beta$-catenin degradation. Increasing steady state levels of endogenous $\beta$-catenin result in its accumulation in the nucleus. There, $\beta$-catenin can bind to transcription factors such as lymphoid enhancing factor (LEF) and T-cell factor (TCF) which regulate gene transcription ${ }^{137,138}$. The expression of several genes has been described to be regulated by $\beta$-catenin (see table 5 ).

The $\beta$-catenin at the plasma membrane is involved in cell-adhesion by linking cadherins to the actin cytoskeleton. Cadherins are $\mathrm{Ca}^{2+}$-dependent adhesion molecules that mediate cell-cell interactions at adherens junctions ${ }^{139}$. $\beta$-Catenin

Table 5. Genes shown to be regulated by the $\beta$-catenin/T CF-LEF complex

\begin{tabular}{|c|c|c|}
\hline Gene & Organism/system & Up/down \\
\hline $\mathrm{C}-\mathrm{myc}^{142}$ & human colon cancer & up \\
\hline Cyclin $D^{143}$ & human colon cancer & up \\
\hline $\operatorname{Tef}-1^{144}$ & human colon cancer & up \\
\hline C-jun ${ }^{145}$ & human colon cancer & up \\
\hline Fra- $1^{145}$ & human colon cancer & up \\
\hline UPAR $^{145}$ & human colon cancer & up \\
\hline Matrix metalloproteinase MMP- $7^{146}$ & human colon cancer & up \\
\hline $\mathrm{CD} 44^{\text {[4? }}$ & human colon cancer & up \\
\hline Fibronectin ${ }^{148}$ & xenopus & up \\
\hline $\mathrm{BMP}^{147}$ & xenopus & down \\
\hline Connexin $43^{\mid 50,15 i}$ & rat cardiomyocytes and xenopus & up \\
\hline Connexin $30^{152}$ & xenopus & up \\
\hline Retinoic acid receptor gamma $^{152}$ & xenopus & up \\
\hline Nacre ${ }^{53}$ & zebrafish & up \\
\hline WISP $^{154}$ & wht- I transformed mouse cells & up \\
\hline Cyclooxygenase $-2^{155}$ & mouse (wntl) & up \\
\hline${ }_{S F R P 2}{ }^{156}$ & mouse (wnt4) & up \\
\hline
\end{tabular}


links the cytoplasmatic tail of cadherin molecules to $\alpha$-catenin, which in turn is linked to actin filaments. Apart from its interaction with cadherins at the plasma membranc, $\beta$-catenin can also bind to platelet-cndothelial cell adhesion moleculc-1 (PICCAM-1) ${ }^{1 \cdot 11}$. This glycoprotein is commonly used as an endothelium-specific marker. It has been demonstrated that the PI:C $/ N$ - $1 / \beta$-catenin association functions to regulate $\beta$-catenin localization and, moreover, to modulate $\beta$-catenin tyrosine phosphorylation levels ${ }^{1+1}$ (sec fig. 5).

\section{Interation of $\beta$-catemin pools}

Analysis of mutant forms of $\beta$-catenin in Drosophila and Xenopus has demonstrated that the $\beta$-catenin at the plasma membrane and the $\beta$-catenin in the cytoplasm and nucleus are in clistinguishable pools ${ }^{15}$. 15\%. However, recent data indicate that regulation of cytoplasmatic $\beta$-catenin can influence $\beta$-catenin at the membrane and vise versa ${ }^{6,3} .15^{\%}$. Therefore a dual role can be anticipated for the wnt-f\% signal transduction pathway; on the one hand the nuclear $\beta$-catenin regulates the cell cycle by turning on oncogenes and other cell cycle regulators, and on the other hand $\beta$-catenin at the cell membrane regulates cell adhesion and polarity by modifying the cytoskeleton.

\section{$\beta$-catenin degradation complex}

In the absence of activated dvl, cytoplasmic $\beta$-catenin levels are low. CSK-3 $\beta$ phosphorylates the serine and threonine residues at the $N$-terminus of $\beta$-catenin ${ }^{16,1}$. Phosphorylation of $\beta$-catenin is promoted in the yuartenary complex between these two proteins and other proteins like the seaffold protein $\Lambda x$, $^{161,}$, 162 and the adenomatous polyposis coli protein $(\Lambda P C)^{16,3,16 . t}$. In uncomplexed form $\beta$-catenin appears to be a poor substrate for GSK-3 $\beta^{161,16.5}$. The phosphorylated $\beta$-catenin is degraded by the ubiquitin-proteasome pathway ${ }^{16,16 .}$. Activation of dvl inhibits (SSK3- $\beta$ activity, thereby promoting the elevation of intracellular $\beta$-catenin levels and accumulation of $\beta$-catenin in the nucleus.

\section{Axin}

$\lambda$ xin serves as a scaffold protein to coordinate the regulation of $\beta$-catenin levels. It possesses a regulator of $(i-p r o t e i n$ signaling domain for $\Lambda P C$ binding, a $\beta$-catenin binding domain and a DIX domain ${ }^{161 .}{ }^{162}$. In addition $A x i n$ binds to protcin phosphatases $2 \Lambda\left(\mathrm{PP}^{2} \Lambda\right)$ and $2 \mathrm{C}$ ( (PP2C), which modulate the phosphorylation of $\Lambda P C$ and $\Lambda$ xin respectively ${ }^{11 \times-1 \% "}$.

Apart from its role in the wnt-fz signal transduction, it has recently been reported that $A$ xin also functions as a JNK activator, like dvl itself $\left.\right|^{-1}$.

$A P C$

$A P^{\prime} C$ is a component of the $\beta$-catenin degradation complex as it binds directly to $\beta$-catenin by two sets of related repeats towards the centre of the molecule ${ }^{\prime \prime 2} . \Lambda P C$ 
is a good substrate for CSK-3 3 in vitro and association of $\beta$-catenin with $\triangle P C$ appears to depend on phosphorylation of $\Lambda P C$ by $\left(\right.$ SSK-3 $\beta^{1-3,1-4}$. Two $\triangle P C$ genes and several protein isoforms have been described ${ }^{1-5.1 \%}$.

Based on its role in $\beta$-catenin degradation, APC. can be predicted to act as a functional antagonist for $\beta$-catenin, but the opposite has been found in Xenopus ${ }^{1 \%}$. Axis duplication in Xenopus embryos is known to be induced by $\beta$-catenin overexpression but also by $A P C$, overexpression ${ }^{\text {t" }}$. $\triangle P C$ might have additional functions in the wht signaling independent of its role in the downregulation of $\beta$ - catconin $^{1-3.1 \% 1}$.

In mammals $A P C$, was discovered as a tumor suppressor gene before it was known to be involved in $\beta$-catenin degradation. Mutations in this gene not only lead to the development of familial colon cancer, but also to other sporadic colorectal cancers ${ }^{131}$. The activation of $\beta$-catenin signaling, cither by $\triangle P C$. inactivation but also by mutations in $\beta$-catenin, plays a kcy role in both colon cancer and melanoma ${ }^{161-18:}$.

\section{Plakoglobin}

Plakoglobin is a structural component of desmosomes, a cell adhesion complex. In addicion, like $\beta$-carenin it is a component of the cadherin-catenin complexes in another type of cell adhesion complex, the adherens junctions. Furthermore, both $\beta$-catenin and plakoglobin are able to bind to PSCAM-1 ${ }^{1+1}$. $\beta$-catenin and plakoglobin (which is also called $\gamma$-catenin) are highly homologous proteins. In PC12 cells wnt 1 expression results in an increase of plakoglobin ${ }^{|x|}$. It has becn suggested that plakoglobin, like $\beta$-catenin, can act as a transcription factor in the wnt cascade ${ }^{15.5}$. Plakoglobin can bind to LE: ${ }^{i}-1$, and, when overexpressed in mammalian cells, cnhances IEl'-1 directed gene transcription ${ }^{186}$. However, in vitro the formation of a plakoglobin-IEI:TC.I: DNA complex is very inefficient compared to a complex containing $\beta$-catenin-IEF DN $\Lambda$. Moreover, in plakoglobin-transfected cells plakoglobin-J.EI/TCI'-DNA complexes were not formed; rather, endogenous $\beta$-catenin, which is upregulated by plakoglobin transfection, formed a $\beta$-catenin-JEF DNA complex ${ }^{186}$. This indicates that, although theoretically possible, plakoglobin is not likely to replace $\beta$-catenin in the wnt signaling.

\subsection{Potential involvement of the frizzled cascade in other signal transduction pathways}

Members of the wnt-f $x$ cascade are able to influence other signaling pathways. The Notch gene cncodes a receptor implicated in a signaling pathway essential for many developmental processes in Drosophila and vertebrates. The $\mathrm{N}$-terminal part of dvl binds to the C-terminus of Notch, providing a mechanism by which Notch and wnt interact. (ienetic experiments in Drosophila have revealed that wnt, through dvl, can inhibit Notch signaling, while an increase in Notch gene also dosedependently reduced the action of $\mathrm{dvl}^{15 ?}$. In other systems, however, Notch and 
wnt signals do not appear to interact ${ }^{18 x}$. The Notch pathway has been described to be involved in the development of $A$ zheimer discase ${ }^{1 x^{\prime \prime}}$. The wnt-f 7 cascade is also directly involved in $A l$ theimers disease through $\beta$-catenin. The Alzheimers discase gene presenilin has been found to interact with $\beta$-catenin ${ }^{1 \% 1}$. The function of this interaction is not yet clarified, but presenilin mutations alter the intracellular trafficking of $\beta$-catenin after activation of the wnt-fz cascade ${ }^{131}$. Epidermal growth factor ( $\mathrm{EC}(\mathrm{il})$ and insulin-like growth factor (IGi) signaling can also interact with $\beta$-catenin, since ECII and IC $\mathrm{II}^{*}$ signaling promote its tyrosine phosphorylation and increase cytoplasmatic $\beta$-catcnin levels ${ }^{1,2}$. "\%;.

\section{Frizzled cascade in development of the heart}

In several studies it has been shown that genes that are expressed during cardiac development are re-expressed during remodeling of the heart. This phenomenon is called a re-expression of the fetal gene expression pattern ${ }^{1 \% 4}$. Wnt-f\% signaling is involved in a varicty of developmental processes, including cell proliferation, differentiation and cpithelial-mesenchymal interactions, through which it contributes to the development of tissues and organs such as the limbs, the brain, the reproductive tract and the kidncy ${ }^{105.19 \%}$.

In Drosophila wg, the homologue for wnt, is required for heart development. In absence of the wg function, overexpression of dvl can restore heart formation, indicating a role for the wg- $f \%$ cascade in this process ${ }^{19 \%}$. Nthough cardiac morphogenesis in Drosphila and vertebrates is different, the wnt-f\% cascade might also play a role in vertebrate heart formation.

\subsection{Expression of frizzled cascade during vertebrate heart development}

Members of the wnt cascade are expressed in the heart during embryogenesis and are able to modulate cardiogenesis. During mouse heart morphogenesis, wnt 8 is expressed in cardiomyocytes from 8.5 until 17.5 days after conception ${ }^{138}$. Wnt5a is expressed in neonatal rat hearts ${ }^{15 \%}$. In birds, wnts also play a role in cardiac development; wnt11 is expressed in precardiac mesoderm, and is able to induce cardiac differentiation in noncardiac tissuc ${ }^{1 \% \%}$.

Several f\% homologues are expressed in the heart during development. In neonatal rat hearts $f \approx 1, f \approx 2$ and the rat homologuc of mousc $f \approx 4^{+6,15^{\prime \prime}}$ are expressed. f 77 expression is found in the cmbryonic Xenopus heart ${ }^{2+1}$ and mouse f 710 RN $\Lambda$ has been found in the mouse heart during late embryonic development ${ }^{55}$. lippl is also expressed during murine cardiomorphogenesis ${ }^{10 \%}$. These expression patterns indicate a role for the pathway in cardiac development, but the mechanism remains to be clucidated. 


\subsection{Proposed working mechanisms for the frizzled cascade during cardiac development}

Wh-cascade in nesral arest

The neural crest plays an important role in cardiovascular development. It participates in outflow tract septation, media formation of the pharyngeal arch arterics and it contributes to parasympathetic cardiac innervation ${ }^{124.211 .21 .5}$. Wht 1 and wnt3a are cxpressed in neural crest cells and have been found to play a role in cardiac mophogenesis ${ }^{13}$, 2114. In cultured mouse cmbryos, the inhibition of wnt 1 expression has been described to be associated with abnormal cardiac development, probably mediated by neural crest cell disruption ${ }^{2+4}$. In Xenopus I $r \% A$, a secreted homologuc of $f \%$, has been shown to antagonize the function of xwnt8 ${ }^{\prime \prime \prime}$. Xf $\% \Lambda$ is expressed in Xenopus in neural crest cells, neural crest-derived tissues and in the developing heart" ${ }^{\prime \prime}$. Furthermore, the mouse f $\% 4$ gene is localized in a region deleted in mice with cardiac neural crest-derived abnormalities ${ }^{2115}$. These findings indicate a role for the wnt- $f$ \% cascade during neural ceest cell patterning.

$\Lambda$ possible role for the wnt-f\% cascade in neural crest could be the regulation of connexin-43 expression. (jap junction channels composed of connexin-43 are essential for normal heart function. The analysis of transgenic and knockout mice with perturbations in connexin-43 function has revealed its important role in cardiac development. This probably involves the modulation of cardiac crest migration and function ${ }^{2146,210}$. Wht is able to induce connexin-43 expression in cultured PC12 cells ${ }^{151}$ and in rat neonatal cardiomyocytes ${ }^{151}$. The inductive effect of wht is transcriptionally mediated, as was shown by transfecting a connexin-43 promotor construct ${ }^{15 i}$. 15!. Iinhanced expression of connexin-43 increased cardiomyocyte cell coupling ${ }^{151}$. These findings indicate a possible mechanism by which the wnt cascade can affect heart morphogenesis.

\section{Fiziascade and the $\beta$-iatenin/N-iadberin complex}

During early vertebrate heart development the expression pattern of the $\beta$-catenin/N-cadherin complex suggests its involvement in morphoregulation and the stabilization of cardiomyocyte differentiation. It has also been shown that perturbation of $\mathrm{N}$-cadherin inhibits normal early heart development ${ }^{2118}$. A mechanism by which the wnt cascade could be involved in this process has been studied in neonatal rat cardiomyocytes and fibroblasts in culture ${ }^{15 \%}$. Media containing wnt $3 a$ or wnt5a both induced aggregation of cardiomyocytes co-cultured with fibroblasts. In the absence of fibroblasts the cardiomyocytes did not aggregate. Media containing wnt3a or wnt5a induced increased levels of both $\beta$-catenin/ $\mathrm{N}$-cadherin complexes and free $\beta$-catenin in the cardiomyocytes. The transcription of $\beta$-catenin and $\mathrm{N}$-cadherin $\mathrm{RN} \Lambda$ was not upregulated, indicating that wnt inhibited the degradation of the proteins. lirec $\beta$-catenin is able to bind to TCFi proteins and induce gene transcription. TCF -mediated gene transeription was, however, not involved in the aggregation process since overexpression of neither a dominant positive nor a dominant negative construct of $\mathrm{TCl}$ i influenced cardiomyocyte aggregation. The formation of cardiomyocyte aggregates was 
dependent on $\mathrm{N}$-cadherin-mediated cell-cell adhesion, as perturbation of $\mathrm{N}$-cadherin disrupted the aggregates. These findings suggest that the wnt cascade could be involved in the archirectural arrangement of cardiomyocytes during cardiac development through the stabilization of the $\beta$-catenin/cadherin complex.

\section{Plakogglobin and cardiac development}

Plakoglobin is essential for heart development, as demonstrated in the plakoglobin null mutant mice ${ }^{3+1}$. 21". These mice dic from embryonic day 10.5 onward, due to severe heart defects. The cardiac ventricle often ruptures and blood is found between the cardiomyocytes. This tissue instability correlates with the absence of desmosomes in heart. lixtra adherens junctions are formed in the heart, which contain desmosomal proteins, but apparently this is not sufficient to maintain the architecture of intercalated discs and stabilization of heart tissuc ${ }^{31 \%}$. 211". The expression of plakoglobin can not be detected before stage 13 in the myocardium of the developing chick heart ${ }^{211}$, indicating an important role at the later stages of heart development for the desmosomes and plakoglobin. $\beta$-Catenin expression has been found at much earlier stages in heart development, but because null mutant mice do not live beyond the gastrula stage, the role of $\beta$-catenin in heart development can not be studied ${ }^{211}$.

\section{Frizzled cascade in cardiac disease}

\subsection{Functions of the frizzled cascade in cells relevant for the cardiovascular system.}

\section{Frizzled signaling in endothelial cells}

Neovascularization is important in ischemic heart disease. It requires endothelial cell proliferation as well as endothelial cell migration. Findothclial cell culture experiments suggest that the whe cascade is involved in the proliferation of endothelial cells ${ }^{212}$, 1; . Wnt expression in primary endothelial cells induced an increase in the pool of free $\beta$-catenin and increased $L \mathrm{~L}: \mathrm{F} / \mathrm{TC}^{\mathrm{i}}$ mediated gene transcription. Moreover, wntl was capable of stimulating proliferation of these cells ${ }^{22}$. Iir $\% \wedge$ (FRPI), a secreted homologue of $f \%$, which is expressed in highly differentiated cells like neurons and cardiomyocytes, has been found to reduce the proliferation of enclothelial cells. It was suggested that this reduction in proliferation resulted from antagonism of whe family members ${ }^{214}$. These findings suggest that wnt signaling might be involved in neovascularization.

VIE(il: is a major modulator of angiogenesis and is known to play a role cluring

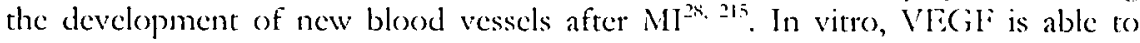
stimulate tyrosine phosphorylation of $\beta$-catenin in endothelial cells ${ }^{213}$. It has been demonstrated that tyrosine phosphorylation of $\beta$-catenin is associated with disruption of the $\beta$-catenin/ cadherin complex ${ }^{316}$. This suggests that the stimulation of blood vessel formation after MI by VI:Cil may, at least in part, be $\beta$-catenindependent. 


\section{$\beta$-Catenin in cardiomyocytes \\ Cell adbesion}

Cardiomyocytes are terminally differentiated cells that have a rate of proliferation that has been estimated by different researchers between very low and completely absent. A role for the wnt-f\% signaling pathway in their proliferation secms therefore unlikely. However, $\beta$-catenin is also present in the adherens junctions, which are located in the intercalated discs. These intercalated dises are situated at the junction of two neighboring cardiomyocytes and are, besides in cell-cell adhesion, also involved in the electrical coupling between the cells. In a guinea pig model of congestive heare failure it was demonstrated that, although the level of $\beta$-carenin remained unchanged, it was relocated from the intercalated dises to the cytoplasm in a large fraction of left ventricular cardiomyocytes. Both the amount and distribution of $\mathrm{N}$-cadherin remained unchanged in this model-12-

Cardiomyocyte cell culture experiments have demonstrated that both wnt3a and wnt5a can stabilize the $\beta$-catenin/ $\mathrm{N}$-cadherin complexes ${ }^{15}$, so the relocation of $\beta$-catenin away from intercalated discs in failing cardiomyocytes may be induced by a change of wnt signaling.

\section{Electrical coupling}

$\Lambda$ part from adherens junctions, gap junctions are also important for cardiac function. Connexin-43 is necessary for the electrical coupling of cardiomyocytes. Wnt is able to induce connexin-43 expression in cultured rat neonatal cardiomyocytes ${ }^{151}$. The accumulating connexin-43 was observed to be colocalized with $\beta$-catenin in the junctional membranc in response to wnt signaling; moreover, forced expression of connexin-43 reduced the transcription activity of $\beta$-catenin ${ }^{151}$. This suggests mutual regulation of both proteins.

\subsection{Frizzled and frizzled like proteins in cardiovascular disease}

l\%2 expression is upregulated in the rat heart during hypertrophy ${ }^{21 x}$. One of the proto-oncogenes that are considered to be regulators of the development of cardiac hypertrophy is c-jun ${ }^{194}$. In colorectal carcinomas, it has been shown that $\beta$-catenin acts as a regulator of the expression of $c$-jun ${ }^{1+5}$. This suggests that the wnt-f\% cascade is involved in the regulation of the development of cardiac hypertrophy. Fo2 is also expressed by the fibroblast-like cells during their migration and proliferation after $M I$ but this expression is restricted to the migratory phase ${ }^{38}$, suggesting a role for the wnt-fz cascade in this process.

Schumann and coworkers have reported the expression levels of sLRP3 and sLRP4 to be elevared in hearts of patients with dilated cardiomyopathy and coronary heart discase compared to non-failing donor hearts ${ }^{1 \text { t! }} \beta$-Catenin levels tended to be decreased in myocardial samples with high slRP3 and 4 cxpression levels, suggesting an active role for the wnt-fz cascade in failing myocardium ${ }^{11 "}$. 


\section{Hypotheses}

As discussed in the previous paragraphs, the wnt-fz cascade plays an important role in developmental and pathological processes as diverse as organogenesis and cancer. There is increasing evidence that the wnt-fz cascade is also implicated in cardiac development and the repair process after MI.

In a previous study we have demonstrated that f $z 2$ expression was upregulated in the myofibroblasts during their migration and proliferation in the infarct. Because genes that are expressed in the heart during cardiac remodeling often are involved in cardiac development, the first hypothesis of the present thesis is that the $f z 2$ receptor plays a role during the developtment of the heart.

The wnt-f\% cascade has been shown to have a role in architectural control in several processes. The second hypothesis is that the wnt- $f$. cascade has a role in the architectural control of infarct healing, which includes cell proliferation, migration, alignment and apoptosis.

In vitro experiments suggest a role for the wnt-fy cascade in endothelial cell proliferation. Therefore the third hypothesis is that this signal transduction pathway is involved in neovascularization during infarct healing.

\section{Oulline of this thesis}

This thesis is divided into four parts; in the first part, expression of the wnt-fz cascade in the heart after $\mathrm{MI}$ and during cardiac development will be described. In the second part, the signal transduction of $f z$ will be further examined in in vivo and in vitro experiments. In the third part, the function of the wnt-f7 cascade during infarct healing will be discussed. In the final part, the findings of the experimental chapters are discussed and put into a broader context. 
Chapter 1 


\section{Chapter 2}

\section{FRIZZLED EXPRESSION IN THE MOUSE} HEART AFTER MI

M.E. van Gijn, Y.P.G. Essers-Janssen, J.F.M. Smits, and W.M. Blankesteijn 


\begin{abstract}
I'z proteins constitue of a large family of scven-transmembrane receptors that function in the wnt-fz signal transduction pathway. They are widely expressed in different tissues in vertebrates. Recently a family of secreted frizzled homologues (FRJ's) has been described. Several frizzled proteins and IRPs are cxpressed during cardiac development. It is known that genes that play a role during heart development can be upregulated during cardiac remodeling duc to pathology. In a previous study we reported the expression of $f \geq 2$ in the myofibroblasts in the early wound healing phase after $\mathrm{MI}$ in rats. In the present study we demonstrate the upregulation of the f $z 1,2$ and 7 and the FRP 1,2 and 3 gene expression seven days after $\mathrm{Ml}$ in mice. I'urthermore, we demonstrate that in mice, like in rats, the fz2 expression is localized to the borderzone of the infaret 7 days after $\mathrm{Ml}$, indicating that the mouse is a suitable animal model for these studies. These findings further suggest a role for the wnt-fz cascade in the wound healing after Ml.
\end{abstract}

\title{
Introduction
}

The fz proteins constitute a large family of seven-transmembrane receptors with at least 10 members in mammals ${ }^{+1 .} .45,55$. These serpentine receptors function in the wnt-fz signal transduction pathway. All fz protcins share the following features; a signal sequence at the $N$-terminus, a conserved motif of 10 invariantly spaced CRD, a seven transmembrane region and a cytoplasmatic tail ${ }^{+1}$. Most family members are widely expressed in a variety of tissues, with overlapping patterns ${ }^{41}$. The $f z$ and the wnts consist both of extensive families in vertebrates, and although it is likely that each member has a specific function, this raises questions regarding specificity and function of the wnt- $f$, interaction, which still remains unclear. Recently, a family of secreted Frizzled-likc-l'poteins (FRl's) has been described. Iive lRPs have been identified so far. These proteins are proposed to scavenge wnt proteins and thereby antagonize their function.

Several fzs and lRPs are expressed in the heart during vertebrate development ${ }^{\text {*k. }} .5,1 \%, 213$. In a number of studies it was shown that genes, which are expressed during cardiac development, are re-expressed during remodeling of the heart. This phenomenon is called a re-expression of the fetal gene expression pattern ${ }^{19 .}$. The expression of fzs and FRPs during cardiac development could suggest a role for these genes in cardiac pathology.

In previous studies we have found the upregulation of $f>2$ during cardiac hypertrophy and after $\mathrm{MI}$ in rats ${ }^{38.21 \mathrm{~s}}$. Furthermore it was reported that the expression levels of IRP3 and IRP4 were elevated in hearts of patients with dilated cardiomyoparhy and coronary heart discase ${ }^{111}$. In order to achicve a more complete understanding of the role of frizzled and liRP genes during cardiac remodeling a characterization of the expression of these families is necessary. The present study was undertaken to study the expression of $\mathrm{fz}$ and $F \mathrm{RP}^{\mathrm{P}}$ homologues in a mousc model of MI with RT-PCR. Furthermore we wanted to localize the fz2 expression 
at 7 days after MI using in situ hybridization, to study if this was similar to the pattern found in the rat model for $\mathrm{MI}^{38}$.

\section{Material and methods}

\section{Animals and surgery}

Adult male Swiss mice were used in this study. MI was induced as described previously ${ }^{38}$. The infarcted hearts were used if the infarct area was approximately $30 \%$ or more of the left ventricle.

\section{Reverse transcriptase polymerase chain reaction}

The expression of the genes was determined in left ventricles of SHAM operated animals and of left ventricles containing the infarct area, 7 days after the induction of MI as described previously and RNA samples obtained from three different hearts were used. Briefly, total RNA was isolated from left ventricles, which contained the infarct area, and sham left ventricles by $\mathrm{LiCl} /$ urea method ${ }^{219}$. Aliquots of $500 \mathrm{ng}$ of total RNA were reverse-transcribed using 100 units of Moloney murine leukemia virus (MoMuLV) reverse transcriptase. After amplification by PCR with the primers described in table $1\left(1 \mathrm{~min}\right.$ at $94^{\circ} \mathrm{C}, 1 \mathrm{~min}$ at $55^{\circ} \mathrm{C}$ and 1 minute at $72{ }^{\circ} \mathrm{C}$ for 30 cycles), the PCR fragments were separated on ethidium bromide-containing agarose gel.

Table I. Primer-sets for the fz PCRs

\begin{tabular}{|c|c|c|}
\hline Gene & Upper primer & Lower primer \\
\hline Mfzl & GCCCTGCGAACCCACTAAAGTATA & CCCGTCCTCTGCAAACTTGTCGTT \\
\hline Mfz2 & GIICTGGGTGAGGCGATTGT & CAGCAGGAAGGATGAACCGAT \\
\hline $\mathrm{Mfz} 3$ & TGTCGGCCTCTACGACG & CTGAAAACACCAATCCGG \\
\hline Mfz4 & CGCTCATCCAGTACGGC & CAGCCATCCAAATATCCG \\
\hline $\mathrm{Mfz5}$ & GTCACACCCGCTCTACAACAAGGT & CTCGTAGTGGATGTGGTTGTGCTC \\
\hline Mfz6 & GGITCTITAAGCGAAACCG & TITCTTCAAGCGTCGGA \\
\hline Mfz7 & TGGTGCTTGCTCTICTGGGCG & CACGGAGGAATGGCTTGGTCG \\
\hline Mfz8 & TGCCAAGAGATCACGGTGCCG & AGTGTCCGGGTTGCCCTGCTC \\
\hline MFRPI & CAGCATITCAAAGACTAACGTCG & TGAAACATCTCCTCGGATAG \\
\hline MFRP2 & TTACAAGCTGAACGGCGT & GCAACCTAAGTGCACGGTA \\
\hline MFRP3 & CAGCACCCAGGCTAACGC & TTACATITGCAACGTTCGC \\
\hline MFRP4 & CGATGAGCTGCCGGTCTA & GAGIIAACCAGGGCGATAC \\
\hline GAPDH & ACGGATTGGCCGTATTG & CGTCAGATCCACGACGGA \\
\hline
\end{tabular}




\section{In situ hybridization}

The expression of the $\mathrm{fz} 2$ gene was studied by in situ hybridization. These experiments were performed on paraffin sections $(5 \mu \mathrm{m})$ from formalin-fixed infarcted rat hearts. The in situ hybridizations were performed as described previously $^{38}$. Briefly, a radiolabeled riboprobe was transcribed from a 566-bp fz2 polymerase chain reaction product, obtained by amplification of reverse-transcribed RNA isolated from rat heart as previously described ${ }^{38}$ (primer set $f z 2$ upper GCCTCAACAGGCTGGACCCG, lower GGTGCACCCCCCTCCCGAGT) and cloned into a pCRII cloning vector (Invitrogen Corp., San Diego, CA). The identity and orientation of the polymerase chain reaction products were verified by sequencing. RNA transcription was performed using an RNA labeling kit (Amersham, Little Chalfond, UK) in the presence of $\left.{ }^{35} \mathrm{~S}\right]$-UTP. The sections were hybridized overnight at $55^{\circ} \mathrm{C}$ with the radiolabeled probes. After washing the sections, unbound probe was digested with RNase $(20 \mu \mathrm{g} / \mathrm{ml}$; Promega), the sections were dehydrated, dried, dipped in photographic emulsion (Kodak NTB2; Technorama, Zürich, Switzerland) and exposed for 1 to 2 weeks in the dark at $4^{\circ} \mathrm{C}$. After development, the sections were briefly stained with hematoxylin (1:500; $\mathrm{DAKO}$.

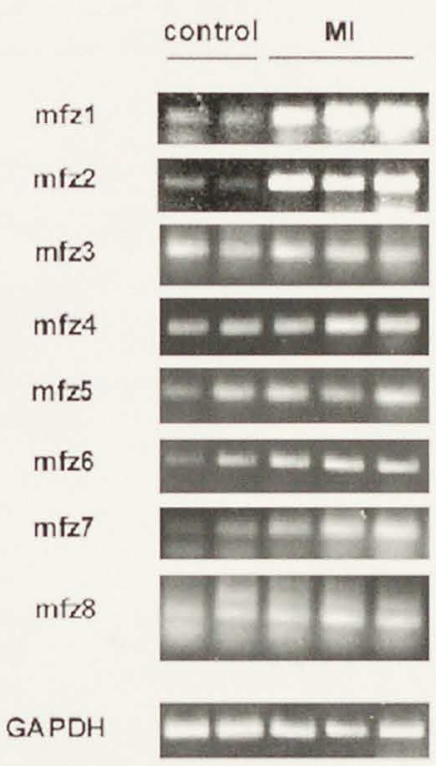

Figure I. The RT-PCR reaction of different $f z$ homologues in the left ventricle 7 days after $\mathrm{MI}$ visualized on an ethidium bromide containing agarose gel. The expression of $\mathrm{fzl}, 2$ and to a lesser extent 7 appeared to be upregulated after Ml compared to the SHAM.

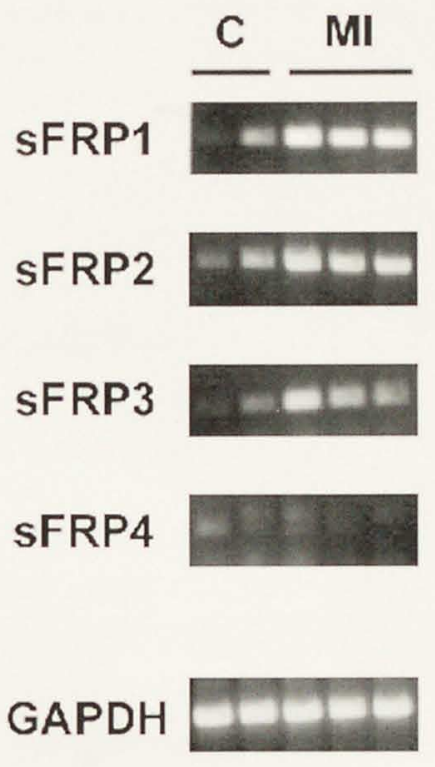

Figure 2. The RT-PCR reaction of different FRP homologues 7 days after MI. The expression of FRPI, 2 and 3 appeared to be upregulated after MI compared to the SHAM. 


\section{Results}

Using RT-PCR, the expression of $\mathrm{fz}$ homologues was studied in the mouse model for MI. The transcripts of all $\mathrm{fz}$ homologues could be detected in the adult mouse heart (fig. 1). The expression of $f z 1$ and 2 was clearly upregulated seven days after MI compared to the SHAM operated controls. To a lesser extent the expression of $f z 7$ was also upregulated. The other $f z$ homologues ( $f z 3-f z 6$ and $f z 8$ ) showed no regulation of their expression after MI.

The expression of the FRPs was also studied in the mouse model for MI. Fig. 2 shows that FRP1, and to a lesser extent FRP2 and 3 were upregulated seven days after MI, compared to the SHAM operated controls. FRP4 was only weakly expressed in the adult heart and its expression was not regulated after MI.

In a previous study we localized the $\mathrm{fz} 2$ expression to the myofibroblasts in the granulation tissue after $\mathrm{MI}$ in rats. To confirm that in mice this expression pattern was similar, we performed in situ hybridization on infarcted mouse hearts seven
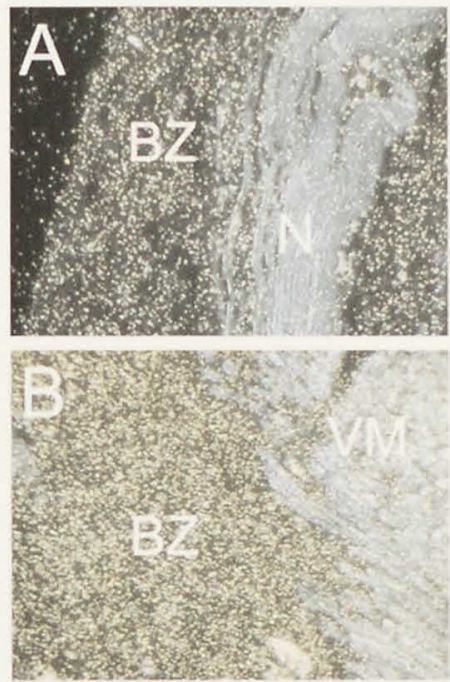
days after infarction $(n=2)$. At this timepoint the necrotic area is still present in the infarcted left ventricular wall. The expression signal of $\mathrm{fz} 2$ was mainly localized over the border zone around the area of necrosis, but some signal could also be observed over the viable cardiomyocytes (fig. 3).

Figure 3. Dark field image of the in situ hybridization of $f z 2$ on a mouse left ventricle 7 days after MI (A). The white spots represent the expression signal. Signal could clearly be observed over the borderzone of the infarct (BZ). Over the necrotic area some background signal could be observed (N) (magnification $\times 200$ ). Dark fiend image of the in situ hybridization of $\mathrm{fz} 2$ on a second mouse left ventricle 7 days after MI (B). The white spots represent the expression signal. Intense signal could be seen in the borderzone (BZ) between the viable myocytes (VM) and the necrotic area (N). Some signal could also be observed above the viable myocytes (magnification $\times 200$ ).

\section{Discussion}

Seven days after MI the expression of $f z 1,2$ and to a lesser extent $f z 7$ are upregulated in the murine heart. We localized the fz2 expression to the borderzone of the necrotic area. Furthermore, FRP1 and 2 and to a lesser extent FRP3 were also upregulated 7 days after $\mathrm{MI}$ in mice. The $f_{z} 1$ and $f_{z} 2$ genes in mice and rat are very similar. The expression similarity of $\mathrm{fz} 2$ after MI in rats ${ }^{38}$ and in mice suggest that both the experimental rat and mouse model can be used to study the role for $\mathrm{fz} 2$ during infarct healing. The regulation of the $\mathrm{fz} 1$ expression seems, however, to be different between the species; in rat the f $z 1$ expression is not upregulated after $\mathrm{MI}^{38}$, whereas we did observe upregulation of the $\mathrm{f} z 1$ expression after MI in mice. 
So far the only frizzled genes described in rats are $f z 1$ and $f z 2^{46}$, therefore no comparison could be made for the expression of other frizzled genes in rats and mice. In humans $f z 1,2$ and 7 are also expressed in adult hearts ${ }^{45}$. These genes might participate in the cardiac wound healing process following MI in humans.

The FRP homologues are proposed to function as antagonists for the $f z$ proteins. The CRD domains of fzs ad FRPs are proposed to be involved in wnt binding ${ }^{5.4}$ 1(1), 1122. The CRDs of the FRPs can be divided into two groups; FRP1 and 2 are very similar and FRP3 and FRP4 are very similar (see chapter 1). FRP1 and 2 are more upregulated after MI. Their CRDs are very different from the CRDs of the $f z 1,2$ and 7, the upregulated fzs after MI. Although the precise mechanism of the wnt- $f z$ and wnt-FRP interaction still has to be clarified, this might suggest that the upregulated FRPs interact with different wnts as $f z 1,2$ and 7 . So far the expression or role of wnt proteins in cardiac remodeling has not been studied, but the expression of wnt1, 8 and 11 during vertebrate cardiac development ${ }^{198,}$ 199. 204 suggest a role for these wnts during the wound healing after MI.

Another study in humans reported that the expression levels of FRP1 and 2 were not elevated in hearts of patients with dilated cardiomyopathy and coronary heart disease compared to non-failing donor hearts, in contrast to FRP3 and 4, whose expression levels were upregulated ${ }^{110}$. These findings are not in agreement with our observations. This difference could be explained by the species studied. Moreover, both studies investigated different cardiac remodeling processes.

FRPs have been shown to influence the sensitivity to apoptosis ${ }^{104}, 113$. Overexpression of SARP1 (=FRP2) has been shown to make cells more resistant to apoptosis, but overexpression of SARP2 (=FRP1) has been shown to make cells more susceptible to apoptosis ${ }^{10.4}$. Apoptosis is involved in the healing process after $\mathrm{MI}$; it contributes to the death of cardiomyocytes and other cells like endothelial cells and fibroblasts. A role for FRP1 and 2 in the apoptotic process after MI could therefore be anticipated. Opposite roles in apoptosis have been described for FRP1 and FRP2 ${ }^{104}$, but both FRPs were upregulated seven days after MI. The exact functions and interaction patterns of the FRP family still have to be clarified, but an explanation might be that FRP1 and 2 exhibit effects on different cells in the infarct area. No expression localization studies were done to verify this theory.

In conclusion, the present study demonstrates the expression of $f z 1,2$ and 7 and FRP1, 2 and 3 , seven days after MI in mice, suggesting a role for the wnt-fz signal transduction pathway in the remodeling process after MI. Furthermore we localized the $f z 2$ expression to the borderzone of the infarct area, which is similar to the $f z 2$ expression in the rat model for MI. This indicates that also the mouse model for MI can be used to study the role for $f z 2$ in the healing process after MI. 
Chapter 3

FRIZZLED 2 RNA EXPRESSION AND PROTEIN LOCALIZATION IN INTESTINAL EPITHELIAL CELLS DURING THEIR MIGRATION ALONG THE VILLI.

ME van Gijn, P Eftekhari,YPG Essers-Janssen, C den Bakker, J Hoebeke, JFM Smits and WM Blankesteijn

Submitted 


\begin{abstract}
F\%2, a homologue of the Drosophila tissue polarity gene frizzled, is expressed in myofibroblasts migrating into the granulation tissue in the heart after myocardial infarction, a highly organized process. In order to study if the family of frizzled receptors is also expressed in other highly organized proliferation/migration processes, we studied the f $\%$ expression in the crypt villus units of the rat and mouse intestine. The proliferation and migration of epithelial cells in the cryptvillus units is also highly organized. Furthermore an antibody was produced against the third extracellular loop of $\mathrm{f} z 2$ in order to study the receptor at protein level. We demonstrated that in the mouse intestine $6 \% 1-7$ were expressed and that the expression of $f: 2$ was predominantly localized in the crypts, but that the $f z 2$ protein was localized at the membrane of the villus epithelial cells. The presence of $\mathrm{f} \approx 2$ expression in this highly organized cellular proliferation and migration model suggests that $f \% 2$ expression is not unique for migrating cardiac myofibroblasts, but is a more general phenomenon in proliferating and migrating cells.
\end{abstract}

\title{
Introduction
}

$F z$ is a family of seven-transmembrane receptors that is involved in the control of planar polarity in Drosophila. In a previous study we have observed that $f \% 2$ was expressed in myofibroblasts in the rat heart after myocardial infarction during their proliferation and migration into the necrotic area ${ }^{36}$. $\Lambda$ fter alignment of the cells the expression was found to be decreased. The migration of the myofibroblasts is a highly organized process: after migration the myofibroblasts in the granulation tissue are orientated parallel with the epi- and endocardium. We suggested that $f z 2$ might have a role in the control of the migration.

Another process that involves highly organized migration and proliferation can be found in the intestine. In the crypt-villus units of the intestine, the epithelial cells proliferate in the crypts of lieberkühn after which they differentiate during a highly organized, rapid migration to the top of the villi. Cells on the villus tip undergo apoptosis and are removed by extrusion into the lumen. In healthy intestine $\beta$-catenin and $\triangle P C$ protein, proteins involved in the signal transduction in the wnt-f\% cascade ${ }^{220}$, are expressed in the cells distributed along the length of the crypt-villus units and involved in intestinal cpithelial homeostasis ${ }^{221-223}$. A dysfunctional degradation of $\beta$-catenin can lead to uncontrolled intestinal epithelial cell proliferation and migration. Mutations in $\triangle P C$ and $\beta$-catenin itself, which influence the stabilization of $\beta$-catenin, lead to intestinal adenomas and adenocarcinomas in humans and mice ${ }^{181-183,224.225}$. Therefore it can be anticipated that the wnt- $f \%$ cascade plays a role in the control of the migration and proliferation of the intestinal epithelial cells.

So far is not clear which member of the fz family is involved in the control of epithelial cell proliferation and migration. The fz family is large with already more than 10 members described. Human $f z 1$, rat $f z 1$ and 2 and to a lesser extend mouse 
fz10 have been found to be expressed in intestinal tissue ${ }^{45,46,55}$, but localization of the expression has not been studied. Moreover, it has not been possible so far to study $f z$ at protein level due to the lack of antibodies. To characterize the $f z s$ in mouse and rat intestine we performed RT-PCR for the different mouse fzs, and we localized the $f z 2$ expression in the rat intestine with in situ hybridization. Furthermore a polyclonal rabbit antibody was produced against a synthetic peptide corresponding to the third extracellular loop of rat $f z 2$, which was used in immunohistochemistry to detect $\mathrm{fz} 2$ in the rat intestine.

\section{Methods}

\section{Animals and tissue preparation}

Adult male Wistar rats, rat embryos of a gestational age of 17 days Winkelmann, Borchen, Germany) and adult male mice (Swiss, Charles River Laboratories, Maastricht, The Netherlands) were used in this study. They were housed in groups of 3 to 4 animals with free access to food and tap water. The embryos and the adult intestine were fixed overnight with $4 \%$ paraformaldehyde in $0.1 \mathrm{M}$ phosphate buffer ( $\mathrm{pH}$ 7.4), dehydrated and embedded in paraffin. The mouse intestine was rinsed in phosphate-buffered saline (PBS), frozen in liquid nitrogen and kept at $80^{\circ} \mathrm{C}$ until RNA isolation.

\section{Reverse transcriptase polymerase chain reaction}

RNA was isolated from the small intestine by $\mathrm{LiCl} /$ urea method ${ }^{219}$. Aliquots of $500 \mathrm{ng}$ of total RNA were reverse-transcribed using ready-To-Go RT-PCR beads (Pharmacia, Uppsala, Sweden). After amplification by PCR using the primer sets shown in table $1\left(1 \mathrm{~min}\right.$ at $94^{\circ} \mathrm{C} 1 \mathrm{~min}$ at $55^{\circ} \mathrm{C}$ and 1 minute at $72{ }^{\circ} \mathrm{C}, 30$ and 35 cycles), the PCR fragments were separated on ethidium bromide containing agarose gel.

Table 1. Primer sets for the $\mathrm{fz}$ PCR reactions

\begin{tabular}{|c|c|c|}
\hline Gene & Upper primer & Lower primer \\
\hline $\mathrm{Mfzl}$ & GCCCTGCGAACCCACTAAAGTATA & CCCGTCCTCTGCAAACTIGTCGTT \\
\hline Mfz2 & GIICTGGGTGAGGCGATTGT & CAGCAGGAAGGATGAACCGAT \\
\hline $\mathrm{Mfz} 3$ & TGTCGGCCTCTACGACG & CTGAAAACACCAATCCGG \\
\hline Mfz4 & CGCTCATCCAGTACGGC & CAGCCATCCAAATATCCG \\
\hline Mfz5 & GTCACACCCGCTCTACAACAAGGT & CTCGTAGTGGATGTGGTTGTGCTC \\
\hline Mfz6 & GGTICTITAAGCGAAACCG & TIICTICAAGCGTCGGA \\
\hline Mfz7 & TGGTGCTTGCTCTTCTGGGCG & CACGGAGGAATGGCTIGGTCG \\
\hline$M f z 8$ & TGCCAAGAGATCACGGTGCCG & AGTGTC CGGGTTGCCCTGCTC \\
\hline GAPDH & ACGGATITGGCCGTATTG & CGTCAGATCCACGACGGA \\
\hline
\end{tabular}




\section{Radioactive in situ byloridization}

The probe used for in situ hybridization was derived from a 566 bp PCR fragment of $\mathrm{rf}^{2}$ 2. The PCR fragment was cloned into the $\mathrm{pCll}$ vector (Invitrogen Corp., San Dicgo, $C A$ ), and the correct orientation of the insert was confirmed by sequencing. The plasmid was linearized with $S / m$ I (Pharmacia), that cuts at a unique site in the sequence of the PCR fragment, resulting in a 327-base RNA transcript. RNA transcripts of the digested insert were made with SP6 RNA polymerase by using $\left[{ }^{35} \mathrm{~S}\right]$ UTP and the RN $\Lambda$ labeling kit (Amersham, Little Chalfond, UK). Hybridization of $5 \mu \mathrm{m}$ paraffin embedded sections and visualization of the in situ signal were done as described previously ${ }^{38}$.

\section{Non-radiocative in situ bybridization}

Sense and antisense digoxygenin (DIG) labeled RN $A$ probes derived from a 566 bp PCR fragment of rat $\mathrm{fz} 2$ were generated, cloned in pTZ18 (Pharmacia) in both orientations. After linearization with BamH1, DIG labeled RNA was transcribed from the T7 promoter. Hybridization of $5 \mu \mathrm{m}$ paraffin embedded sections, and visualization with alkaline phosphatase coupled anti-DIG antibodies and indoxilnitroblue tetrazolium (NBT/BCIP) substrate were done essentially as described previously ${ }^{226}$. Sections were counterstained with nuclear red.

\section{Peptide}

$\Lambda$ peptide was synthesized corresponding to the sequence of the third extracellular loop of rat $f z 2$ : WERSWVSOHCKSLAIPC(AcM)PAHYTPRTSPDF (W29F peptide)

The underlined part corresponds to the predicted T helper cell epitope ${ }^{227}$; the part that is not underlined encompasses B-cell epitopes, involved in the humoral response. AcM is an acetomethoxy group, blocking the sulhydryl group of the cystein.

The peptide was synthesized by the solid phase method using Fmoc reagents in a $430 A$ automated peptide synthesizer (Applied Biosystems, Foster City CA, USA) and its purity was checked by HPIC after cleavage and desalting on a P2 (Biorad, Hercules $C A, U S A$ ) column and by mass spectrometry.

\section{Inmmunization schedule}

A rabbit was immunized subcutaneously with $250 \mu \mathrm{g}$ peptide $+3 \mathrm{mg}$ methylated bovine serum albumine (BSA) (Calbiochem-Nevabiochem Corporation, San Diego CA, USA). Primo-injections were performed in Complete Freund's adjuvant and three booster injections at three week intervals in Incomplete Freund's adjuvant. Serum was collected one week after the last booster injection.

\section{Antibody purification}

The rabbit IgG fraction was precipitated at $40 \% \quad\left(\mathrm{NH}_{4}\right)_{2} \mathrm{SO}_{4}$ saturation and redisolved in PBS $(\mathrm{pH}=7.4)$ at 1:1 dilution. The $\mathrm{W} 29 \mathrm{~F}$ peptide was coupled to an activated EAH-Sepharose column (Pharmacia), according to the manufacturer's 
instructions. The immunoglobulins of the rabbit were diluted 5 times in PBS $(\mathrm{pH}=7.4)$ and centrifuged at $200 \mathrm{~g}$ for $5 \mathrm{~min}$. They were then passed through the column with a flow of $6 \mathrm{ml} / \mathrm{h}$ for $3 \mathrm{~h}$ at $4^{\circ} \mathrm{C}$. Finally the absorbed antibodies were eluted with $3 \mathrm{ml} \mathrm{KSCN} 3 \mathrm{M}$ and dialysed directly against $61 \mathrm{PBS}$ overnight at $4{ }^{\circ} \mathrm{C}$. The final concentration was $3.9 \mathrm{mg} / \mathrm{ml}$. They were stored at $-20^{\circ} \mathrm{C}$.

\section{Ensyme immmmoassay}

W29F pepticle was coated in $100 \mathrm{mM} \mathrm{Na} \mathrm{CO}_{3}(1 \mu \mathrm{g} / \mathrm{ml})$ at $\mathrm{pH}=9.6$ for $1 \mathrm{~h}$ on microtiter plates (Falcon 3912, Microtest III, Oxnard, Canada) at $37^{\circ} \mathrm{C}$. After four washes with PBS supplemented with $0.1 \%$ Tween 20 (PBS-T) (Merck), the wells were saturated with PBS-T and $1 \% \mathrm{BSA}$ for $1 \mathrm{~h}$ at $37^{\circ} \mathrm{C}$. Fifty $\mu \mathrm{l}$ of serum $(1: 500$ to $1: 256000)$ or affinity-purified antibody $(1: 250$ to $1: 32000)$ were added to the saturated microplates and incubated for $1 \mathrm{~h}$ at $37^{\circ} \mathrm{C}$. After washing the wells four times with PBS-T, affinity purified goat anti-rabbit $\operatorname{lgG}(1: 33000)$ conjugated to horsradish peroxidase (HRP) (Jackson Immunoresearch Laboratoria, USA) were allowed to react for $1 \mathrm{~h}$ at $37^{\circ} \mathrm{C}$. The wells were washed three times with PBS-T and two times with PBS before the color reaction with 3,3, 5,5'-tetramethyl benzidine (TMB) in the presence of $\mathrm{H}_{2} \mathrm{O}_{2}$ took place.

\section{Immmunobistocbemistiy}

Paraffin sections $(5 \mu \mathrm{m})$ were deparaffinized and submerged in methanol to which $0.3 \% \mathrm{H}_{2} \mathrm{O}_{2}$ was added to inhibit endogenous peroxidase activity. Then they were rehydrated and pretreated with $1 \mathrm{mg} / \mathrm{ml}$ pepsine in $0.1 \mathrm{M} \mathrm{HCl}$. Sections were incubated with the polyclonal frizzled antibody $(1: 25)$ for $1 \mathrm{~h}$ at room temperature or incubated with the antibody $(1: 25)$ that was pre-incubated with the blocking peptide $(50 \mu \mathrm{g} / \mathrm{ml})$ for $1 \mathrm{~h}$ (negative control). Subsequently, the sections were incubated with a biotinylated goat anti rabbit antibody (1:400, Dako Corporation, Carpinteria, CA USA) for $30 \mathrm{~min}$, followed by a $30 \mathrm{~min}$ incubation with a peroxidase coupled $A B C$ reagent (1:100, Dako). The staining reaction was performed by exposing the slides to diaminobenzidine (DAB) diluted in $0.05 \mathrm{M}$ Tris for 5 minutes, to which $0.005 \% \mathrm{H}_{2} \mathrm{O}_{2}$ was added, followed by rinsing in water. Finally, the sections were counterstained with Mayer's hematoxylin, dehydrated, and coverslips were mounted using enthellan (Merck)

\section{Results}

\section{Frexpression in the small intestine}

The expression of different $f z$ homologues in the mouse was studied using RT-PCR (fig. 1). The expression of all the $f z$ isoforms, except f $z 8$, could be detected in the small intestine. Although the RT-PCR was only a semi-quantitative method, the most abundant signal could be observed for $f z 5$, which was clearly detected with 30 PCR-cycles. For $f z 4$ and $f z 7$ a band was also demonstrated at 30 cycles. The expression signal of $f z 1, f z 2, f z 3$ and $f: 6$ could be detected at 35 cycles, 


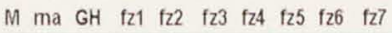

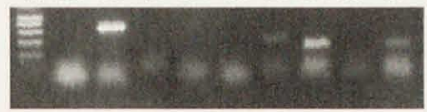

30 cycles

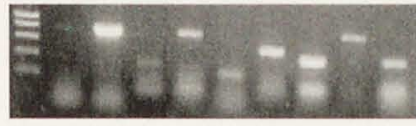

Figure I. The expression of different $f z$ homologues in the adult mouse intestine studied by RT-PCR. The PCR products were analyzed after 30 and 35 cycles. In lane 2 and 3. PCR products with the GAPDH primer set are shown. In lane 2. the RNA was not subjected to an RT reaction (negative control), whereas in lane 3 , the PCR 35 cycles reaction was performed on RNA reverse transcribed into DNA, In lane 4-10 the RT-PCR of $f z \mid-f z 7$ are shown.

but the expression signal of $f z 1$ and $f z 3$ appeared to be low in the intestine. Fz 8 could not be detected in the intestine (not shown). To analyze the RNA for potential contamination with genomic DNA, we performed a PCR reaction on a sample of RNA, which was not transcribed into cDNA. After 35 cycles a very faint signal could be detected with the GAPDH primer set, pointing to a slight contamination of the RNA sample with genomic DNA. The signal obtained with the fz primer sets, however, was considerably stronger, which suggests that this signal can not be attributed to amplification of genomic DNA rather than cDNA.

\section{Localization of the f2 2 expression}

The $f z 2$ expression in the adult rat intestine was localized with non-radioactive in situ hybridization (fig. 2). The signal obtained with the antisense probe was most abundant in the crypt cells, although some signal still could be detected in the epithelial cells in the villi (fig. 2 a). No signal could be detected with the sense probe (fig. $2 b$ ). Apart from $\mathrm{fz} 2$ expression in the adult intestine, $\mathrm{f} z 2$ expression could also be detected with radioactive in situ hybridization in the rat fetal intestine. At the gestational age of 17 days, the expression could predominantly be detected in the intestinal crypts (fig. 3), similar to the adult expression pattern.

\begin{tabular}{|c|c|}
\hline $\mathrm{E} Z 2$ & WERSWUSQHCKSLA TPCP-----AHYTPR--TSPDF \\
\hline HE 22 & WERSWVSQHCKSLAIPCP-----AHYTPR-MSPDE \\
\hline & WERSWVAQSCKSYAIPCPHLQA.GGGA.PPHPEM SPDE \\
\hline & WERSWVAQSCKSYAI PC PHLQGGGGV PRH PEM SPDE \\
\hline & WERSWVAQSCKSYAI PCPHLQGGGGVPPH PPM \\
\hline & 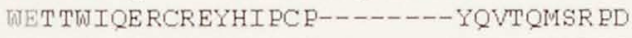 \\
\hline & WETTWIQERCREYHIPCE----- \\
\hline & ARV $---2--1$ \\
\hline & \\
\hline & 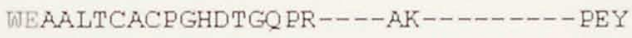 \\
\hline & YHIECP------ \\
\hline & YRIPCP-- - - - - \\
\hline & YAVPCP---- PGHE P PIי--- \\
\hline & YAVPCE----PRHES EM---S \\
\hline & LQPDQA-----RR-- \\
\hline & LQPDQA $----\mathrm{RF}$ \\
\hline & A.A.GEGG----1 \\
\hline & ATVPGG----RF \\
\hline & $-\mathrm{NN} Q \mathrm{TK}----\mathrm{TL}$ \\
\hline & ESIPCPAARA.PGS---- PEAH \\
\hline & K--GPGKK- \\
\hline
\end{tabular}

Figure 4. Part of the third extracellular loops of several $\mathrm{fz}$ homologues are shown. The bold printed amino acids represent the peptide (W29F) towards which the antibodies were directed. The amino acids in italic represent the predicted T cell epitope. 
Frizoled in small intestinc
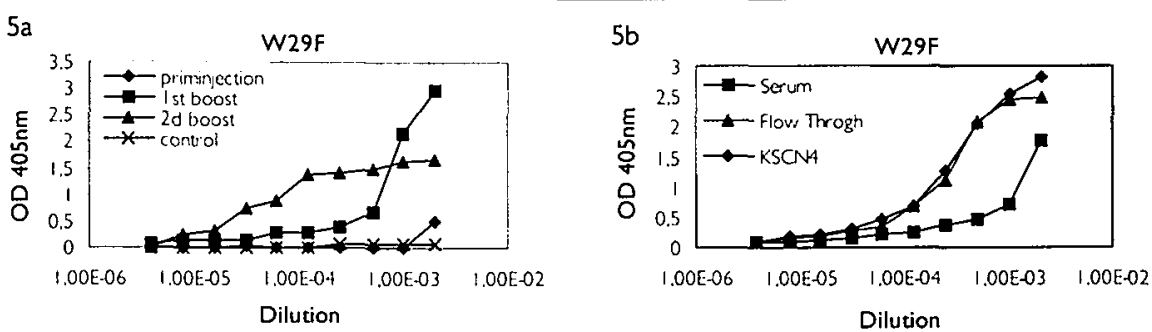

Figure 5a+5b. Enzyme immunoassay on the serum of a rabbit, immunized with the W29F peptide (5a). Blood samples were taken after the different W29F peptide injections. Enzyme immunoassay on the purified antibodies is shown in fig. (5b). The KSCN4 fraction is the fraction that bound to the W29F column, the "flow through" is the fraction that did not bind to the W29F column, furthermore the crude serum is shown. The response (absorbance at $405 \mathrm{~nm}$ ) is shown as a function of the dilution.

\section{Production and purification of antitody directed against $\mathfrak{Z Z}^{2}$}

A peptide (W29F) corresponding to the third extracellular loop of $f z 2$ was synthesized. The sequence of the $B$ cell epitope, which is responsible for the functional recognition by the antibodies, has a minor homology to other fzs (fig. 4). Therefore, the developed antibody is likely to be specific for $\mathrm{fz} 2$ and not to crossreact with other members of the f\% family.

The immunized rabbit produced high titres of anti-peptide W29F antibody. The ELLISA test using serum (fig. 5a) and purified antibody (fig. 5b) revealed a positive response even up to 1:100.000 dilutions.

\section{Immunobistochemistry with the antibody' directed against fi2 2}

In fig. $6 a$ and $b$ the detection of the f $\% 2$ protein using the antibody directed against the W29F peptide is shown. At the membrane of the crypts cells no fz2 could be detected, but in the villi the epithelial cells showed a clear staining at the membrane. Some cytoplasmic staining was visible in the epithelial cells in the crypt and the villi. This staining, however, did not disappear after incubation with the blocking peptide, suggesting it to be non-specific staining. The staining at the cell membrane disappeared when a pre-incubation step with the blocking peptide $(\mathrm{W} 29 \mathrm{~F})$ was performed (fig. 6c), indicating that the signal at the cell membrane was specific.

\section{Discussion}

In this study the different fzs that are expressed in the small intestine were characterized. In the mouse, expression of $f z 1-f z 7$, but not $f z 8$, could be detected, although there were differences in expression levels. With RT-PCR we have found an abundant expression of $f \times 5$ but $f z 1$ expression was low. The expression of different $f z$ homologues suggests that the wnt-fz cascade plays a role in normal intestinal epithelial homeostasis. Furthermore we localized the f $z 2$ expression in the intestine. The RNA expression was most abundant in the crypts in the adult intestine as well as the fetal intestine. 
We developed a polyclonal rabbit antibody directed against the third extracellular loop of $f z 2$. The synthetic $f z 2$ peptide was very potent in inducing an immune response, as shown by the high titer of the antibodies. The $f z 2$ protein in the intestine was visualized at the membrane of the epithelial cells in the villi in the rat, which could be expected, as $\mathrm{f}_{\mathrm{z}} 2$ is a seven-transmembrane receptor. Although the antibody induced background staining in the cytoplasm, the staining at the membrane was specific for $\mathrm{fz} 2$, as this signal could be blocked by a pre-incubation step with the blocking peptide. The $B$ cell epitopes of the peptide, involved in the humoral response, had only minor homologies with other fzs, while the sequence of the $T$ cell epitope had similarities with $f z 1$. Although the $T$ cell epitope is involved in B cell stimulation rather than in antibody recognition, we can not exclude that the antibody cross-reacts with $f z 1$. Since the expression of $f z 1$ in the intestine in the mouse was lower than $f z 2$ and potential cross-reactive antibodies will be less efficient in $f_{z} 1$ immunolocalization, we expect the contribution of $f z 1$ to the signal to be small or neglectable.

In the small intestine processes such as cellular proliferation, differentiation, migration/adhesion, and death can be found in well-defined domains of the anatomically distinct crypt-villus units. The cells proliferate in the crypts of Lieberkühn and differentiate during a highly organized rapid migration to the top of the villus. The $f z$ protein could be detected in the villi, where the epithelial cells are in a differentiation/migration phase, which suggests a role for $f z 2$ in these processes. Interestingly, while mRN $\Lambda$ was most abundant in the crypt cells, the receptor protein was mainly expressed in the epithelial cells of the villi where mRNA expression was much lower. The dissociation between the sites of transcription and translation might be explained by the migration of the cells from crypts to villi.

In this respect we suggest a parallel with the migrating and proliferating myofibroblasts in the heart after myocardial infarction, which also express fz2 during their migration phase ${ }^{38}$. The migration and proliferation of myofibroblasts is a highly organized process. The finding that proliferating and migrating myofibroblasts as well as proliferating and migrating intestinal epithelial cells express $f z 2$ suggests that the proposed role for $f \% 2$ in organized migration and proliferation is a more general phenomena and not restricted to only a single cell type.

Recently the $f z 5$ expression in the adult mouse intestine has been localized to the crypts, but unfortunately no protein data were available ${ }^{228}$. Further experiments are necessary to see if this expression pattern is shared between more $f z$ receptors. The expression of wnts, the proposed ligands for the $f z$ receptors, has been studied as well. Wnt2, 4, 5b and 13 have been found to be expressed in the human colon $^{72,229,230}$. Furthermore wnt 2 and 5 a have been hypothesized to play a role in tumor progression in human colorectal cancer ${ }^{229}, 230$. These findings are in agreement with the hypothesis that the wnt-fz casade is involved in the control of the migration and proliferation of the epithelial cells of the intestinal tract.

In conclusion, the expression of $\mathrm{f} z 1-\mathrm{fz} 7$ in adult mouse intestine suggests an important role for the wnt- $f z$ cascade in intestinal physiology. The expression of 
fz2 was predominantly localized to the crypt epithelial cells, but could also be observed in the epithelial cells in the villi. Furthermore, we have produced a polyclonal antibody against $f z 2$. This is the first described antibody that reacts with the $f z 2$ protein. So far it has been difficult to study the wnt-fz cascade due to the lack of antibodies and purified ligands for wnt and fz proteins. Our antibody can be a useful tool in studies that involve fz2 proteins. Moreover, the peptide sequence, to which the antibody was directed, is identical to the third extracellular loop of the human fz2, so we expect that the antibody could also be used in human tissues. The observation that $f z 2$ is expressed in two models of highly organized cell migration and proliferation strengthens our hypothesis that $f z 2$ is involved in the control of cell migration and proliferation. 

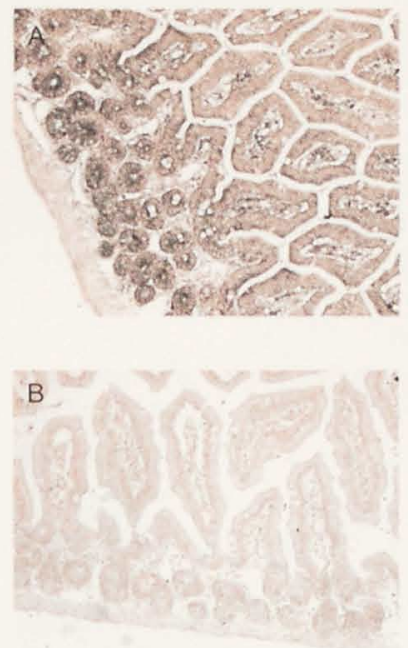

Figure 2. In situ hybridization with the antisense $f z 2$ probe (A). Note that the purple signal was more prominent in the crypts than in the villi. No signal could be observed in the in situ hybridization with the sense probe (B) (magnification $\times 200$ ).

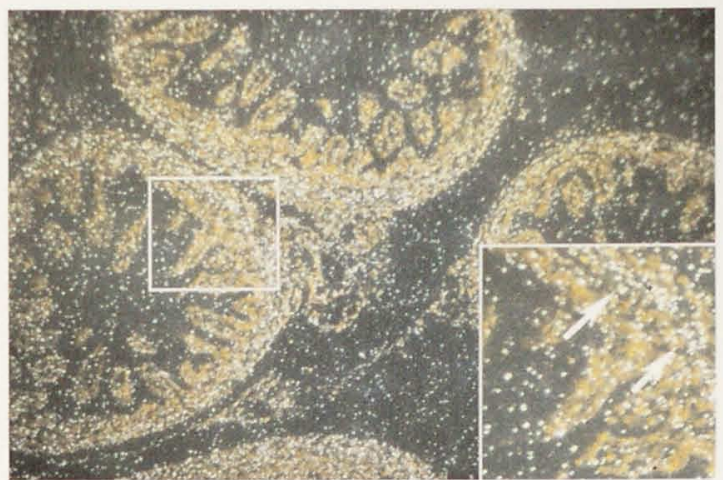

Figure 3. Dark field image of the radioactive in situ hybridization of $f z 2$ on fetal rat ( 17 days gestational age) intestine. The white spots represent the photographic grains. More signal was observed over the crypts than over the villi (magnification $\times 100$ ).
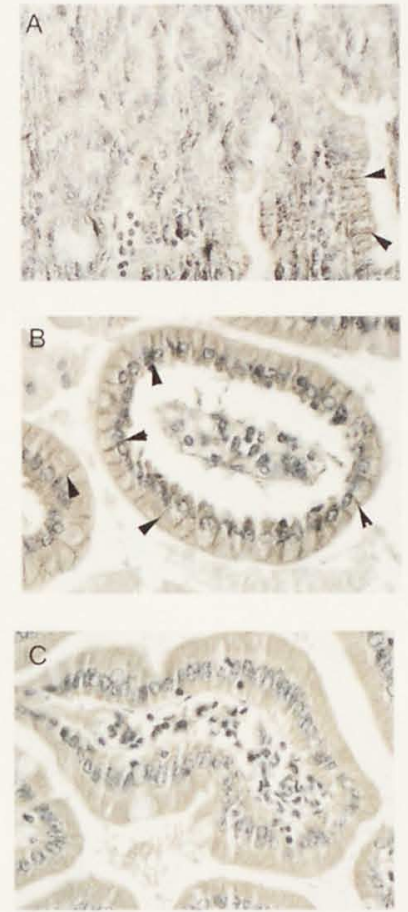

Figure 6. Immunohistochemistry of sections of rat intestine with the $\mathrm{fz} 2$ antibody. (A) no signal at the membrane of the crypt cells could be detected, but an intense brown signal was observed at the membranes of the epithelial cells in the villi (see arrows) (magnification $\times 400)$. (B) higher magnification $(\times 800)$ of the villi, where signal at the membranes was observed (see arrow). (C) When the antibody was pre-incubated with the blocking peptide the $\mathrm{fz} 2$-specific signal at the membrane of the epithelial cells disappeared, although some non-specific cytoplasmatic signal remained present (magnification $\times$ 800) 


\section{Chapter 4}

\section{FRIZZLED 2 IS TRANSIENTLY EXPRESSED IN NEURAL CREST CONTAINING AREAS DURING DEVELOPMENT OF THE HEART AND GREAT ARTERIES IN THE MOUSE}

M. E. van Gijn, W. Matthijs Blankesteijn, Jos F.M. Smits, B. Hierck and A. C. Gittenberger-de Groot

adapted from Anat Embryol 2001; 203: 185-192 


\begin{abstract}
Frizzled 2 ( $f z 2)$ acts as a 7 -transmembrane receptor in the wnt-fz signal transduction cascade. Among others, this cascade has been associated with neural crest cell proliferation and early migration during development in mammals. The genes for some components of this cascade are located in chromosomal regions that are deleted in human syndromes associated with neural crest cell defects, like DiGcorge and Velo-Cardio-Facial Syndrome. These syndromes are often accompanied by abnormalities in cardiac morphology. Furthermore, we have reported in previous studies the upregulation of the tissue polarity gene $f z 2$ in myofibroblasts during their migration into the necrotic area after myocardial infarction in the adult heart. It is known that genes that are upregulated during cardiac remodeling due to pathology often play a role during development. To investigate whether $f z 2$ can be associated with the process of cardiac morphogenesis we studied its expression in the thoracic arterial system and heart of mouse embryo's of $10,12,14,16$ and 18 days after conception by means of in situ hybridization. At day 10 after conception signal could be found in the pharyngeal arches and arch arteries. The outflow tract, the ascending aorta and the pulmonary trunk were positive for $\mathrm{f} z 2$ from day 12 on. This expression decreased with time and at day 18 only some signal could be detected in the aorta and pulmonary trunk. In contrast, in coronary and pulmonary arteries no expression was observed at any time point. Minor myocardial expression was observed in the ventricular septum at day 12 and 14. Atrial expression, although considerably lower than ventricular expression, could be detected somewhat later at days 14 and 16. Our results indicate that there is transient expression of $f z 2$ in areas that are invested by neural crest cells. This expression is downregulated upon neural crest cell differentiation. The $f z 2$ expression supports a role for the wnt-fz pathway in neural crest related disorders.
\end{abstract}

\title{
Introduction
}

The mammalian homologues of Drosophila tissue polarity gene 'frizzled' consist of a family with multiple members, all encoding seven transmembrane receptor proteins". In developing Drosophila wings, transcripts of the 'frizzled' gene have been demonstrated to transduce and translate polarity signals for hair and bristle development on the epidermal cells, probably through an interaction with the cytoskeleton ${ }^{231}$. This involvement in the spatial control of wing hair polarity during development may suggest a similar role in architectural control in mammals. The current theory about the function of the $\mathrm{f} z$ proteins is that they act as receptors for the wnt proteins ${ }^{32}$. The function of the wnt family has already been studied during mammalian embryology. It was observed that wnt 1 and wnt 3 a signaling can regulate the dorsal-ventral patterning in mammalian CNS through the control of cell proliferation ${ }^{201}$. Furthermore, in in vitro assays that aimed at investigating neural crest induction by surface ectoderm, a correlation between appearance of 
wnt 1 expression and migration of neural crest cells was found ${ }^{232}$. The expression of the wnt 1 in early migrating neural crest cells and the observation that this gene is not expressed afterwards in any other place during development ${ }^{233}$ has been used to construct a Cre/lox neural crest reporter mouse ${ }^{23+4}$. This mouse model shows the fate of neural crest cells after homing to the target organs. These data indicate that members of the wnt family are involved in neural crest migration. The role of $\mathrm{fz}$ proteins in this process, however, has not been studied.

In recent years, a relation between the wnt-fz pathway and several birth defect syndromes has been suggested. The Williams-Beuren syndrome is a neurodevelopmental disorder with multiple manifestations, including supravalvar aortic or pulmonic stenosis. It is associated, with a deletion on chromosome 7 , known to contain a $\mathrm{f} \%$ homologue ${ }^{-17}$. Furthermore, syndromes associated with neural crest defects, like the 22q11 deletion associated DiGeorge (DGS) and Velo-Cardio-Facial syndrome (VCFS), are often accompanied by abnormalities in cardiac morphology. Several deletions on chromosome 22 , known to contain homologues of dvl and $\beta$-catenin, which are both members of the wnt-fz signal transduction pathway, have been described ${ }^{235,236}$. These findings suggest a relation between the syndromes and the wnt-f $\%$ cascade.

The expression of the wnt- $f z$ cascade is not strictly a developmental process, since $f \%$ is also expressed during tissue repair. In previous studies, our group has found that the expression of a rat homologue of $f z, f z 2$ is upregulated in the heart after left ventricular hypertrophy ${ }^{218}$. Furthermore we have found that the $f z 2$ expression is upregulated in the myofibroblasts after myocardial infarction during the proliferation and migration of these cells in the necrotic area ${ }^{38}$.

In this study we investigated in mouse embryos the hypothesis that $\mathrm{f} z 2$ has a role during cardiac morphogenesis and more specifically during the migration and proliferation of neural crest cells into the heart during development.

\section{Materials and methods}

\section{Tissue preparation}

Mouse embryos (Albino Swiss CF-1) were collected at day 10, 12, 14, 16 and 18 after fertilization. Whole embryos were fixed overnight with $4 \%$ paraformaldehyde in $0.1 \mathrm{M}$ phosphate buffer ( $\mathrm{pH} 7.4$ ), dehydrated and imbedded in paraffin. Sections of $5 \mu \mathrm{m}$ were made of the thoracic region and serially mounted; because of the size of the embryo of 10 days after conception, the complete embryo was cut for this stage.

\section{In situ bybridization}

The sense and antisense cRN $A$ probe used for in situ hybridization were derived from a 566 bp PCR fragment of rat fz2. The PCR fragment was cloned into the $\mathrm{pCIl}$ vector (Invitrogen Corp., San Diego, $\mathrm{CA}$ ), and the correct orientation of the insert was confirmed by sequencing. The plasmid was linearized with Stul (Pharmacia, Uppsala, Sweden), that cuts at a unique site in the sequence of the PCR 
fragment, resulting in a 327-base RNA transcript. RNA transcripts of the digested insert were made with SP6 RNA polymerase by using $\left[{ }^{35} \mathrm{~S}\right]$ UTP and the RNA labeling kit (Amersham, Little Chalfond, UK).

The sections were deparaffinized and rehydrated, followed by an incubation of 20 minutes with 4\% paraformaldehyde in PBS on ice. Then the sections were treated with proteinase $\mathrm{K}(20 \mathrm{mg} / \mathrm{ml})$ for 5 minutes at room temperature. After this step a second incubation with $4 \%$ paraformaldehyde for 5 minutes and a 10 minute incubation with $0.1 \mathrm{~mol} / 1$ triethanolamine $(\mathrm{pH} 8.0)$ plus $25 \mathrm{mmol} / 1$ acetic anhydride was performed. Then the sections were dehydrated and hybridized overnight at $55^{\circ} \mathrm{C}$. The hybridization mix consisted of $50 \%$ formamide, $0.3 \mathrm{~mol} /$ $17 \mathrm{NaCl}, 20 \mathrm{~mol} / 1$ Tris-HCl pH 8.0, $5 \mathrm{mmol} / \mathrm{l}$ EDTA, $10 \%$ Dextran sulfate, $1 \mathrm{x}$ Denhardt's, $0.5 \mathrm{mg} / \mathrm{ml}$ calf t-RNA and $100 \mathrm{mmol} / 1$ DTT. The probe $\left(10^{6} \mathrm{cpm} / \mu \mathrm{l}\right)$ was diluted $1: 10$ in the hybridization mix. After incubation with the probe for 16-18 hours, the sections were washed for 15 minutes at $55^{\circ} \mathrm{C}$ with $5 \mathrm{x} \mathrm{SSC} /$ $10 \mathrm{mmol} / \mathrm{l}$ DTT, followed by a wash of 45 minutes at $65^{\circ} \mathrm{C}$ with $50 \%$ formamide $/ 2 \mathrm{xSC} / 100 \mathrm{mmol} / 1 \mathrm{DTT}$. Then the unbound ribonucleotides were digested $(20 \mu \mathrm{g} / \mathrm{ml}$ RNAse $A$ in $0.5 \mathrm{~mol} / 1 \mathrm{NaCl}, 10 \mathrm{mmol} / 1$ Tris $\mathrm{pH} 8.0$ and $5 \mathrm{mmol} / \mathrm{l}$ EDTA) for 30 minutes at $37^{\circ} \mathrm{C}$. $\Lambda$ fter a second wash of 45 minutes at $65^{\circ} \mathrm{C}$ with $50 \%$ formamide/ $2 \mathrm{xSSC} / 100 \mathrm{mmol} / \mathrm{I} \mathrm{DTT}$, the sections were washed 15 minutes at $37^{\circ} \mathrm{C}$ with $2 x$ SSC and 15 minutes at $37^{\circ} \mathrm{C}$ at $0.1 \mathrm{X} \mathrm{SSC}$, followed by dehydration and drying. The sections were dipped in photographic emulsion (Ilford G5 emulsion, Ilford, Mobberley, England) and exposed for one week in the dark at $4^{\circ} \mathrm{C}$. Exposed slides were developed in Kodak D19 developing solution (Kodak, Rochester MD, USA) for $3 \mathrm{~min}$ at room temperature, rinsed in distilled water, and fixed in a solution containing $20 \mathrm{~g} \mathrm{~K}_{2} \mathrm{~S}_{2} \mathrm{O}_{4}$ and $200 \mathrm{~g} \mathrm{Na}_{2} \mathrm{~S}_{2} \mathrm{O}_{3}$ per liter water. Finally, the sections were counterstained with Mayer's hematoxylin, dehydrated, and embedded in enthellan.

\section{Whole-mount in situ bybridization}

Embryos for whole-mount ISH were fixed at embryonic day 10 in $4 \%$ paraformaldehyde. Embryos were bleached in $6 \% \mathrm{H}_{2} \mathrm{O}_{2}$, permeabilized with 10 $\mu \mathrm{g} / \mathrm{ml}$ proteinase- $\mathrm{K}$, and re-fixed in a $0.2 \%$ glutaraldehyde $/ 4 \%$ paraformaldehyde solution. An antisense and sense cRNA probe (see previous section) was labeled with digoxygenin using a DIG RNA labeling kit (Roche/Boehringer Mannheim), according to the manufacturer's protocol. Hybridization was performed in a $50 \%$ formamid solution, containing $5 \mathrm{xSC}, 1 \% \mathrm{SDS}, 50 \mu \mathrm{g} / \mathrm{ml} \mathrm{tRNA}$, and $50 \mu \mathrm{g} / \mathrm{ml}$ Heparin, at $55{ }^{\circ} \mathrm{C}$. DIG detection with an alkaline phosphatase-conjugated monoclonal antibody (Roche) followed posthybridization washes. Staining in a NBT/BCIP solution was performed until sufficient signal was obtained. Negative control embryos were made omitting the cRNA probes in the procedure.

\section{Immmno-bistocbemistry mith the anti smootb muscle actin antibody 1 A4}

The sections were deparaffinized and rehydrated, followed by incubation at $121^{\circ} \mathrm{C}$ 
(microwave) in $0.01 \mathrm{M}$ citrate buffer pH 6.4 for 20 minutes. After rinsing twice in PBS, the sections were submerged in PBS, pH 7.4 to which $0.3 \% \mathrm{H}_{2} \mathrm{O}_{2}$ was added to inhibit endogenous peroxidase activity. After rinsing twice in PBS for 10 minutes and once in PBS with 0.05\% tween-20 (PBS-tween, Sigma, St. Louis MO, USA) for 10 minutes, overnight incubation (at room temperature) took place with the $1 \wedge 4$ antibody [Sigma, St. Louis MO, USA]. The antibody was diluted in a solution of $1 \%$ ovalbumine in PBS-Tween. After rinsing twice in PBS for 10 minutes and once in PBS-tween for 10 minutes, the second incubation was performed for at least $2.5 \mathrm{~h}$ with the rabbit anti-mouse peroxidase conjugated antibody, diluted 1:200. Subsequently, all sections were rinsed twice in PBS, 10 minutes and once in $0.05 \mathrm{M}$

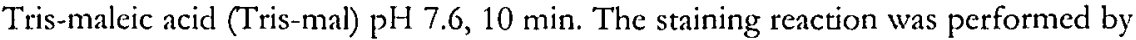
exposing the slides to $\mathrm{D} A \mathrm{~B}$ diluted in Tris-mal for 10 minutes, to which $0.006 \%$ $\mathrm{H}_{2} \mathrm{O}_{2}$ was added, followed by rinsing in water. Finally, the sections were counterstained with Mayer's hematoxylin, dehydrated, and embedded in enthellan (Merck, Darmstadt, Germany).

\section{Apoptosis (TUNEL)}

The sections were deparaffinized and rehydrated. The sections were treated with $0,020 \mathrm{mg} / 1$ proteinase $\mathrm{K}$ in $0,01 \mathrm{~mol} / 1$ Tris $\mathrm{HCl}$ at $37^{\circ} \mathrm{C}$ for 20 minutes. After rinsing three times in PBS the sections were immersed in PBS, pH 7.4 to which $0.3 \% \mathrm{H}_{2} \mathrm{O}_{2}$ was added to inhibit endogenous peroxidase activity. After rinsing three times in PBS the Tdt-mediated dUTP-X nick end labeling (TUNEI) reaction was performed at $37^{\circ} \mathrm{C}$ for 90 minutes (Boehringer, Mannheim, Germany). After rinsing three times with PBS, the sections were incubated with go/HRP- $\alpha-$ FITC at $37^{\circ} \mathrm{C}$ for 45 minutes. Subsequently, all sections were rinsed twice in PBS,

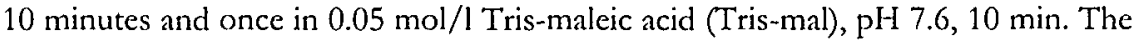
staining reaction was performed by exposing the slides 10 minutes to $D A B$ diluted in Tris-mal, to which $0.006 \% \mathrm{H}_{2} \mathrm{O}_{2}$ was added, followed by rinsing in water. Finally, the sections were counterstained with Mayer's hematoxylin, dehydrated, and embedded in enthellan (Merck, Darmstadt, Germany)

\section{Results}

The localization of the expression of the $f z 2$ gene during cardiac and thoracic arterial development was investigated by means of in situ hybridization. At day 10 after conception (fig. 1) the signal in the pharyngeal arch mesenchyme and the pharyngeal arch artery condensations was abundant, especially in the first and second arch. The signal in the aortic sac was lower than that of the pharyngeal arches. In contrast, the signal in the ventricles, atria and outflow tract was not distinct from the background. The signal in the veins in the neck region was above background levels (not shown), but the veins in the thoracic region showed no signal.

At E12 expression patterns resemble those at E10. Additional signal was found in the aorta, pulmonary trunk, and mesenchyme of the outflow tract of the heart 
(fig. 2), where neural crest cells ${ }^{234}$ are embedded in the now fused endocardial outflow tract cushions. The ventricular myocardium showed some expression but the signal in the atria was similar to background levels (fig. 2). Moreover, photographic grains were detected over the carotid arteries but the veins in the thoracic region and the subclavian arteries did not show any signal (not shown).

At 14 days after conception a marked $f z 2$ signal in the aorta (fig. $3 \mathrm{a}$ ), the pulmonary trunk and the condensed mesenchyme of the outflow tract was still present, although less pronounced than at 12 days after conception. There was some labeling of the ventricular myocardium as well as in the epicardium. The atria showed hardly any $f: 2$ expression. An anti smooth muscle antibody recognizes smooth muscle cells of the arteries as well as cardiomyocytes. In the outflow tract it shows a low level of staining in the condensed mesenchyme of the outflow tract indicative of neural crest cells in that area (fig. 3b). This area also shows marked apoptosis by TUNEL, staining (fig. 3c). In chicken embryos, in which neural crest cells were retrovirally traced it has been shown that many of the labeled cells in the outflow tract undergo apoptosis, upon the stage of completion of septation ${ }^{237}$. Combination of the data on smooth muscle cell markers, the occurrence of apoptosis and the expression of $f \% 2$ in the same location in the condensed mesenchym, as well as the results of the wnt1 neural crest reporter mouse ${ }^{234}$ support a relation with neural crest derived cells (fig. $3 a, b, c)$.

The amount of labeling for $f \% 2$ at 16 days after conception was intermediate between 14 and 18 days after conception, therefore the results are not shown. At 16 days still a marked $f z 2$ expression in the aorta, the pulmonary trunk and the descending aorta could be observed. The atria showed little signal. The ventricles showed only a low level of staining in the trabecular myocardium. The coronary arteries, which are present at this stage, did not show a marked staining.

At the stage of 18 days after conception in the pulmonary trunk and the ascending aorta the in situ signal, although diminished, could still be detected (fig. 4). No photographic grains could be observed above the atria and ventricles. The pulmonary arteries and the descending aorta did not show any signal (fig. 4).

At all time points investigated in this study the f $z 2$ signal was not exclusive for the arteries and heart, but labeling was also detected in the trachea, around the ribcartilage and in the muscle forming mesenchyme.

\section{Discussion}

In this study the expression of $f z 2$ during the development of the thoracic arterial system and the heart was investigated. At 10 days after conception, abundant fz2 expression could be observed in the pharyngeal mesenchyme. The cardiac region showed only background levels of signal. At 12 days after conception fz2 expression could, apart from the wall of the great arteries, also be observed in the still mesenchymal part of the outflow tract septum. At 14 days the expression pattern was similar to 12 days, although less pronounced. Finally, at day 16 and 18 , the signal gradually disappeared; only in the media of the aorta and pulmonary 


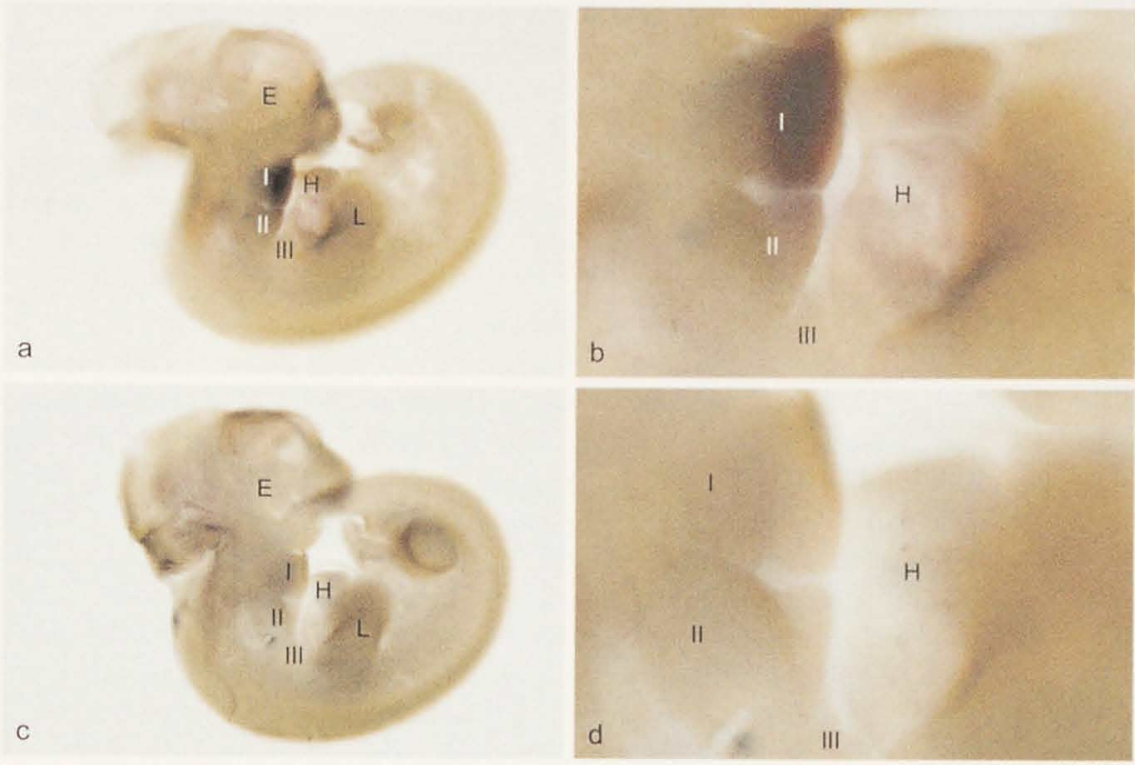

Figure 1. Whole mount in situ of a 10-day mouse embryo with the $\mathrm{fz} 2$ anti-sense probe ( $\mathrm{a}, \mathrm{b}$ detail of a) and a control embryo (c, d). a. The fz expression is marked in the first (I) and second (II) pharyngeal arches. The third arch (III) as well as the heart have no detectable levels at this stage (H). The expression in the limb bud (L) is not specific as it is present in both $\mathrm{fz}$ stained and control embryos (c, $\mathrm{d}$ detail of $\mathrm{c}$ ). E: eye

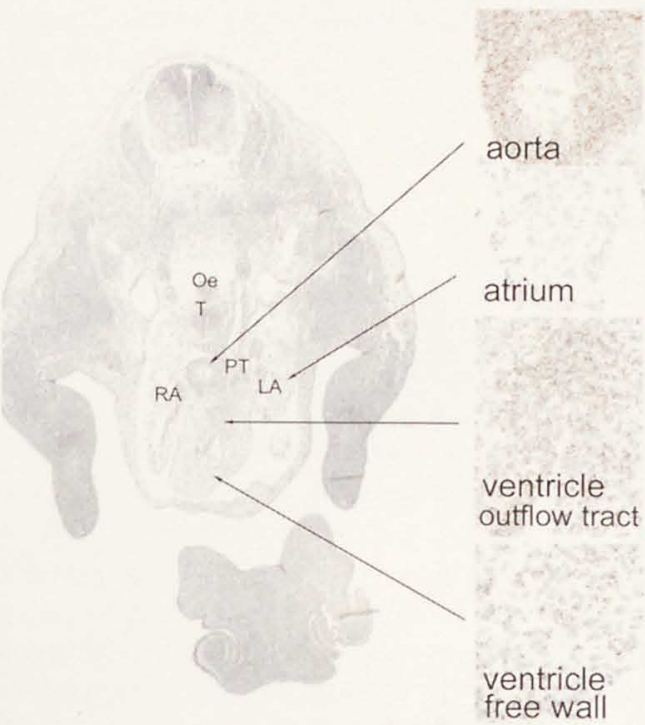

Figure 2. Transverse section of a 12-day mouse embryo (haematoxylin staining) The in situ anti-sense $\mathrm{fz}_{2}$ - staining shows the grains in red. In the aorta and the mesenchyme of the outflow tract septum a marked expression is seen. The free ventricular wall has a moderate expression, next to an almost absent expression in the atrial wall.(OE: oesophagus, PT: pulmonary trunk, $\mathrm{T}$ : trachea, $\mathrm{RA}$ : right atrium, LA: left atrium) 
trunk expression could be observed at day 18. This expression pattern for $f z 2$ is similar to the migration pattern for ncural crest cells during development as described for the chick embryo ${ }^{201,203}$. Recently, there were reports on neural crest cell tracing in transgenic mice using the promotor sequence for connexin 43 linked to a lac $Z$ reporter ${ }^{207}$ as well as a $C r e / l o x$ system in which the wnt- 1 gene expression was used to drive a lac $Z$ reporter ${ }^{234}$. These studies show that neural crest cells migrate into the first to sixth pharyngeal arches where they contribute to pharyngeal and aortic arch structure $201,203,207,234$. Here they also contribute to the condensed mesenchyme of the outflow tract that is involved in the septation of the truncus arteriosus into the pulmonary trunk and ascending aorta as well as in the separation of the right and left ventricular outflowtract ${ }^{234,237}$. Fz2 expression was still observed at 14 days in the outflow tract of the heart, in the area where the formation of the outflow tract septum (or conotruncal septum) occurs. From retrovital-lac Z neural crest cell tracing experiments in chicken and chimeric studies it is known that the labeled cells in this region show apoptosis as well as a moderate $1 A 4$ staining as compared to the vessel wall and the myocardium ${ }^{203,237}$. The TUNEL and $1 A 4$ staining in our study of the mouse embryo were performed on serial sections, and showed signal in the outflow tract, which is in agreement with the above mentioned findings in the chicken embryo. From detailed studies in chicken embryos on the contribution of neural crest cells to the vascular wall it was evident that the coronary and pulmonary arteries and the descending aorta remained devoid of neural crest cells ${ }^{203}$. These findings are confirmed by the neural crest cell reporter studies in mice with exception of the proximal part of the main coronary arteries ${ }^{207,234}$. The expression pattern found for $f z 2$ in the mouse arteries correlates with the neural crest cell contribution in the circulatory system, as described for the chick embryo as well as for the mouse embryo, in that the distal coronary arteries (proximal part not studied), the pulmonary arteries and the descending aorta did not express $f z 2$.

In our study we have focussed on the $f: 2$ expression in the thoracic arteries and the heart. However, the $\mathrm{f} z 2$ expression was not restricted to these regions, since we observed a strong fa 2 expression in the lungs and in the bone forming regions, as well as expression in the muscle forming mesenchyme. These results are consistent with the previously published fetal expression of $f z 1$ and $f z 2$ in the rat ${ }^{46}$.

The human homologue of $\mathrm{fz} 2$ is located on chromosome $17 \mathrm{q} 21.1$, but until now no neural crest defect has been related to this region ${ }^{47}$. Another human homologue of $\mathrm{f} z, \mathrm{FZD} 3$, recently renamed as $\mathrm{F} Z \mathrm{DD} 9^{238}$, has been localized to a $2 \mathrm{Mb}$ region on chromosome $7 \mathrm{q} 11.23$, which is associated with the Williams syndrome $e^{54}$. Although not a typical neural crest disorder, this elastin-related syndrome has a high incidence of stenosis predominantly in neural crest derived arteries, like supravalvular aortic stenosis ${ }^{54}$. Human homologues of $\mathrm{dvl}$ and $\beta$-catenin, members of the wnt- $f z$ signal transduction pathway ${ }^{235,236}$ are located in the region on chromosome $22 \mathrm{q} 11$, which is deleted in neural crest related syndromes like DiGeorge and Velo Cardio Facial syndrome. These syndromes are accompanied by conotruncal cardiac defects ${ }^{236,239}$. Moreover, wnt proteins, the 
ligands for the $f z$ receptors, are involved in neural crest patterning ${ }^{234}$ 2*0. These findings are in agreement with the hypothesis that $f z$ plays a role in cardiac neural crest patterning during development in the mouse.

$\mathrm{Fr} 2$ has been hypothesized to have a role in the architectural control of migration and proliferation of myofibroblast during cardiac healing after myocardial infarction ${ }^{38}$. The myofibroblasts after infarction can be found in arrays completely aligned with the epi- and endocardium ${ }^{38}$. Because it has been found that fibroblast-like cells migrate from the epicardium into the myocard during development ${ }^{241-243}$, a similar role for $\mathrm{f} z 2$ during cardiac healing and development could be anticipated. We observed a moderate $f z 2$ expression in the epicardium overlying the ventricles. It remains to be investigated whether these cells play a role in the adult cardiofibroblast behaviour. Regions that are known to contain neural crest cells were positive for $f z 2$, but no neural crest contribution for cardiofibroblasts has been found so $\mathrm{far}^{201-2013}$, 237. This suggests that $f z 2$ expression is linked to migrating cells during development as well as to pathology in the adult heart, but that these cells do not necessarily have to be from the same developmental origin.

Neural crest cells contribute importantly to morphogenesis of the heart, forming the smooth muscle cell population of the ascending aorta, pulmonary trunk and main arch arteries $203,207,234$. Also, septation of the pulmonary and systemic outflow tract depends on the contribution of neural crest cells $\mathrm{s}^{201,237}$ The results from this study are consistent with the concept that $f z 2$ is involved in the migration and patterning of neural crest cells. The conotruncal and aortic arch abnormalities seen in the neural crest associated $22 \mathrm{q} 11$ deletion-associated syndromes ${ }^{2.44}$ support this finding. The option that the wnt-fz cascade is involved in the regulation of cardiac morphology during development deserves further research. 


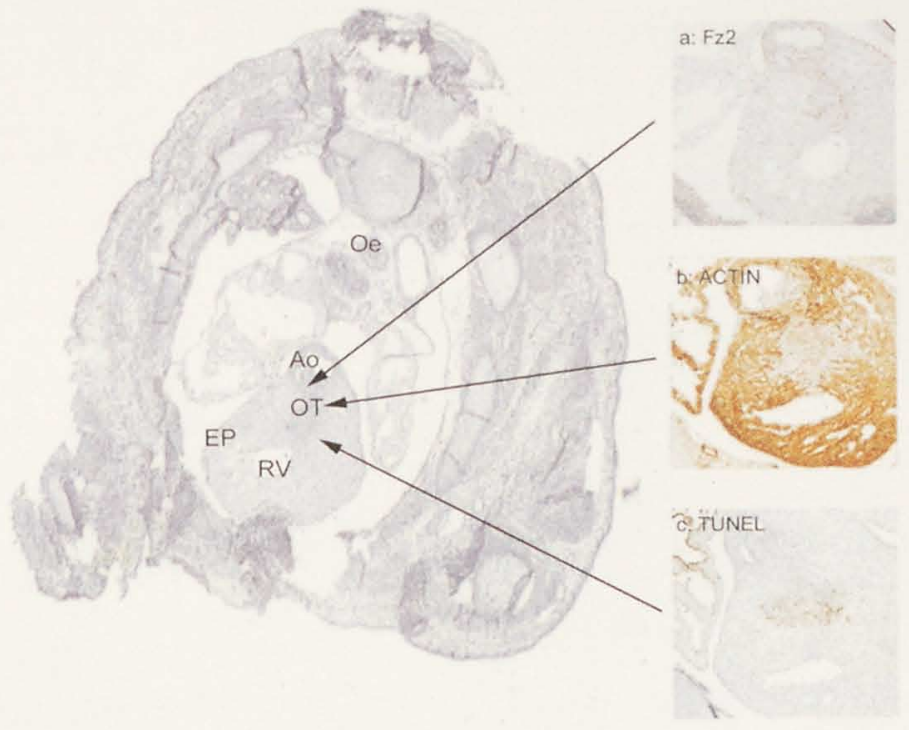

Figure 3. Transverse section of the outflow tract of a 14-day mouse embryo; subsequent sections of the embryo show specific staining patterns indicative for neural crest cell presence. (a) In situ hybridisation with the $\mathrm{fz} 2$ anti-sense probe shows marked expression in the condensed mesenchyme of the outflow tract (see actin staining in b) as well as in the aortic wall. There is also some staining in the epicardium (EP) overlying the ventricles. (b) Staining with the anti smooth muscle antibody (1 A4) that markedly stains cardiomyocytes of the ventricles as well as the smooth muscle cells of the aortic wall. It is also positive in the mesenchyme, which contains a population of neural crest cells of the outflow tract septum. (c) In the mesenchyme there is marked apoptosis as detected by the TUNEL technique. (OT: outflow tract mesenchyme, RV: right ventricle, Oe: oesophagus)

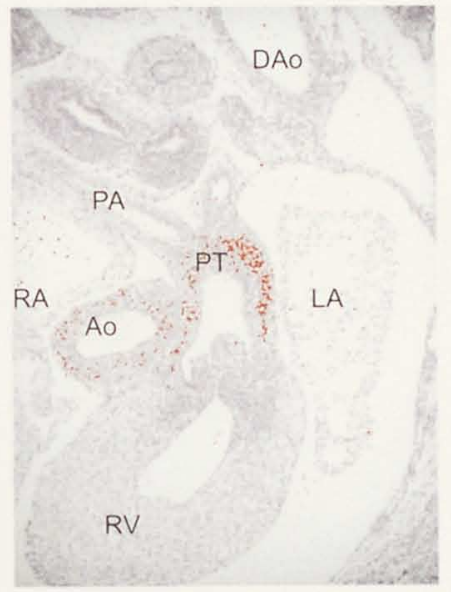

Figure 4. Transverse section of the heart of an 18-day mouse embryo with computer modulated expression of the anti-sense $\mathrm{fz} 2$ probe. The expression is still present in the wall of the ascending aorta (AO) and the pulmonary trunk (PT). The pulmonary arteries and the descending aorta (DAO) have no marked expression in their wall. This also counts for the left and right atria (RA, LA) and the myocardium of the right ventricle (RV) and the mesenchyme of the pulmonary valves situated between the PT and the RV. 
Chapter 5

\section{POSSIBLE SIGNAL TRANSDUCTION PATHWAYS OF FRIZZLED 2 IN MYOFIBROBLASTS IN THE HEALING INFARCT}

M.E. van Gijn, Y.P.G. Essers-Janssen, S. Heeneman, J.F.M. Smits and W.M. Blankesteijn 


\begin{abstract}
The seven-transmembrane receptors of the $f z$ family are involved in wnt signaling. Several signal transduction pathways for these receptors have been described, although the picture still is far from complete. From studies in Drosophila it is known that one of the pathways involves $\beta$-catenin stabilization and another pathway involves JNK and the small G-protein RhoA. In mammalian cells, both signal transduction pathways have been conserved. In a previous study we have observed elevated $\mathrm{f} z 2$ expression in the myofibroblasts after $\mathrm{MI}$. In order to characterize the signal transduction route activated by $f z 2$ in the myofibroblasts, the expression of several possible signal transduction molecules for the $\mathrm{f} z 2$ receptor, like dvl, $\beta$-catenin, cdc42, and phosphorylated JNK (P-JNK) were studied by immunohistochemistry and in situ hybridization. The expression of dvll, together with the previously described expression of $f z 2$ in the myofibroblasts during their migration into the infact area, suggests that a wnt-fz signal transduction route is activated. However, we have not been able to demonstrate $\beta$-catenin, P-JNK or cdc42 in the myofibroblasts after MI. Therefore the signal transduction pathways downstream of dvl remain to be clarified.
\end{abstract}

\title{
Introduction
}

Fz proteins are well-conserved receptors that function in wht signaling. Although the signal transduction mechanism for these receptors has not been completely elucidated several signal transduction routes have been described. In Drosophila, two signal transduction pathways have been found. The first involves Dfz2 and preferentially activates the $\Lambda$ rmadillo $(\Lambda \mathrm{rm}) / \beta$-catenin pathway leading to cell fate determination. The second involves $f z$, another Drosophila frizzled homologue, and preferentially activates the planar polarity cascade, which involves JNK and the small G-protein Rho ${ }^{130,131}$. The signal transduction molecule dvl is suggested to be the branch-point for the two pathways as activated $\mathrm{dvl}$ inhibits the degadation of $A \mathrm{rm} / \beta$-catenin and $\mathrm{dvl}$ is able to induce planar polarity by activating $\mathrm{JNK}$ and Rho $A^{130.13 !}$. In mammalian cells both signal transduction pathways have been conserved $^{132,245}$.

In a previous study we have observed elevated $f z 2$ expression in the myofibroblasts after $\mathrm{MI}^{38}$. Although a role for this receptor in the myofibroblast alignment was suggested, the exact function for $f z 2$ in the myofibroblasts has not been clarified. Therefore, in a first step towards the elucidation of the function of this receptor we have studied the possible the signal transduction route activated by $\mathrm{Fz} 2$ in the myofibroblasts in the infarct area after MI. The expression of several possible signal transduction molecules for the frizzled receptor, like $\mathrm{dvl}, \beta$-catenin and the phosphorylated form of JNK (P-JNK) was studied using immunohistochemistry, Western blotting and in situ hybridization, in the myofibroblasts after MI. The small GTP-binding protein cdc42 has been described to act in several 
pathways leading to JNK activation ${ }^{246-248}$. For this reason, the localization of the cdc42 protein was also studied.

\section{Material and methods}

\section{Animals and surgery}

Adult male Wistar rats (250 to $300 \mathrm{~g}$; Winkelmann, Borchen, Germany) were used in this study. They were housed in groups of 3 to 4 rats with free access to food and tap water. MI was induced as described previously ${ }^{38}$. Infarcted hearts were used if the infact area was approximately $30 \%$ of the left ventricle or more.

\section{In situ bybridization for dvl-bomologues}

The expression of the three dvl genes was studied by in situ hybridization. These experiments were performed on paraffin sections $(5 \mu \mathrm{m})$ from formalin-fixed infarcted rat hearts. The in situ hybridizations were performed as described previously ${ }^{38}$. Briefly, radiolabeled riboprobes were transcribed from polymerase chain reaction products of $d v 11, d v 12$, and $d v 13$, obtained by amplification of reverse-transcribed RNA isolated from rat heart as previously described ${ }^{218}$ and cloned into a pGEM-T cloning vector (Promega, Madison, WI). The identity and

Table I. Primer sets for the $f z$ PCR reactions

\begin{tabular}{l|l|l}
\hline Gene & Upper primer & Lower primer \\
\hline$d v l l$ & CAGGGCACTGACAGCCAC & CAGTAGATGCACTGTCTGGAGG \\
\hline dv12 & AAGAGCGTIITGCAGCGG & GACACAAGCCAGGAGACAAC \\
\hline dv13 & CCCCIIICTGTGCTGACAAC & GCTCAATCCGGGAGACCTT
\end{tabular}

orientation of the polymerase chain reaction products were verified by sequencing. RNA transcription was performed using an RNA labeling kit (Amersham, Little Chalfond, UK) in the presence of $\left[{ }^{35} \mathrm{~S}\right]-\mathrm{UTP}$. The sections were hybridized overnight at $55^{\circ} \mathrm{C}$ with the radiolabeled probes. After washing the sections, unbound probe was digested with RNase $(20 \mu \mathrm{g} / \mathrm{ml}$; Promega), the sections were dehydrated, dried, dipped in photographic emulsion (Kodak NTB2; Technorama, Zürich, Switzerland) and exposed for 1 to 2 weeks in the dark at $4^{\circ} \mathrm{C}$. After development, the sections were briefly stained with hematoxylin, dehydrated and embedded in enthellan (Merck, Darmstad, Germany).

\section{Immunobistochemistry}

Immunohistochemistry was performed according to routine procedures. Paraffin sections were mounted on aminopropyltriethoxysilane-coated slides. A monoclonal mouse antibody against P-JNK was obtained from Santa Cruz Biotechnology (Santa Cruz Biotechnology, Santa Cruz, CA USA). After blocking the endogenous peroxidase, sections were pretreated with $1 \mathrm{mg} / \mathrm{ml}$ of pepsin (Bochringer, 

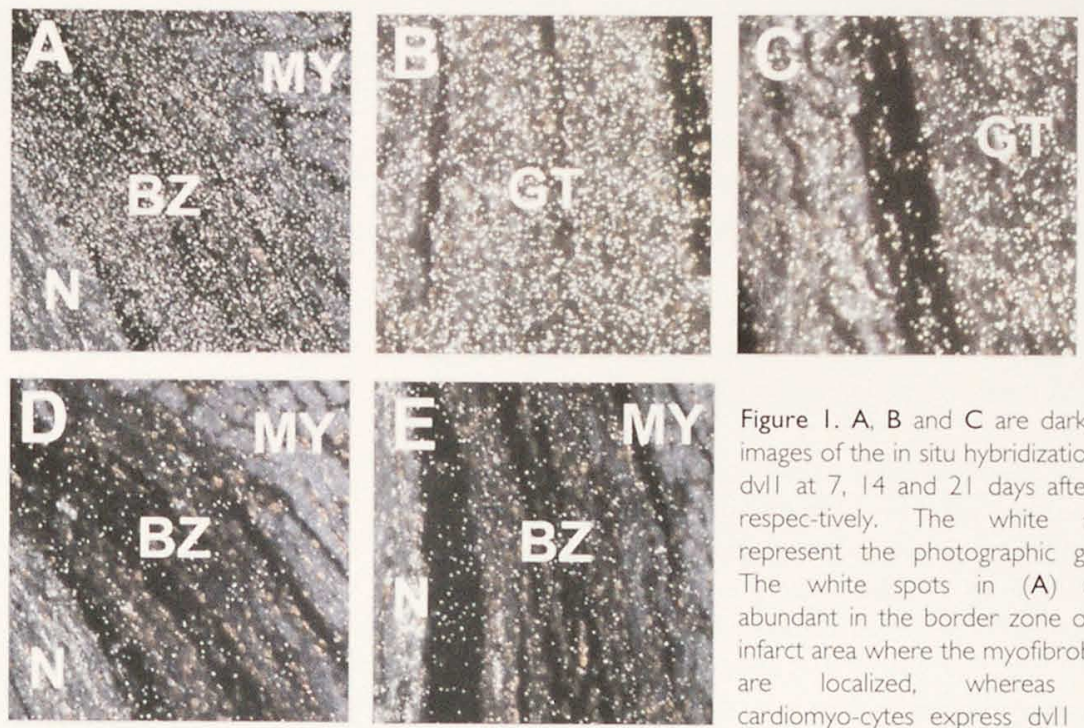

Figure I. A, B and C are dark-field images of the in situ hybridizations of dvll at 7, 14 and 21 days after Ml respec-tively. The white spots represent the photographic grains The white spots in (A) were abundant in the border zone of the infarct area where the myofibroblasts are localized, whereas the cardiomyo-cytes express dvll to a lesser extent. At 14 days after M

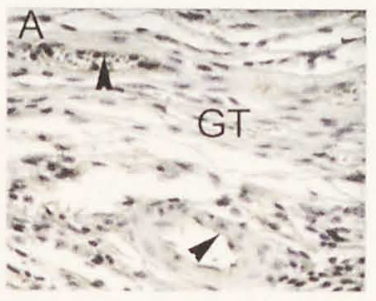

(B) abundant signal could be observed in the scar tissue that had replaced the death cardiomyocytes in the center of the necrotic area. At 21 days after $M I$ (C) signal could still be observed in the scar tissue, although less intense than on 14 days after MI. D and $E$ are dark-field images of the in situ hybridization of $d v 12$ and $d v / 3$ respectively 7 days after $\mathrm{MI}$. In (D) only background signal could be observed and in (E) only low expression signal was seen. ( $N=$ necrotic area, $B Z=$ borderzone, $M Y=$ cardiomyocytes and ST=scar tissue) (magnification $\times 400$ ).
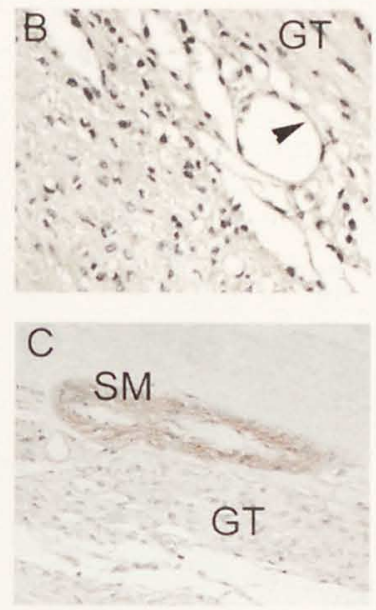

Figure 2. In (A) the $\beta$-catenin staining of the border zone of the infarct area 7 days after $M I$ is shown. The vascular endothelial cells stained positive (arrowheads) but the myofibroblasts (spindle shaped nuclei) in the granulation tissue remained negative (magnification $\times 800$ ). In (B) the staining for $\mathrm{cdc} 42$ in the border zone of the infarct area 7 days after $\mathrm{Ml}$ is shown. No staining could be observed in the granulation tissue, only some endothelial cells were positive (arrowhead) (magnification $\times$ 800). In (C) P-JNK staining is shown for the border zone in the infarct area 7 days after MI. No P-JNK staining could be detected in the myofibroblasts, but the smooth muscle cells (SM) in the artery did stain positive for P-JNK (magnification $\times 400$ ). (GT = granulation tissue containing, among others, (myo)fibroblasts and inflammatory cells) 
Mannheim, Germany) and incubated overnight with the primary antibody in a $1: 25$ dilution at room temperature. Biotinylated sheep anti mouse $\lg$ G $(1: 250$, Amersham, Life Science, little Chalfont, Buckinghamshire, UK) was used as secondary antibody. After incubation with an alkaline phosphatase-coupled avidinbiotin complex ( $\mathrm{ABC}$ complex, Dako), the binding of the primary antibody was visualized with an alkaline substrate kit I (Vector SK-5100, Vector Laboratories, Inc., Burlingame, $\mathrm{CA}, \mathrm{US} A$ ). Immunohistochemistry for $\mathrm{cdc} 42$ was performed using a rabbit polyclonal antibody against cdc42 (Santa Cruz Biotechnology). The sections were pretreated with $1 \mathrm{mg} / \mathrm{ml}$ pepsin and incubated with the primary antibody in a 1:100 dilution and for 1 hour at room temperature. $A$ monoclonal mouse antibody against $\beta$-catenin was obtained from Transduction labs (Jexington, KY, USA). After blocking the endogenous peroxidase, sections were boiled twice for 5 minutes in $10 \mathrm{mM}$ citrate buffer ( $\mathrm{pH} \mathrm{6.0)}$ and incubated with the primary antibody in a 1:500 dilution overnight at room temperature.

Biotinylated multilink swine antibody directed against goat, mouse and rabbit primary antibodies (dilution 1:100; DAKO, Glostrup, Denmark) and the Vectastain $A B C$ kit (Vector, Burlingame $C A$ ) were used according to the manufacturers' instructions to visualize the binding of the primary $\beta$-catenin and cdc42 antibody. All sections were briefly counterstained with hematoxylin and mounted with entellan (Merck).

\section{Western blotting}

Protein was extracted from the borderzone and the infarct area of the left ventricles of rat hearts (MI) or complete left ventricles (SHAM). The left ventricles, frozen in liquid nitrogen immediately after removal from the animal, were crushed in a liquid nitrogen-cooled mortar. The protein was suspended in a buffer containing $0.5 \%$ Triton, $0.5 \%$ Nonidet P-40, $10 \mathrm{mM}$ Tris ( $\mathrm{pH} 7.5$ ), $2.5 \mathrm{mM} \mathrm{KCl}$, $150 \mathrm{mM} \mathrm{NaCl}, 20 \mathrm{mM} \beta$-glycerol phosphate, $50 \mathrm{mM} \mathrm{NaF}, 1 \mathrm{mM}$ orthovanadate, $10 \mu \mathrm{g} / \mathrm{ml}$ leupeptin, $1 \mathrm{mM}$ dithiothreitol, $10 \mu \mathrm{g} / \mathrm{ml}$ soybean trypsin inhibitor, and $200 \mathrm{mM}$ benzamidine. The protein mixture was further homogenized with an Ultra-Turrax, and centrifuged for 10 minutes at $14.000 \mathrm{rpm}$. The supernatant was transferred to a new tube and stored at $-20^{\circ} \mathrm{C}$ in different aliquots. For Western blotting $20 \mu \mathrm{g}$ protein per lane was used.

The Western blotting was performed using the PhosphoPlus SAPK/JNK (Thr183/Tyr185) Antibody kit (New England Biolabs Inc., Beverly, MA, USA) following the manufacturer's protocol.

\section{Results}

The localization of the expression of the dvl genes in the heart after MI was studied using the in situ hybridization technique. Seven days after MI abundant dvll signal could be observed in the granulation tissue around the necrotic area (fig. 1a). The cardiomyocytes also expressed dvl1, although the signal was considerably lower than that observed in the granulation tissue. At 14 days after MI abundant dvil 
expression signal could be detected in the scar tissue that had replaced the necrotic area (fig. 1b). At 21 days after MI dvll expression signal could still be detected in the scar tissue, although the detected expression was lower than the expression observed at 14 days (fig. 1c). Expression signal of dv12 could not be detected in the granulation tissue seven days after MI (fig. 1d), and only low levels of signal of the $\mathrm{dvl} 3$ gene could be detected in the infarct area (fig. 1e).

Immunohistochemistry was used to localize the $\beta$-catenin protein in the heart at $4,7,14$ and 21 days after infarction. $\beta$-Catenin staining was observed in the intercalated discs of the viable cardiomyocytes at all time points (not shown). In the infarct area $\beta$-catenin staining could be observed at 4 and 7 days after $M I$ in the endothelial cells of newly formed blood vessels. The myofibroblasts did not show $\beta$-catenin staining at any time point. Fig. 2 a shows the $\beta$-catenin expression in the granulation tissue 7 days after MI.

The immunohistochemical staining for cdc42 of a section of an infarct area 7 days after MI is shown in fig. $2 b$. Seven days after infarction cdc 42 could be observed in the cardiomyocytes and several endothelial cells in the granulation tissue. Again, the myofibroblasts were negative.

Another possible signal transduction molecule is JNK: therefore the phosphorylation of $\mathrm{JNK}$ in the borderzone of the infacted area was determined with Western blotting (fig. 3) and immunohistochemistry (fig. 2c). Seven days after MI the level of total JNK in the left ventricle does not differ between MI and sham operated rats. The levels of P-JNK, however, were diminished in the infarct group (fig. 3). Immunohistochemistry with an antibody against P-JNK was performed on sections of hearts 7,14 and 21 days after infarction. At all time points the smooth muscle cells of the coronary arteries stained positive for P-JNK. At seven days after infarction (fig. 2c) the inflam-matory cells and some endothelial cells in the infarct area also stained positive for P-JNK. In contrast, the myo-fibroblasts were negative at all time points for P-JNK (fig. 2c).

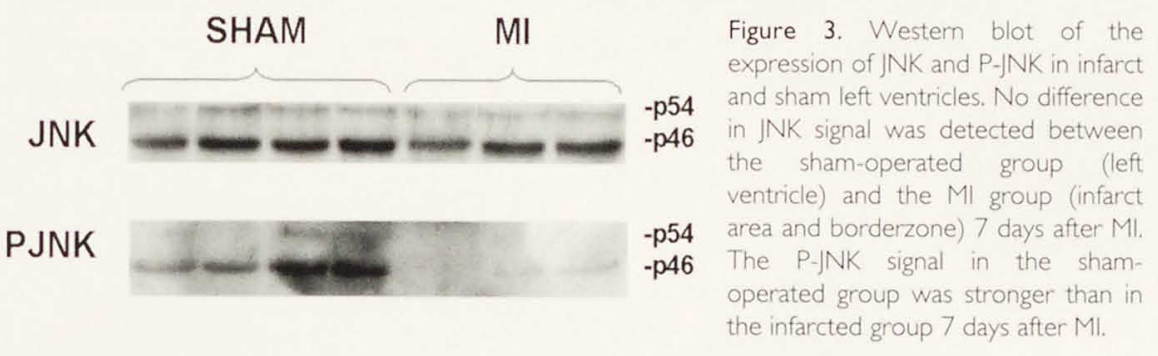

\section{Discussion}

In this study we attempted to delineate the possible signal transduction pathway of $\mathrm{fz} 2$ in the myofibroblasts after MI. The most upstream signal transduction molecules described for the wnt-fz cascade are the dvl proteins. The expression of dvll was elevated in the borderzone seven days after MI, whereas no dvl 2 and only 
low levels of dvi3 expression could be detected. At 14 and 21 days the dvll expression was localized in the center of the infarct area were the necrotic myocytes had been replaced by granulation tissue. We have previously found a similar expression pattern for $f z 2^{38}$. The co-localization of the $f z 2$ and the $d v 11$ expression suggests a role for dvl1 in the signal transduction of $f z 2$.

The activation of the wnt-f $z$ signal transduction pathway can lead to elevated cytoplasmatic $\beta$-catenin levels. For this reason we studied the localization of $\beta$-catenin using immunohistochemistry. No $\beta$-catenin protein could be detected in the cytoplasm of the myofibroblasts at any time point after MI. Cytoplasmatic $\beta$-catenin could be detected in the vascular endothelial cells at 4 and 7 days after MI (see chapter 8 ), suggesting that the method would have been adequate to detect cytoplasmatic $\beta$-catenin in myofibroblasts. Rfz2 RNA injection in Xenopus embryos does not lead to the expression of $\mathrm{Xnr} 3$ and siamois, target genes of $\beta$-catenin, whereas rfz1 RNA injection $\operatorname{did}^{2+9}$. Although the lack of target gene expression could be caused by a lack of appropriate ligand in the Xenopus study, these findings are in agreement with our observations which suggest that $\beta$-catenin is not a second messenger for $\mathrm{f} z 2$ in myofibroblasts after $\mathrm{MI}$.

A second possible signal transduction mechanism for the receptor $f z 2$ involves the activation of JNK. The small GTP-binding protein cdc42, which is involved in JNK activation by many stimuli ${ }^{246.2+8}$, could not be observed in the myofibroblasts seven days after MI. In the mean time, it has been demonstrated in COS1 cells that the small $G$-protein cdc42 does not play a major role in dvl-mediated JNK activation ${ }^{132}$. Therefore a role for $\mathrm{cdc} 42$ in the wnt-fz signaling seems unlikely.

The levels of P-JNK were lower in the infarct area as compared to the left ventricles of sham operated rats seven days after infarction, as determined with Western blotting. Granulation tissue and viable heart tissue consist of different cell types. Using immunohistochemistry, we have observed that P-JNK was mainly localized in the vascular smooth muscle cells of arteries. Therefore the difference in the P-JNK levels as seen on Western blot could be explained by the fact that healthy heart tissue contains much more arteries than the infarct tissue. P-JNK, however, could not be demonstrated in the myofibroblasts at any time point after MI. Although dvl1, the homologue suggested to be implicated in the f $z 2$ signaling in our study, has been described to activate JNK in COS1 cells ${ }^{132}$, our findings do not point to a role for the activation of JNK in the $f z 2$ pathway in the myofibroblasts.

Recently, rf $z 2$ has been shown to stimulate $\mathrm{Ca}^{2+}$ fluxes in a $\mathrm{G}_{\mathrm{i}}$-protein dependent pathway when overexpressed in zebrafish embryos ${ }^{118}$. Furthermore, ff $_{2} 2$ RNA injection in Xenopus embryos stimulated the activity of PKC in a $G_{i}$-protein dependent pathway ${ }^{249}$. The different vertebrate $f z$ receptors have been classified into groups that preferentially activate the $\mathrm{Ca}^{2+}$ or the $\beta$-catenin pathway ${ }^{117}$. Rfz2 has been classified as a receptor that preferentially activates the $\mathrm{Ca}^{2+}$-mediated pathway $^{117}$, and not the $\beta$-catenin pathway, which is in agreement with the lack of $\beta$-catenin observed in this study. It remains to be established if $f \geq 2$ in the myofibroblasts after $\mathrm{MI}$ in rats signals through the $\mathrm{Ca}^{2+}$-mediated pathway. The 
planar polarity in Drosophila is mediated by a pathway involving JNK and Rho $A^{130,131}$. So far, it has not been clarified if the $\mathrm{Ca}^{2+}$-mediated pathway in vertebrates has a similar function, but this would fit in the hypothesis that $f z 2$ in the myofibroblasts is involved in the polarity or alignment of those cells.

In conclusion, the co-localization of $f z 2$ and $d v 11$ expression in the myofibroblasts after $\mathrm{Ml}$ suggests that a wnt-fz signal transduction pathway is activated during the migration phase of these cells into the infarct area. This suggests a role for the cascade in architectural control of the wound healing process. We were unable to demonstrate cytoplasmatic $\beta$-catenin, cdc42 or P-JNK in the myofibroblasts, suggesting that another signaling route, possibly $\mathrm{G}$-protcin/ $\mathrm{Ca}^{2+}$-mediated may participate in the signal transduction. 


\section{Chapter 6}

\section{OVEREXPRESSION OF COMPONENTS OF THE WNT-FRIZZLED CASCADE RESULTS IN APOPTOTIC CELL DEATH, MEDIATED BY $\beta$-CATENIN.}

M.E. van Gijn, F. Snel, J.P.M. Cleutjens, J.F.M. Smits and W.M. Blankesteijn

Adapted from Experimental Cell Research 2001; 264: 1-8 


\section{Abstract}

Frizzled ( $f z$ ) functions as a 7-transmembrane receptor in the wnt-fz signal transduction cascade. It is involved in architectural control of development in species as divergent as Drosophila and vertebrates. Regulation of multicellular architecture requires control of cell alignment, but also involves an equilibrium between cell proliferation, differentiation and apoptosis. Recently, modulation of the wnt-fzcascade has been related to apoptosis. However, the role of $\beta$-catenin, a sccond messenger in the wnt-fz cascade, in programmed cell death is a matrer of debate. To elucidate the role of this cascade in apoptosis, we studied the effect of overexpression of $f z 1, f z 2$, dvl1 and $\beta$-catenin. The signal transduction pathway and the involvement of $\beta$-catenin were further investigated by using different inhibitors. These experiments were performed in different cell types: COS7, 293 and PC12. Overexpression of $f \geq 1, f \geq 2$ and dvl1 induced apoptosis in COS7 and 293 cells. $\beta$-Catenin appears to be the mediator for this process since $\beta$-catenin overexpression as well as lithium and valproate induced apoptosis. In contrast, lithium treatment did not result in apoptosis in PC12 cells. We conclude that different components of the wnt-fz cascade can induce apoptosis, but that this effect is dependent on the cell type.

\section{Introduction}

The family of frizzled genes encodes seven transmembrane receptor proteins" $"$. In Drosophila these proteins have been found to be involved in the architectural control of wing hair growth by translating polarity signals ${ }^{2501}$. Recently a similar role has been proposed for these proteins during vertebrate development ${ }^{5 *}$. The ligands for these receptors are secreted glycoproteins from the wnt family ${ }^{\text {+1) }}$. Whts are involved in processes as diverse as growth regulation, cell fate detcrmination and oncogenesis in vertebrate cmbryos and in adult tissue ${ }^{62,214.251}$. One of the best described functions of wnt is stabilization of $\beta$-catenin, a protein implicated in uncontrolled cell proliferation and migration in malignancies ${ }^{183,224}$. 225. In the absence of wnt signaling, GSK3- $\beta$ phosphorylates $\beta$-catenin, which then forms a complex with the $A P C$ protein, axin and other proteins, targeting $\beta$-catenin for degradation by the ubiquitin-proteasome pathway ${ }^{252}$. Wnt signaling via $f$ a activates dishevelled (dvl), which inhibits GSK3- $\beta$ activity, thereby promoting the elevation of intracellular $\beta$-catenin levels and accumulation of $\beta$-catenin in the nucleus. In the nuclcus $\beta$-catenin interacts with HMG-box transcription factors such as lymphoidenhancer factor/T-cell factor $(\mathrm{L}, \mathrm{EF} / \mathrm{TCF})$ to regulate gene expression that mediates the downstream effect of wnt ${ }^{2211}$.

Originally, Frizzled was considered to control tissue architccture by regulating cell alignment ${ }^{23}$. However, modulation of the wnt- $f z$ pathway has recently been associated with apoptosis ${ }^{114.253 .254}$. Apoptosis or programmed cell death is of fundamental importance to biological processes ranging from embryogenesis to 
maintenance of tissue homeostasis ${ }^{255-25 x}$. Fz2 is expressed in the heart during cardiac development, and in a previous study we have demonstrated that its expression was co-localized with TUNEL staining, suggesting a link between fz2 expression and apoptosis ${ }^{25^{\prime}}$. Recently, overexpression of dvl genes has been found to induce apoptosis in COS-1 cells ${ }^{254}$. Furthermore, secreted analogues of $\mathrm{f} z$, like secreted apoptosis related protein (SARP) and human secreted Frizzled Related Protein (hsFRP), have been shown to modulate the $\beta$-catenin levels and influence the sensitivity to apoptosis ${ }^{19 \cdot .253}$. Stimuli for apoptosis, like serum deprivation, have been shown to induce hslRP expression and also to lower $\beta$-catenin levels in HBL-100 cells ${ }^{253}$. However, there is no consensus regarding the role of $\beta$-catenin in apoptosis. Overexpression or stabilization of $\beta$-catenin has been described to protect some cells from apoptosis ${ }^{2(x)}$, but to induce apoptosis in other cell types $^{2(0)}{ }^{2(6)}$. Moreover, it is unknown whether modulation of $\beta$-catenin-through $f z$ affects apoptosis.

To elucidate the possible role for the wnt-fz signal transduction pathway in apoptosis, we studied the effect of overexpression of $f \neq 1, f \neq 2, d v 11$ and $\beta$-catenin on the fraction of apoptotic cells. Because of the discrepancies regarding the proor anti-apoptotic role of elevated $\beta$-catenin levels, reported in the literature, we studied the effects of overexpression in different cell types: COS7 and 293 cells. Morcover, the effect of inhibitors that act at different levels of the wnt-fz cascade, was investigated in COS7 and PC12 cells.

\section{Materials and methods}

\section{Cullure conditions}

COS7 and HEK 293 cells were grown in Dulbecco's modificd Eagle medium (DMEM) (Bio Whittaker Europe, Vervicrs, Belgium) supplemented with $10 \%$ fetal bovine, $1 \%$ glutamine, $100 \mathrm{U} / \mathrm{ml}$ penicillin and streptomycin (Life technologies, Gaitherburg MD, USA). PC12 cells were grown in DMEM supplemented with $10 \%$ fetal bovine serum, $5 \%$ horse serum, $1 \%$ glutamine, $100 \mathrm{U} / \mathrm{ml}$ penicillin and streptomycin (Life technologies). Cells were incubated at $37^{\circ} \mathrm{C}$ and $5 \% \mathrm{CO}_{2}$.

\section{Characterization of the nnt-frizzled signaling cascade}

The inhibitors were added together with the growth medium after transfection. The final concentrations were $0.6 \mathrm{mM}$ lithium chloride (TT Baker, Inc, Phillipsburg N], USA), $1 \mathrm{mM}$ sodium valproate (Rescarch Biomedicals International, Natick $\mathrm{M} \Lambda$, USA), $100 \mathrm{ng} / \mathrm{ml}$ pertussis toxin (Janssen Biochimica, Beerse, Belgium), $20 \mu \mathrm{M}$ I.Y294002 (Sigma, St Jouis MO, USA), $100 \mu \mathrm{M}$ Wortmannin (Sigma), $100 \mu \mathrm{g} / \mathrm{ml}$ IDN 1965 and $40 \mu \mathrm{g} / \mathrm{ml}$ 7VAD (IDUN Pharmaceuticals, La Jolla, C $\Lambda$, USA). 


\section{Transfection}

The cells were transfected using the Lipofectamine plus reagent (Life technologies) according to manufacturers instructions. The COS7 and the 293 cells were plated on $37 \mathrm{~mm}$ culture wells (Greincr Labortechnik, Solingen, Germany). One $\mu \mathrm{g}$ of each plasmide was used for each transfection. The $\beta$-catenin plasmide was a gift from Dr S. Byers (Georgetown Univ. Medical Center, Washington DC, USA), the Frizzled plasmids were a gift from Dr R Nissenson (UCSF, San Francisco CA, USA) and the dvl-1 plasmid was a gift from Dr D. Sussman (University of Maryland, Baltimore MD, USA). The transfection efficiency was determined by $\beta$-gal transfection in parallel cell culture wells and averaged $30 \%$.

\section{Apoptosis (TUNEL)}

Cells were fixed in $2 \%$ paraformaldehyde for 30 minutes. $\Lambda$ fter rinsing twice with PBS the cells were permeabilized with $0.1 \%$ TritonX100/0.1\% sodium citrate for 15 minutes. Then the cells were rinsed twice in PBS and immersed for 20 minutes in $0.5 \% \mathrm{H}_{2} \mathrm{O}_{2}$ in PBS, pH 7.4 to inhibit endogenous peroxidase activity. Then the cells were immersed for 10 minutes in equilibration buffer $(0.2 \mathrm{M}$ sodiumcacodylate, $25 \mathrm{mM}$ Tris $-\mathrm{HCl}, 0.25 \mathrm{mg} / \mathrm{ml} \mathrm{BSA}, 0.03 \mathrm{mM} \mathrm{CoCl}$ ). The TUNEL, reaction was performed at $37^{\circ} \mathrm{C}$ for 60 minures (Bochringer, Mannheim, Germany). Per well, $0.15 \mu \mathrm{l}$ TdT $(25 \mathrm{U} / \mu \mathrm{l}), 0.6 \mu \mathrm{ldig}$-dUTP $(1 \mathrm{mM}), 1.5 \mu \mathrm{l} \mathrm{CoCl} \mathrm{C}_{2}$ $(25 \mathrm{mM}), 5 \mu \mathrm{l}$ equilibration buffer and $17.75 \mu \mathrm{H}_{2} \mathrm{O}$ were added. The reaction was stopped by incubating the cells for 30 minutes at $37^{\circ} \mathrm{C}$ in a stop buffer containing $300 \mathrm{mM}$ sodium chloride and $30 \mathrm{mM}$ sodium citrate. $\Lambda \mathrm{fter}$ rinsing three times with PBS, the sections were incubated with anti-dioxigenin-pcroxidasc-FAB fragments (Bochringer) for 30 minutes. Subsequently, the cells were rinsed three times with PBS. The staining reaction was performed by exposing the cells for 10 minutes to diaminobenzidine diluted in $0.05 \%$ Tris $\mathrm{pH} 8$, to which $0.005 \% \mathrm{H}_{2} \mathrm{O}_{2}$ was added, followed by rinsing with water. Finally, the sections were counterstained with Mayer's hematoxylin, dehydrated, and embedded in immuno-mount (Merck, Darmstadt, Gcrmany).

\section{DNA laddering assay'}

For the DN $\Lambda$ laddering assay the $\Lambda$ po $\Lambda$ lert LM-PCR ladder assay kit (Clontech laboratorics Inc, Palo $\Lambda$ lto, CA, US $\Lambda$ ) was used. The cells were treated according to the manufactorers instructions.

\section{Statistics}

To determine the percentage of TUNEL-positive cells, 1500 cells per transfection were counted. The results were compared with empty vector-transfected cells. The Mann-Whitney test was performed to determine whether differences were statistically significant. Significance was accepted at $p<0.05$. 

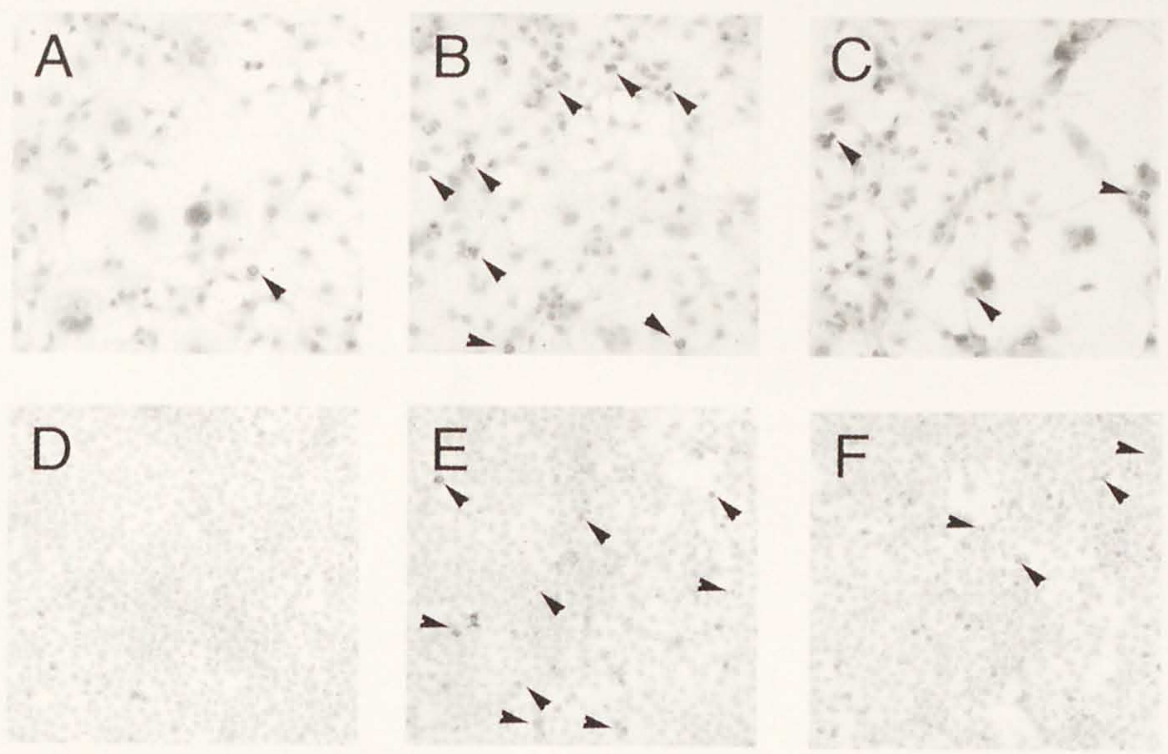

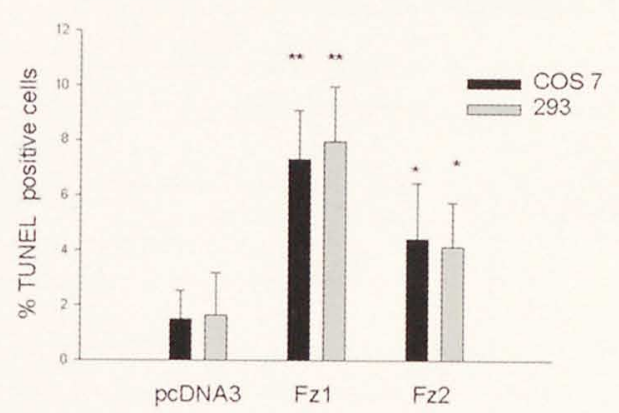

\section{Results}

Friziled overexpression resulted in apoptosis

In fig. 1, the effect of overexpression of $f z 1$ and $f z 2$ on the percentage of TUNEL. positive cells is shown. Our data indicated that transfecting COS7 and 293 cells with fzl-containing plasmid resulted in a significantly higher percentage of TUNEL-positive cells than the empty pcDNA3 vector alone. Fz2-transfected cells also exhibited significantly more TUNEL positive cells than the negative control, although the effect was less pronounced than after fzl overexpression.

Apart from the apoptotic marker TUNEL, a PCR based DNA laddering assay also was used to demonstrate apoptosis. Fig. 2 shows the non-transfected COS7 


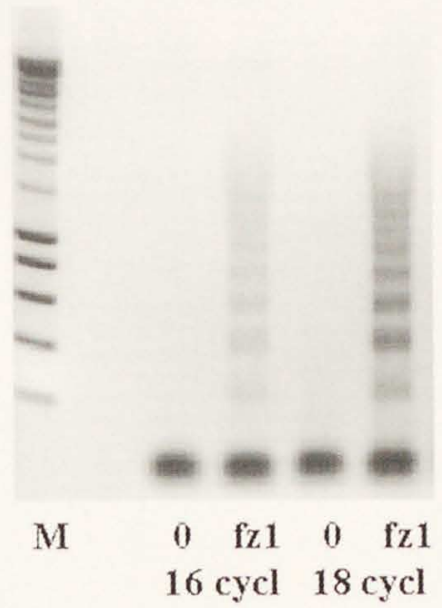

Figure 2. DNA laddering of transfected COS7 cells. Transfection of COS7 cells with $\mathrm{fzl}$ resulted in detectable DNA laddering after 16 and 18 PCR cycles. This laddering was not observed in untransfected COS7 cells $(0)$

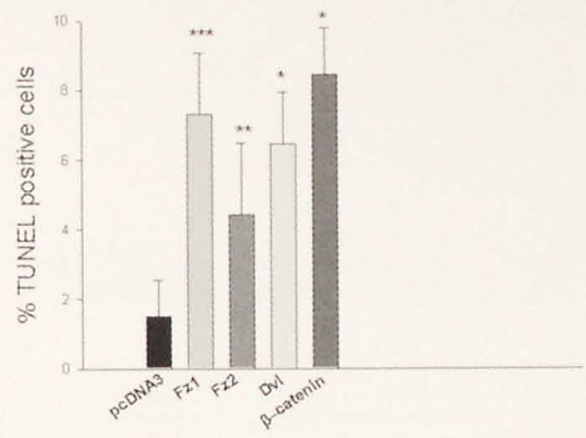

Figure 3. TUNEL-positive cells after transfection with members of the Frizzled cascade. Apart from $\mathrm{fzl}$ $(n=\mid 1)$ and $f z 2(n=\mid 1), d v l \mid(n=4)$ and $\beta$-catenin $(n=4)$ showed a significantly higher percentage of TUNEL-positive cells than the control vector, pcDNA3. Overexpression of $\beta$-catenin induced a similar percentage of TUNEL-positive cells as $\mathrm{fzl}_{2}$ overexpression.

${ }^{*} p=0.01$. ** $p=0.001 * * * p=0.0001$

cells and the fz1 transfected cells. At 16 and 18 cycles no laddering could be detected in the control, but in the fz 1 transfected cells a clear laddering was visible. Finally, the caspase inhibitor IDN 1965 and zVAD lowered the percentage TUNEL-positive cells, providing a third line of evidence that frizzled tranfected cells died due to apoptosis (fig. 4).

\section{Overexpression of $d v l$ and $\beta$-Catenin-induced apoptosis}

To elucidate the signal transduction for the apoptosis induced by fz, COS7 cells were transfected with downstream components of the wnt-fz cascade (fig. 3). Apart from $f z 1$ and $f z 2, d v l 1$ and $\beta$-catenin were transfected. All 4 induced a significantly higher percentage of TUNEL-positive cells than the control plasmid. The $\beta$-catenin plasmid induced a similar percentage of TUNEL-positive cells as the $f z 1$ plasmid.

\section{Modulation of the apoptotic signal transduction with different inhibitors}

To further elucidate the fz-mediated apoptotic pathway, we added different inhibitors of the wnt-fz cascade to the culture medium after the transfection of cells (fig. 4). The GSK-3 $\beta$ inhibitor lithium significantly augmented the percentage TUNEI-positive cells to a level of approximately $13 \%$, regardless of the nature of the transfected plasmid. Valproate had a similar though less pronounced effect on the percentage of TUNEL-positive cells. This suggests that $\beta$-catenin is an 


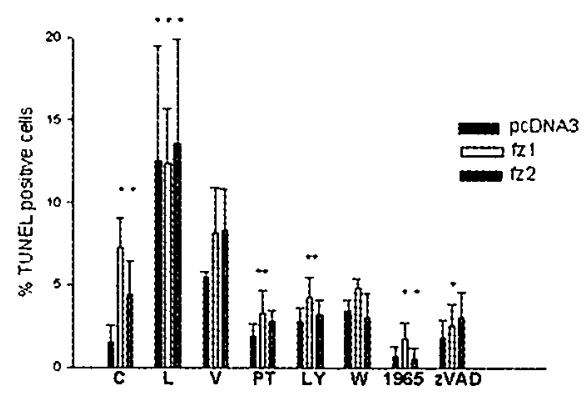

Figure 4. Influence of inhibitors on the percentage of TUNEL-positive cells after transfection. Inhibitors were added to the medium after the cells were transfected (Figure 4). 48 Hours later the TUNEL reaction was performed. The GSK-3 $\beta$ inhibitors lithium $(L)(n=4)$ and valproate (V) $(n=2)$ augmented the percentage TUNEL-positive cells, both in frizzledtransfected as well as in empty vectortransfected cells. Pertussis toxin (PT) $(n=4)$. a Gi-protein inhibitor has an inhibitory effect on the apoptosis induced by the Frizzleds, indicating an involvement of $G$-proteins in the process. LY294002 (LY) $(n=4)$ and wortmannin (W) $(n=2)$, both inhibitors of P13-kinase, are also inhibitors of the apoptotic process. The caspase inhibitor $2 V A D(n=3)$ inhibited the apoptosis but was less potent than IDN 1965. *p=0.05,**p=0.01

important mediator in the apoptotic process.

Pcrtussis toxin, an inhibitor of Gi-proteins, had an inhibitory effect on the apoptosis induced by $f z$ overexpression. For $f z 1$ this effect was significant, indicating an involvement of Gi-proteins in the process. LY294002 and wortmannin, both inhibitors of PI3-kinase, turned out to inhibit the apoptotic process too in fz1-transfected cells; for LY294002 the effect reached statistical significance.

\section{Comparison of apoptosis induction between different cell types}

To study whether $\beta$-catenin was the mediator in the apoptotic process in other cell types as well, we added lithium to COS7 and PC12 cells and performed a TUNEL. assay (fig. 5). In PC12 cells we observed almost no TUNEL-positive cells, whereas in COS7 cells lithium induced TUNEL-positivity in more than $9 \%$ of the cells. In a preliminary experiment, addition of the caspase inhibitor IDN 1965 resulted in a reduction in the amount of TUNEL-positive cells to control levels, confirming that lithium induced cell death through apoptosis.

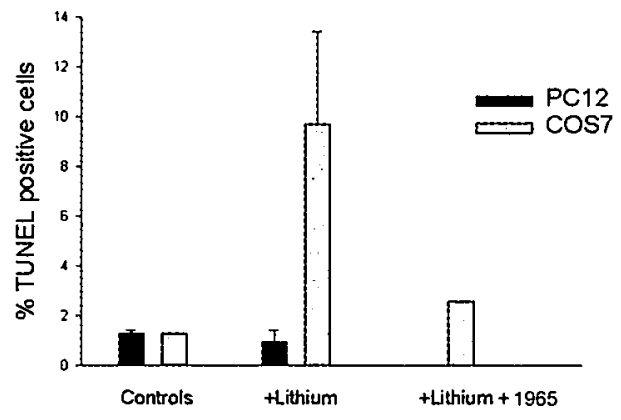

Figure 5. PCI 2 and COS7 cells treated with lithium Lithium $(0.6 \mathrm{mM})$ was added to COS7 and PCI 2 cells $(n=2)$. PCI 2 cells demonstrated almost no TUNEL-positive cells, whereas in COS7 cells lithium induced more than $9 \%$ TUNEL-positive cells. By adding caspase inhibitor IDN 1965 the amount of TUNEL positive cells is lowered to control levels $(n=1)$. 


\section{Discussion}

\section{Frizzled overexpression results in apoptosis}

The aim of the present study was to investigate the effect of activation of the wnt-fz cascade on apoptosis. Because of the recent debate about the specificity of the TUNEL assay ${ }^{262}$, we have used three different techniques to detect apoptosis, the TUNEL assay, DN $\Lambda$ laddering and caspase inhibition. Thus, we have generated three independent lines of evidence demonstrating that overexpression of $f z$ results in apoptosis in COS7 cells. We also studied this apoptotic pathway by overexpressing downstream members of the cascade, and observed that dvl1 and $\beta$-catenin overexpression also induced apoptosis. Lithium and valproate have been known to mimic wnt signaling by inhibiting GSK3 $\beta$, thereby stabilizing $\beta$-catenin 16.5. In our study, exposing COS7 cells to lithium or valproate induced apoptosis. Treatment of the cells with lithium resulted in an even higher percentage of apoptosis than transfecting them with $\beta$-catenin. This could be explained by the transfection efficiency, which was only $30 \%$, whereas lithium treatment affected all cells. Although an effect of litium treatment on other apoptosis-related parhways, like the JNK signaling pathway ${ }^{20.3}$, cannot be ruled out, the apoptosis detected after direct transfection with $\beta$-catenin shows that the $\beta$-catenin pathway can induce apoptosis by itself, and therefore can be considered to be an important factor in the apoptosis observed with lithium and valproate treatment.

During embryonic development, apoptosis plays an important role in the formation of organs and tissues ${ }^{255,25 \%}, F_{72}$ is expressed in the heart during cardiac development, and we have demonstrated in a previous study that its expression was co-localized by TUNEL positivity ${ }^{259}$. This suggests that the wnt-fz cascade might be involved in the apoptotic process during development.

\section{Cell type specificity of apoptosis induction by litbium}

In the present study, it was shown that lithium docs not induce apoptosis in all cell types: the PC12 cells did not show any lithium-induced increase in the number of TUNEL-positive cells. The effect of lithium on apoptosis has been reported to be controversial; it has been found that lithium protects against cell death of mature cerebellar ncurons but that it has an apoptotic effect on immature cercbellar granule cells ${ }^{2(6)}$. HL-60 cells also undergo apoptosis when exposed to lithium ${ }^{261}$. In these cells, the apoptotic process was found to start after 48 hours of lithium treatment, which is why the present study quantified the fraction of apoptotic cells at this specific time point. Interestingly, the apoptotic percentages reported in that study were in the same range as those observed in the present study. Recently, two novel nuclear proteins have been described in Xenopus, which inhibit $\beta$-cateninTCF interaction; Duplin ${ }^{20.4}$ and $\mathrm{ICAT}^{26.5}$. The expression of these proteins might differ between cell types, explaining the diverse effects of stabilizing $\beta$-catenin on apoptosis induction. 


\section{Alternative signal transduction pathnays for frizzled-mediated apoptosis}

$\Lambda$ part from $\beta$-catenin, alternative signal transduction pathways have been described for $f \%$ Several studics have demonstrated that pertussis toxin-sensitive G-protcins arc involved in the wnt-f7. signal transduction pathway ${ }^{114,11 \%, 266}$. Pertussis toxin has been shown to block the stimulation of calcium transients mediated by the $f 72$ receptor in response to wnt5a, but not Xwnt $8^{118}$. Pertussis toxin also blocks the formation of primitive endoderm in F9 stem cells by Xwnt $8^{111}$. In our study pertussis toxin induced a partial inhibition of apoptosis resulting from $f z$ overexpression. Signal transduction by G-protein coupled receptors can involve PI3-kinases ${ }^{267}$. To further elucidate this pathway, we also studied the effect of the PI3-kinase inhibitor LY294002 and wortmannin and found that it inhibited the f7-induced apoptosis. PI3-kinases have several functions, including anti-apoptotic signal transduction by activation of $\mathrm{Akt}^{267}$. 268. Thus, the inhibitory effect of PI3-kinase inhibition on apoptosis was unexpected. However, besides being an apoptosis inhibitor, $\Lambda \mathrm{kt}$ can also inhibit GSK-3 $\beta^{267}$, so inhibiting $A \mathrm{kt}$ results in more active GSK-3 $\beta$. This leads to a higher level of $\beta$-catcnin degradation, which could explain the inhibitory effect of pertussis toxin, LY294002 and wortmannin on apoptosis that we have observed. Recently, GSK-3 $\beta$ deficiency has been associated with apoptosis ${ }^{269}$. GSK-3 $\beta$ deficient mice die between days 13.5 and 14.5 due to hepatocyte apoptosis. Embryonic fibroblasts from these mice are sensitive to TNF- $\alpha$-mediated apoptosis, but not to other apoptotic stimuli.

A third signal transduction pathway has been described for $f z$, which also makes usc of $\mathrm{dvl}$ as a signal transduction molecule ${ }^{121-123}$. In this pathway, dvl stimulates c-Jun-dependent transcription and the kinase activity of the JNK when overexpressed in COS7 cells ${ }^{131.132}$. Dvl proteins contain several functional domains that are also present in other signaling molecules ${ }^{270}$ : an amino-terminal DIX domain, a central region containing a PDZ domain, and a DEP domain upstream of the carboxyl terminus ${ }^{131}$. The DEP domain is essential for JNK activation, whereas all domains of $\mathrm{dvl}$ are necessary for the upregulation of $\beta$-catenin ${ }^{1.31}$. Recently a study has been published in which dvl overexpression in COS1 cells led to apoptosis ${ }^{254}$. Unlike what has been found for activating JNK, this study found all three domains of dvl to be necessary for the signal transduction of the apoptotic effect ${ }^{254}$. Overexpression of axin, a member of the $\beta$-catenin degradation complex, can also cause apoptosis ${ }^{171}$. This $A x i n$ induced apoptosis required JNK activation ${ }^{171}$. Coexpression of $\mathrm{dvl}$ or axin with the protein phosphatase $2 \mathrm{C} \alpha$ $(\mathrm{PP} 2 \mathrm{C} \alpha)$ reduced the percentage apoptotic cells ${ }^{171,254}$. PP2C has been shown to be able to dephosphorylate axin, to activate LEF-1 dependent transcription and to inhibit the JNK cascade ${ }^{271.272}$. Although these findings point to a role for the JNK pathway in the apoptotic process, our results show clearly that $\beta$-catenin is an important mediator in the apoptotic process as well. The experiments of the present study do not provide evidence regarding the involvement of the JNK pathway. 
In Chinesc Hamster Ovary Cells (CHO) cells the axin induced apoptosis could be attenuated by the coexpression of $\beta$-catenin ${ }^{171}$, which seems contradictory to the results of the present study. Axin can, however, act as a scavenger molecule for $\beta$-catenin ${ }^{273}$. If axin and $\beta$-catenin induce apoptosis by separate mechanisms, coexpression could result in axin binding $\beta$-catenin and thereby, possibly, failure of activation of the signaling leading to apoptosis.

\section{$\beta$-catenin and apoptosis}

In Drosophila, overexpression of Armadillo, the homologue of $\beta$-catenin, promotes apoptosis during retinal development ${ }^{274}$, anticipating a similar role for $\beta$-catenin in vertebrates. $A$ mechanism by which $\beta$-catenin, a protein originally described to be involved in cell proliferation, induces apoptosis has recently been proposed. In the nucleus, $\beta$-catenin interacts with HMG-box transcription factors such as lymphoid enhancer factor/T-cell factor (LEF/TCF) to regulate gene expression $^{2211} . \Lambda$ role for the $\beta$-catenin-TCF signaling in apoptosis has recently been described: butyrate, sulindac and trichostatin $A$ upregulate TCF activity, which is reflected by an increase in $\beta$-catenin-TCF formation in the SW620 cell line, and induce apoptosis in these cells ${ }^{275}$. Moreover, $\beta$-catenin has been found to activate c-myc and cyclin D1 gene expression, genes involved in cell proliferation ${ }^{220}$. Intriguingly, c-myc can also act as a potent inducer of apoptosis ${ }^{256}$. Myc-induced apoptosis is dependent upon the level at which myc is expressed and is presumably induced by modulation of target genes ${ }^{256}$. Another possibility could be that the increase in $\beta$-catenin-TCF complex influences the NF- $\kappa B$ signaling, which is implicated in cell survival and which has been shown to be decreased by GSK-3 $\beta$ inhibition $^{2(6)}$. However, $\beta$-catenin transfection in 3T3 fibroblasts induces apoptosis independent of its transactivation function with LEF-1 ${ }^{276}$, suggesting that LEF is not involved in the apoptosis induced by $\beta$-cateninoverexpression. Further work will be needed to discover what the mechanism is by which $\beta$-catenin influences apoptosis.

\section{Extracellular modulation of the frizzled cascade and apoptosis}

Extraccllular modulation of the wnt-fz pathway has been associated with apoptosis ${ }^{114,253}$. Secreted analogues of fz act as scavengers for wnts. Thesc secreted homologues, like SARP and hsFRP, can modulate the $\beta$-catenin levels, thereby influencing the sensitivity to apoptosis ${ }^{104.253}$. Overexpression of SARP 1 has been shown to make cells more resistant to apoptosis, but overexpression of SARP 2 has been found to lower the $\beta$-catenin levels and to make cells more vulnerable to apoptosis $^{1 / 4}$. Stimulators of apoptosis induced hsFRP expression and lowered $\beta$-catenin levels in HBL-100 cells $^{253}$. $\beta$-Catenin therefore scems to be an important modulator in apoptosis, which is in agreement with our results. 


\section{Potential roles for frizzled during wound bealing}

In a previous study we have shown that a member of the frizzled family, $f z 2$, was expressed in the infarcted area of the rat heart after myocardial infarction ${ }^{38}$. The expression signal co-migrated with the myofibroblasts into the granulation tissue. In that report, f 72 was proposed to play a role in the spatial control of myofibroblast alignment, which exhibits a high degrec of organization to prevent the scar from dilatation ${ }^{38}$. However, it is well known that myofibroblasts in the healing heart undergo apoptosis ${ }^{211}$. Therefore the function of the $f z 2$ on the myofibroblasts in an infarcted heart may be expanded to a regulation of apoptosis in these cells.

\section{Conclusion}

In conclusion, $f z$ overexpression can result in apoptosis, and $\beta$-catenin appears to be the mediator for this process since $\beta$-catenin overexpression itself as well as lithium and valproate treatment were found to induce apoptosis. Pertussis toxin and LY294002 have an inhibitory effect on the induced apoptosis suggesting that G-proteins and PI3 kinases are also involved in the process, and pointing to an important role for GSK-3 $\beta$. Finally, we have shown that increased $\beta$-catenin levels can have a stimulatory effect on apoptosis in COS7 cells. This effect appeared to be cell-type dependent because lithium treatment induced apoptosis in COS7 cells, but not in PC12 cells. Further research will be necessary to determine the physiological implications fof this effect, but it can be speculated that the Frizzledmediated apoptosis is implicated in the role for the wnt-fz. cascade in architectural control during embryogenesis and pathological remodeling processes. 
Chapter 6 
Chapter 7

\section{FIBROBLAST ALIGNMENT IN VITRO, IS} THERE A ROLE FOR FRIZZLED?

M.E. van Gijn, J.F.M. Smits, W.M. Blankesteijn 


\section{Abstract}

Myofibroblasts are proposed to play an important role during wound healing after MI. In the scar tissue they can be found aligned in parallel with the epi- and endocardium. This alignment is likely to contribute to the development of a strong scar. So far, little attention has been given to the alignment process. Based on their role in the control of tissuc polarity in Drosophila, $\mathrm{fz}$ proteins could be involved in this process. $F_{z}$ encodes a receptor first identified in Drosophila where this gene coordinates cell alignment. $\Lambda \mathrm{fz}$ homologue is expressed in myofibroblasts during their migration and alignment in the granulation/scar tissue formed in the infarct area after MII. In the present in vitro study, where fibroblasts align in a similar way as is scen in the myofibroblasts after MI, the role for the $f z$ signal transduction pathway in the alignment process was investigared. The fzs, upregulated in the area of infarction after MI, were also expressed in the fibroblasts in the alignment assay. Secreted FRPs were purified in order to study the role of the wnt- $f$ z cascade in fibroblast alignment in another way. By adding several inhibitors it was shown that two of the proposed signal transduction pathways for $f$, GSK-3 $\beta$ and $G_{i}$-proteins, were most likely not involved in the alignment process. The results obtained in the present study do neither confirm nor exclude an involvement for the fz cascade in the fibroblast alignment.

\section{Introduction}

Myofibroblasts play an important role during MI healing. Four days after infarction fibroblasts start to proliferate, transform into myofibroblasts and migrate into the infarct area. Myofibroblasts have characteristics of both fibroblasts and smooth muscle cells in that they synthesize extracellular matrix proteins but also have contractile properties. These cells have been shown to be predominantly responsible for the collagen formation at the infarct site in the rat heart ${ }^{18} . \Delta$ part from synthesis of the extracellular matrix, myofibroblasts play another important role in the preservation of the myocardial architecture: their contractile properties likely prevent the scar from dilatation ${ }^{11}$, 2"1. Myofibroblasts in the granulation tissue are orientated parallel with the epi- and endocardium. Little attention has been given so far to factors that control their proper orientation in the tissue. In order to cope effectively with the strain, these cells should be oriented perpendicular to the force that the scar is subjected to. Based on this hypothesis, myofibroblasts, aligned in the proper orientation, can be anticipated to contribute to the tensile strength of the scar.

Little is known about genes involved in myofibroblast alignment after MI. Cell alignment or polarity in general implicates several molecular components such as adhesion receptors, cytoskeletal linking proteins and extracellular matrix ligands. In a previous study, our group has found that during the alignment and migration of myofibroblasts after $\mathrm{MI}$, the expression of a member of the $\mathrm{f} z$ tissue polarity gene family, fz2, was upregulated ${ }^{38}$. The $f z$ genes are named after the Drosophila tissue 
polarity gene $f z$, which encodes a seven -transmembrane receptor. In Drosophila, f7 coordinates cell alignment ${ }^{41}, 251$. It is required to coordinate the local orientation of cells with respect to their neighbors during the formation of wing-hair polarity $^{+1.251 !}$.

In the present study with neonatal cardiac fibroblast cell culture experiments we observed that a protein extract of heart tissue added to the coating of the culture wells resulted in fibroblasts alignment similar to the myofibroblast alignment in the granulation tissue after MI. When no heart protein was added to the wells no alignment took place. The heart tissue therefore probably contains a signaling protein for cell alignment. The expression of $f z 2$, as previously found by us in the myofibroblasts after MI, made us hypothesize that this signaling protein could be a ligand for the receptor $f z$. The ligands for $f z$ have been described to be a family of sccreted glycoproteins, the wnts". So far no reports of successful purification of wnt proteins have been published. Moreover, the wnt family consists of a family of at least 15 members and the specificity of its interaction with $\mathrm{f} z$ has not been clarified yer. In order to investigate whether the fz receptors and wnt signaling are involved in the alignment of neonatal fibroblasts, we have first studied the expression of $f z$ receptors in these cells, with emphasis on the receptors of which the expression is upregulated after MI. Furthermore, we have tried to influence the alignment with inhibitors that act at different levels of the $f z$ signal transduction pathway. The FRPs are known to antagonize wnt function ${ }^{54,1(11.1112 .1118,}$ although the specificity and selectivity of FRP-wnt interaction is not clarified yet. By expressing and purifying FRPs that are upregulated after $\mathrm{Ml}$, and adding them to the alignment assay we have studied their influence on the alignment of fibroblasts.

\section{Material and methods}

\section{Cell culture}

Hearts were removed from decapitated 1-3 day old Wistar-Kyoto rats. Atria were trimmed off and ventricular tissue was cut into pieces, transferred to a spinner flask, and digested to single cells with collagenase type I (Gibco, Gaithersburg, MD) and pancreatin (Gibco) in $\Lambda$ ds-buffer ( $\mathrm{pH} 7.35$ ) consisting of $116 \mathrm{mM} \mathrm{NaCl}, 20 \mathrm{mM}$ HEPES, $0.9 \mathrm{mM} \mathrm{Na} \mathrm{H}_{2} \mathrm{PO}_{4}$, $5 \mathrm{mM}$ glucose, $5.4 \mathrm{mM} \mathrm{KCl}$ and $0.8 \mathrm{mM} \mathrm{MgSO} \mathrm{m}_{4}$. The cell suspension was loaded on a discontinuous gradient of Percoll (Sigma Chemical Co. St Louis, MO) with two different densities (1.059 and $1.082 \mathrm{~g} / \mathrm{ml}$ ) to separate the fibroblasts from the cardiomyocytes. To further purify the fibroblasts, they were plated and allowed to adhere in tissue culture dishes $\left(75 \mathrm{~cm}^{2}\right)$ for 30 minutes. The medium containing the non-adhered cells, mostly cardiomyocytes, was removed. Fresh DMEM (Bio Whittaker Europe, Verviers, Belgium) supplemented with $10 \%$ fetal bovine, $1 \%$ glutamine, $100 \mathrm{U} / \mathrm{ml}$ penicillin and streptomycin (Life technologies, Gaitherburg MD, US $\Lambda$ ) was added. Cells were incubated at $37^{\circ} \mathrm{C}$ and $5 \% \mathrm{CO}_{2}$. Cells were used in the alignment experiment when $95 \%$ confluence was reached. 


\section{Alignment assay}

Twelve well dishes were coated with collagen (Vitrogen 100, Cohesion, Palo Alto C $\Lambda$, US $\Lambda$ ) to which $0,33,66$ or $100 \mu$ l heart tissue homogenate $(100 \mathrm{mg} / \mathrm{ml} \mathrm{w.w.)}$ per $\mathrm{ml}$ collagen was added. The heart tissue homogenate was obtained by adding $1 \mathrm{ml}$ of PBS per $100 \mathrm{mg}$ heart tissue, and homogenize twice for 30 seconds with an Ultra-Turrax. Then the protein mixture was placed for 15 minutes at $-80^{\circ} \mathrm{C}$, followed by thawing and centrifuging at $4000 \mathrm{rpm}$ for 5 minutes. The supernatant was added to the coating. The coated wells were placed at $37^{\circ} \mathrm{C}$ for at least 3 hours before being used in the experiment.

Neonatal cardiac fibroblasts of a $95 \%$ confluent $75 \mathrm{~cm}^{2}$ tissue culture dish were trypsinized, followed by centrifugation at $1280 \mathrm{rpm}$ for 5 minutes and resuspended in $30 \mathrm{ml}$ DMEM supplemented with $10 \%$ fetal bovine scrum, $1 \%$ glutamine, $100 \mathrm{U} / \mathrm{ml}$ penicillin and streptomycin. Per well $1 \mathrm{ml}$ of suspension was added. Cells were incubated overnight at $37^{\circ} \mathrm{C}$ and $5 \% \mathrm{CO}_{2}$. The next morning the wells were analyzed for cell alignment using an inverted microscope (Nikon, Nippon Kogaku K.K., Tokyo, Japan) at phase contrast illumination.

\section{RNA isolation and amplification}

Cultured fibroblasts of different passages and the fibroblasts in the collagen coated wells in the alignment experiment were used for RNA isolation. Trizol reagent (Gibco) was used to isolate the RN $\Lambda$ following the manufacturers' protocol.

The RT-PCR was performed using Ready-to-Go You-prime-first-strand-beads (Pharmacia Biotech, Uppsala, Sweden), followed by a PCR reaction with primers specific for $\mathrm{rfz}, \mathrm{rf} z 2$ and $\mathrm{mf} z 7$ as described in chapter 2 .

\section{Inbibitors}

Lithium chloride, $1 \mathrm{mM}$ and $2 \mathrm{mM}$ (JT Baker, Inc, Phillipsburg NJ, USA), Genistein, 10 and $20 \mu \mathrm{g} / \mathrm{ml}$ (Research Biomedical International, Natick MA, USA) and Pertussis Toxin, $50 \mathrm{ng} / \mathrm{ml}$ (Janssen Biochimica, Beerse, Belgium) were added to the fibroblast suspension in the wells before the overnight incubation. These concentrations have proven to work in other in vitro assays $1(15,277.27 \%$.

FRPs:

Plasmids with myc-tagged FRP-1, 2 and 3 (kind gifts from $\operatorname{Dr} \Lambda$. Rattner, John Hopkins University school of Medicine, Baltimore, Maryland, USA) were transfected in 293 cells using the lipofectamine plus reagent (Life technologies) according to manufacturers' instructions. $\Lambda$ fter 48 hours the medium of the transfected cells was analysed for secreted FRPs with Western blotting and antibodies directed against c-myc (BabCO, Richmond CA, USA) and SFRP1 (Santa Cruz Biotechnology, Santa Cruz, CA USA). If secreted FRPs were present in the media they were purified with a c-myc antibody (BabCO) coupled sepharose (CnBr4B) column (Pharmacia) as previously described ${ }^{284}$. The purificd FRPs were added to the alignment assay. 


\section{Results}

\section{Alignment}

The first 10 alignment experiments (total $\mathrm{n}=30$ ) were done with thick, gel-like collagen coatings. After the observation that the alignment behavior of the fibroblasts was not dependent on the thickness of the coating, the later experiments were done with thin, film-like coatings. Neonatal fibroblasts cultured in pure collagen-coated culture wells did not demonstrate alignment as can be seen in fig. $1 \mathrm{a}$ and $\mathrm{c}$. After adding $33 \mu \mathrm{l}$ heart tissue homogenate per ml collagen some alignment could be observed, but the best cell alignment could be observed after adding $66 \mu \mathrm{l}$ heart tissue homogenate per $\mathrm{ml}$ collagen to the coating (see fig. $1 \mathrm{~b}$ and 1d). When the wells were coated with $100 \mu$ l heart tissue homogenate per $\mathrm{ml}$ collagen, similar or even less alignment was observed as seen in wells coated with $66 \mathrm{Hl}$ heart tissue homogenate per $\mathrm{ml}$ collagen (not shown). The heart tissue homogenate had to be prepared fresh before each experiment because the protein extract lost its activity after repeated freezing and thawing.
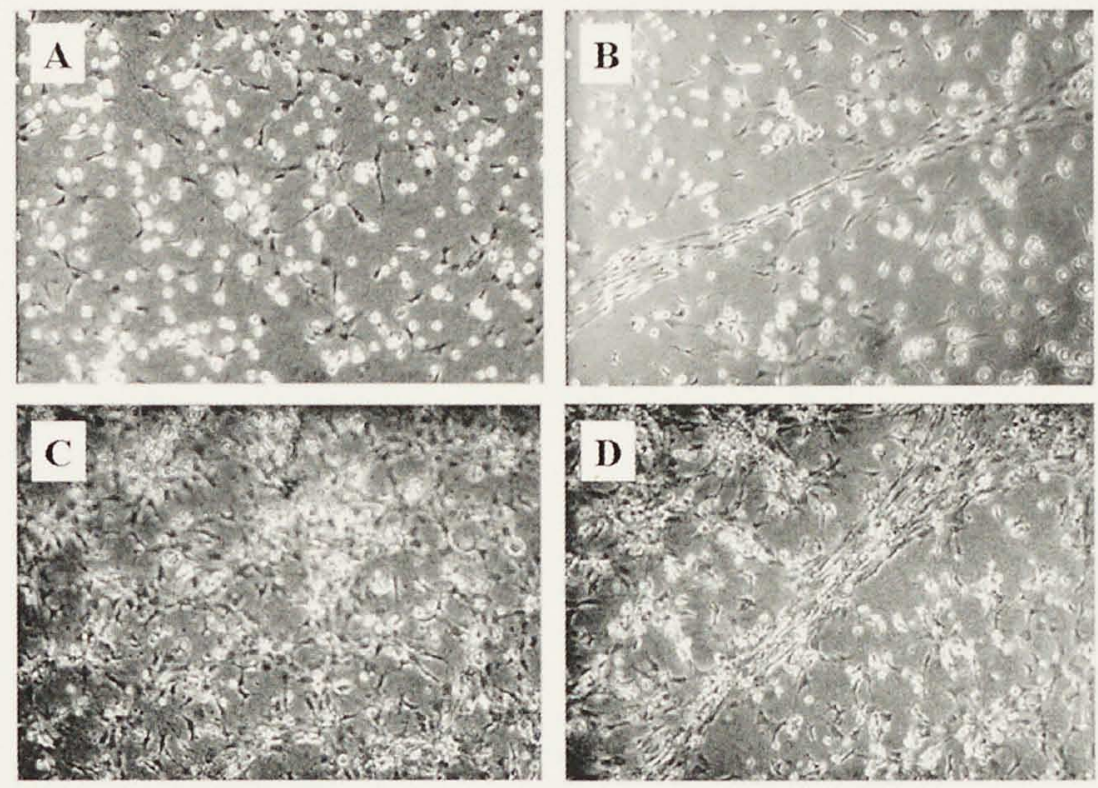

Figure I. ( $\mathrm{A}$ and $\mathrm{C}$ ) are representative images of the fibroblasts in the alignment experiments $(n=30)$, when no heart homogenate was added to the collagen coating. (B and $\mathbf{D})$ are representative images for the fibroblasts in the alignment experiments, when $66 \mu \mathrm{l} / \mathrm{ml}$ heart homogenate was added to the collagen coating. Addition of the inhibitors pertussis toxin, lithium. genestein or FRPs resulted in similar images as shown in $A / C$ and $B / D$. (A and $B$ ) show images of low cell density and (C and D) of high cell density. Note the relatively lower cell density in the areas near the aligned fibroblast bundle. (B and D) (magnification $\times 200$ ). 
Cell density did not influence the alignment process as low cell density (fig. 1a and $1 \mathrm{~b}$ ) and high cell density (fig. 1c and $1 \mathrm{~d}$ ) gave similar results. In fig. $1 \mathrm{~b}$ and $1 \mathrm{~d}$ it can be observed that the cell density in the area close to the aligned fibroblast bundle is lower than in areas further away from the bundle, which suggests that cells aligned into the bundle through migration from the direct periphery.

\section{Frizzled expression}

$\mathrm{Fz} 2$, the receptor that was upregulated in (myo) fibroblasts after $\mathrm{MI}^{38}$ was expressed in the neonatal fibroblasts in culture and the alignment experiment (fig. 2a). Furthermore, the fibroblasts in the alignment experiment expressed fzl (fig. 2b). In mice, more $\mathrm{fz}$ receptors have been described than in rats, where only 2 receptors have been cloned ${ }^{46}$. As the receptors in rats and mice probably are very similar, the expression of $\mathrm{fz} 7$, a homologue that is also upregulated after MI in mice, was studied with primers specific for $\mathrm{Mfz} 7$ and was found to be expressed (fig. 2b).

A
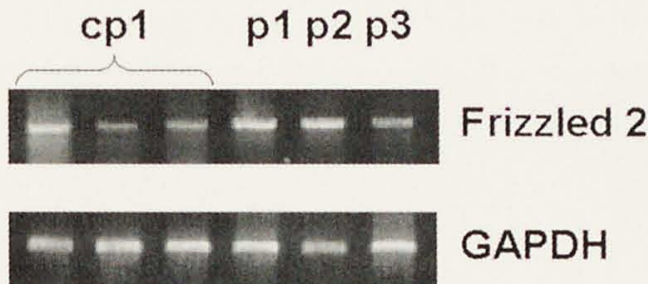

B
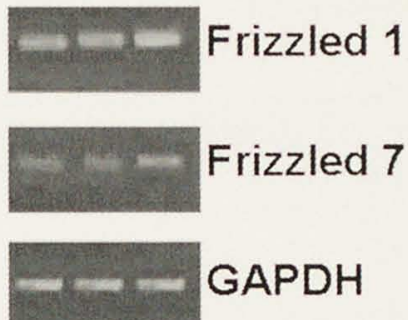

Figure 2. (A) Fz2 expression in fibroblasts in the alignment experiments cultured on collagen matrix $(c p \mid)$ and normal cultured fibroblasts of passage $\mid(p \mid), 2(p 2)$ and $3(p 3)$. (B) Fzl and 7 expression in fibroblasts in the alignment experiment.

\section{Inbibitors and FRPs}

Using inhibitors that act at different levels of the signal transduction pathway of the fz receptors we tried to intervene in the alignment process. The GSK-3 $\beta$ inhibitor lithium chloride, in concentrations of $1 \mathrm{mM}$ and $2 \mathrm{mM}$, had no effect on the alignment $(\mathrm{n}=2)$. The $\mathrm{G}_{\mathrm{i}}$-protein inhibitor pertussis toxin $(50 \mathrm{ng} / \mathrm{ml}, \mathrm{n}=3)$ and the tyrosine kinase inhibitor genistein (10 and $20 \mu \mathrm{g} / \mathrm{ml}, \mathrm{n}=2$ ) neither affected the alignment (fig. 1).

The expression of FRPs in 293 cells resulted in secreted FRPs in the media (fig. 3). Purified FRP2 (20 and $40 \mu \mathrm{g} / \mathrm{ml}, \mathrm{n}=2$ ) and FRP3 (4 and $8 \mu \mathrm{g} / \mathrm{ml}, \mathrm{n}=2$ ) did not have any influence on the alignment of the neonatal cardiac fibroblasts (fig. 1). For FRP1 the purification was not successful.

\section{Discussion}

The purpose of the present study was to investigate, in an in vitro model, whether the wnt-fz cascade is involved in fibroblast alignment. The neonatal cardiac 
mFRP1 cFRP1 MFRP2 cFRP2 MFRP3 cFRP3

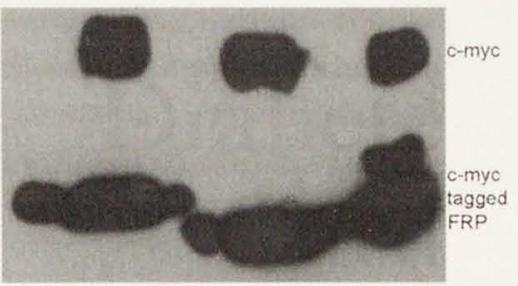

Figure 3. Westem blot of FRP expressed in 293 cells. In lane 1, 3 and 5 the culture media of the FRPexpressing cells (mFRP) are shown and in lane 2. 4 and 6 protein extracts of the 293 cells expressing the myc-tagged FRPs (CFRP) are shown. Furthermore, in the cell homogenates the endogenous c-myc protein is depicted. $F R P I=35,5 k D, F R P 2=33,5 k D$ and FRP3 $=36 \mathrm{kD}$

fibroblasts in the alignment assay demonstrated a similar alignment as was observed for myofibroblasts in the infarct area after MI. In a previous study we have demonstrated the overexpression of $\mathrm{fz} 2$ in myofibroblasts after $\mathrm{MI}^{38}$. The alignment assay could thus be a tool to study in vitro whether the fz cascade is involved in the alignment of fibroblasts. However, several difficulties arise for studying the fz cascade in vivo and in vitro. The number of antibodies available to study fzs, wnts and most of the other members of the signal transduction route is limited. In the mean time we have developed an antibody against fz2 (chapter 3 ) that can be used to study the function of $\mathrm{fz} 2$ protein in fibroblast alignment in the future. Furthermore, the specificity and the selectivity of the fz-wnt interaction and the signal transduction pathways for the fzs are not completely clear yet. A final problem is that neonatal cardiac fibroblasts are very difficult to transfect; therefore it is not possible to study the effect of overexpression of members of the fz cascade via plasmid transfection.

The relatively low cell densities close to the aligned fibroblast bundles suggest that the alignment process involves cell migration rather than cell proliferation. We have attempted to investigate fibroblast proliferation by BrdU incorporation, which failed due to technical reasons. Alternative methods like PCNA, ${ }^{3} \mathrm{H}$-thymidine incorporation and time-lapse video could be used to study the mechanism by which fibroblasts align.

The first step that was taken to investigate the hypothesis that $\mathrm{fz}$ receptors are involved in the fibroblast alignment was to study whether fz2, which is upregulated in the myofibroblasts in the heart after MI, was expressed in the neonatal cardiac fibroblasts as well. The fz family of genes is large ${ }^{40}$, therefore other fzs apart from fz 2 could be involved in the alignment as well. For this reason we have also studied the expression of $\mathrm{fz}, 1$ and 7 , which are also upregulated in the heart after MI in mice (see chapter 2). Fz2 was expressed in the fibroblasts in culture from the first passage on and in the fibroblasts in the alignment assay. Furthermore the expression of $\mathrm{fz} 1$ and 7 was demonstrated in the neonatal fibroblasts in the alignment assay. These findings are in agreement with the hypothesis that the $\mathrm{fz}$ cascade is involved in the fibroblast alignment.

In a pilot study we tried to separate the non-aligned and aligned fibroblasts in order to investigate whether there was a difference in $\mathrm{fz}$ expression, but no difference in expression pattern were observed. An explanation could be that the population of aligned fibroblasts contained still too many non-aligned fibroblasts to observe a difference. 
To further investigate if $\mathrm{f} z$, is involved in fibroblast alignment, threc different inhibitors were used that act at putative sites in the $f z$ cascade. There is increasing evidence that $G_{i}$-proteins are involved in the signal transduction pathway of $f z$. $R f z 2$, when overexpressed in zebrafish or Xenopus embryos, activates a $G_{i}$-protein dependent pathway ${ }^{118,24)}$. Furthermore, rf $\geq 1$ - mediated endoderm differentiation of mouse F9 teratocarcinoma cells requires $G_{i}$-proteins ${ }^{11 \%}$. The $G_{i}$-protein inhibitor pertussis toxin, however, did not exert any effect on cell alignment in the alignment assay.

Fy has sequence similaritics with several receptor tyrosine kinases, which might indicate a similar working mechanism ${ }^{281}$. Furthermore, GSK-3 $\beta$ can be activated by tyrosine kinases ${ }^{282}$. GSK-3 $\beta$ is an important phosphatase in the wnt-fz signal transduction route, as it is involved in $\beta$-catenin degradation ${ }^{1,3.3}$. Neither the tyrosine kinase inhibitor Genistein, nor the GSK-3 $\beta$ inhibitor lithium had any effect on fibroblast alignment in the assay. These findings are in agreement with our observations in chapter 5 , where no involvement of $\beta$-catenin in the myofibroblast alignment after MI could be demonstrated. The findings are in conflict with the hypothesized role for a signaling route involving GSK-3 $\beta$ or $G_{i}$-proteins. Apart from the inhibition of GSK-3 $\beta$ other signal transduction mechanisms, like the JNK, have been described for wnt signaling and $f \mathrm{~s}^{1313.132}$. JNK, however, can be activated by other mechanisms as well. Additional experiments should further explore these pathways.

Recently a family of secreted proteins similar to the extracellular ligand binding domain of $\mathrm{f}$, has been identified in vertebrates ${ }^{54},{ }^{98 \cdot 112}$. These FRPs can bind wnts directly and the FRPs are proposed to scavenge the wnts ${ }^{54,10 \%, 1112,108}$. In a previous study we have found that the expression of FRP-1, 2 and 3 is upregulated in the heart after MI (see chapter 2). Therefore, the influence of these proteins on fibroblast alignment was investigated. Purified FRP-2 and 3 exerted no effect on the alignment process. Our experiments do, however, not definitely exclude a role for FRPs on fzs in fibroblast alignment. Nothing is known about the dynamics of wnt-FRP interaction. Therefore the concentration used could be too low to obtain an effect. Furthermore, since a denaturation step was used in the purification procedure, it is possible that the proteins were no longer in the active conformation when added to the assay, which would hamper the wnt binding.

Another approach, which may be followed in the future to overcome the purification and the secretion problem, is to use adenoviruses containing FRPs to infect the fibroblasts directly. In contrast to plasmids, these viruses are able to infect fibroblasts with high efficiency. This approach could also be used for other members of the $f z$ signal transduction pathway.

In conclusion, the alignment similarity between fibroblasts in the granulation tissue in the heart after MI and the fibroblasts in the alignment assay could make this assay a tool to study fibroblast alignment in vitro. Although we have found that different fzs were expressed in the fibroblasts in vitro we have not obtained conclusive cvidence regarding an involvement for the $f z$ cascade in the fibroblast alignment. However, alternative signal transduction pathways for $f z$ could be 
present, so a role for $f z$ in the alignment process can not be ruled out. The experiments with the FRPs were inconclusive and more experiments have to be performed in order to determine if FRPs are able to influence the alignment process. The results with pertussis toxin, genistcin and lithium suggest the lack of a role for $G_{i}$-proteins or $G S K 3 \beta$ inhibition in the alignment process. 
Chapter 7 
Chapter 8

\section{BETA-CATENIN, AN INDUCER OF UNCON- TROLLED CELL PROLIFERATION AND MIGRATION IN MALIGNANCIES, IS LOCALI- ZED IN THE CYTOPLASM OF VASCULAR ENDOTHELIUM DURING NEOVASCULARIZA- TION AFTER MYOCARDIAL INFARCTION.}

W.M. Blankesteijn, M.E. van Gijn, Y.P.G. Essers-Janssen, M.J.A.P. Daemen and J.F.M. Smits

Adapted from American Journal of Pathology 2000; 157: 877-883 


\begin{abstract}
Beta-catenin is a protein involved in cell-cell adhesion and proliferation. In neoplastic discases, defects in the regulation of the cellular $\beta$-catenin content and cytoplasmic accumulation of the protein contribute to the uncontrolled cell proliferation and migration. Whether $\beta$-catenin plays a role in the controlled proliferative and migratory responses to injury, e.g. of vascular endothelial cells during neovascularization after $\mathrm{MI}$, is not known. In the present study, we examined the localization of $\beta$-catenin in the infarcted rat heart at different time points after MI. Cytoplasmic $\beta$-catenin was observed in the endothelial cells of the newly formed and preexisting blood vessels in the infarct area in the first week after MI, but not in the uninjured parts of the heart and not at later time points. APC protein was also detected; interaction of $A P C$ with $\beta$-catenin has been reported to be critical in epithelial tube formation in vitro. Moreover, the expression of dishevelled 1 (dvl1), an upstream regulatory molecule of the cellular $\beta$-catenin content, was observed in vascular endothelial cells in the infarct area. These findings suggest a role for the $\beta$-catenin- $A P C$ complex in the proliferation and migration of vascular endothelial cells during neovascularization of the infarct area.
\end{abstract}

\title{
Introduction
}

Beta-catenin is an intracellular protein, which can interact with different cellular targets. It was originally described as a component of adherens junctions. Recently, however, it has also been identified as an activator of gene expression. In cell adhesion, it functions in a complex of proteins that links cadherins, a family of transmembrane cell-cell adhesion receptors, to the actin cytoskeleton ${ }^{283-285}$. Modulation of gene expression by $\beta$-catenin is mediated through its interaction with transcription factors of the TCF/LEF family in the nucleus $58,181,286,287$.

Beta-catenin has recently received considerable attention in cancer research ${ }^{288}$, ${ }^{289}$. Elevated levels of $\beta$-catenin and a translocation of this protein to the cytoplasm have been associated with the development of colon carcinoma as well as a rapidly increasing number of other neoplastic diseases ${ }^{181}, 183,286$. These elevated levels of $\beta$-catenin can be caused by mutations in the protein itself, but are more frequently the result of mutations in the $\triangle P C$ protein, which regulates the degradation of $\beta$-catenin ${ }^{225}$. Mice lacking the $\beta$-catenin gene show lethal organizational defects early during development ${ }^{201}$, underscoring the crucial role for this protein in embryogenesis. This is further supported by studies, which report a role for $\beta$-catenin during normal development ${ }^{133,139,291}$.

Taken together, the abovementioned studies clearly define a role for $\beta$-catenin in the proliferative and migratory responses of cells during embryogenesis and in neoplastic disease. In contrast, little is known about a potential role for $\beta$-catenin in normal, controlled cell proliferation and migration during repair processes after 
injury, e.g. of vascular endothelial cells during neovascularization of the infarct area following $\mathrm{MI}$ in adult animals ${ }^{27 .}{ }^{292}$. In vitro studies, however, have identified the cadherin-catenin complex as a crucial component of endothelial cell-cell junctions, which has to be dissociated and reorganized during angiogenesis ${ }^{293}$. In several reports, a decrease of membrane-bound and a concomitant increase in cytoplasmic $\beta$-catenin during the migration of human umbilical vein endothelial cells (HUVECs) ${ }^{294 .}{ }^{295}$ and cpithelial cells ${ }^{296}$ has bcen described, underscoring the importance of the dissociation of the cadherin-catenin complex during angiogenesis.

The aim of the present study was to investigate the potential role of $\beta$-catenin in the neovascularization, which occurs in vivo during infarct healing after MI. To this end, infarcted rat hearts were obtained at different time points (2-21 days) after $\mathrm{MI}$ and the $\beta$-catenin contents of the vascular endothelial cells around the infarct area and in the uninjured myocardium were compared. Since $\beta$-catenin-APC interactions have been shown to be critical for epithelial tubule formation in vitro $^{297}$, we have performed immunohistochemical staining for $A P C$ as well. Moreover, $\beta$-catenin recently has been identified as a second messenger molecule in the wnt- $\mathrm{f} z$ signal transduction pathway ${ }^{13.3 .173}$. In this pathway, genes from the dvl family are known to regulate the degradation of $\beta$-catenin by controlling its phosphorylation by GSK-3 $\beta^{58}$. Therefore we have studied the expression of the three murine dishevelled (dvl) genes ${ }^{121-123}$ in the infareted rat heart by in situ hybridization.

\section{Materials and Methods}

\section{Animals and sungery}

Adult malc Wistar rats (250-300 gr., Winkelmann, Borchen, Germany) were used in this study. They were housed in groups of 3-4 (rats) with free access to food and tap water. MI was induced as described previously $y^{298}$.

\section{In situ bybridization for dol-bomologues}

The expression of the three dvl genes was studied by in situ hybridization. These experiments were performed on paraffin sections $(4 \mu \mathrm{m})$ from formalin-fixed infarcted rat hearts. The in situ hybridizations were performed as described previously $^{36}$. Briefly, radiolabeled riboprobes were transcribed from PCR products of dv11, 2 and 3, obtained by amplification of reverse-transcribed RNA isolated from rat heart as previously described ${ }^{218}$ and cloned into a pGEM-T cloning vector (Promega, Madison WI, USA). the sections were dehydrated, dried, dipped in photographic emulsion (Kodak NTB2, Technorama, Zürich, Switzerland) and exposed for 1-2 weeks in the dark at $4 \mathrm{C}$. After development, the sections were briefly stained with hematoxylin. 

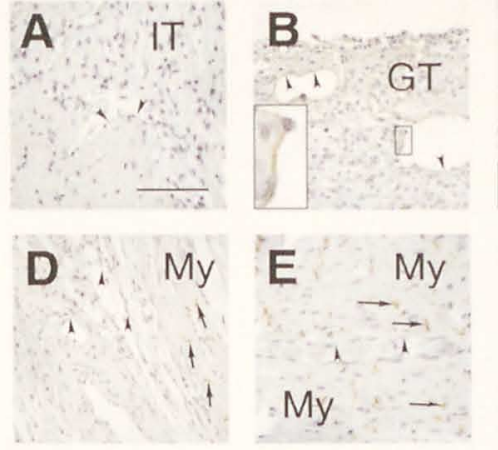

Figure I. Time course of cytoplasmic $\beta$-catenin localization in small blood vessels in the area of infarction in sections of infarcted rat hearts. Arrowheads indicate the vascular endothelial cell layer whereas arrows indicate the intercalated disks of cardiomyocytes. (A) 2 days after MI neovascularization has not yet started. The small vessels in the infarct area do not show $\beta$-catenin staining, probably because these vessels are remnants of the vasculature present before infarction. The borderzone of the infarct consists of inflammatory tissue (IT). Bar represents $100 \mu \mathrm{m}$. (B) 4 days after Ml many newly formed small vessels were present in the border zone of the infarct area. In the cytoplasm of the endothelial cells $\beta$-catenin staining was observed (see high power magnification in inset), In contrast, the granulation tissue (GT), which is formed in the border zone of the infarct, did not show detectable $\beta$-catenin staining. (C) 7 days after Ml, the cytoplasm of the vascular endothelial cells of small vessels in the infarct area was still positively staining for $\beta$-catenin (inset shows high power magnification). The granulation tissue again was negative. (D) 21 days afer MI. no $\beta$-catenin staining could be detected in most of the vascular endothelial cells of the small vessels. The intercalated disks of the cardiomyocytes (My) stained positively for $\beta$-catenin. (E) shows a small vessel in a non-infarcted area of the heart, 4 days after MI. No $\beta$-catenin staining of the cytoplasm of the vascular endothelial cells could be observed. The intercalated disks of the myocytes were positively staining for B-catenin. (F) small vessel in an non-infarcted part of the heart, 7 days after MI. Again no positive staining of vascular endothelial cells was observed.
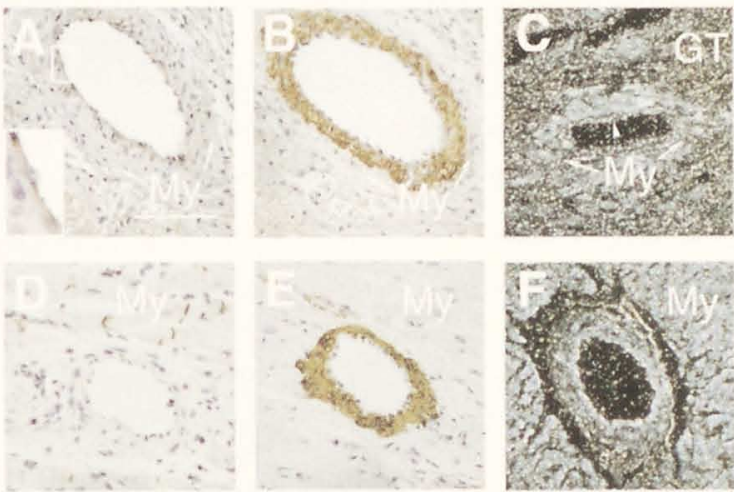

Figure 2. (A) $\beta$-catenin staining of endothelial cells of a larger. preexisting artery in the area of infarction, 4 days after MI. Around the artery a thin layer of surviving cardiomyocytes (My) was present, confirming that the artery was present before infarction. Bar represents $100 \mu \mathrm{m}$. (B) Immunohistochemistry for $\alpha$ - smooth muscle actin (ASMA) shows staining of the vascular smooth muscle cells in the media of the same artery, but not of the endothelial cell layer or the cardiomyocytes. (C) Dark field image of an in situ hybridization with a dvil probe of a section of rat heart, 4 days after MI. The photographic grains are represented as white spots. Note that grains are localized over the vascular endothelium (arrowhead). whereas the amount of grains over the cardiomyocytes (My) is lower. A high density of grains was observed over the granulation tissue (GT) in the border zone of the infarct. (D and $E$ ) muscular arteries in the non-infarcted parts of the myocardium did not show endothelial $\beta$-catenin staining, but the vascular smooth muscle cells stained positively for (ASMA). (F) No dvll expression was observed in muscular arteries in the noninfarcted areas of the heart. 


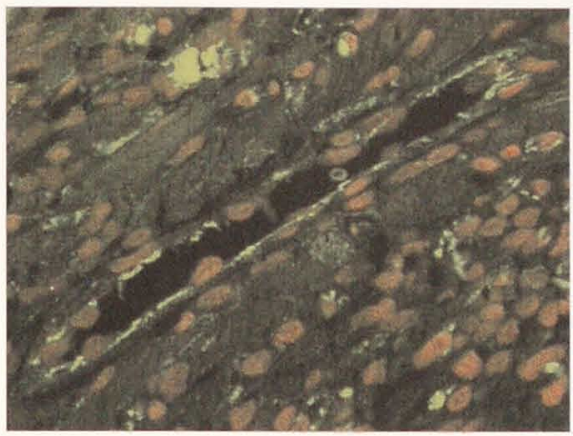

Figure 3. Confocal microscopy of a small vessel in the infarct area of a rat heart, 7 days after Ml. $\beta$-catenin staining is depicted in green and the nuclear counterstain (propidium iodide) is depicted in red. Note that the $\beta$-catenin staining is present in the cytoplasm of the vascular endothelial cells, whereas $\beta$-catenin staining in the nuclei could not be detected.
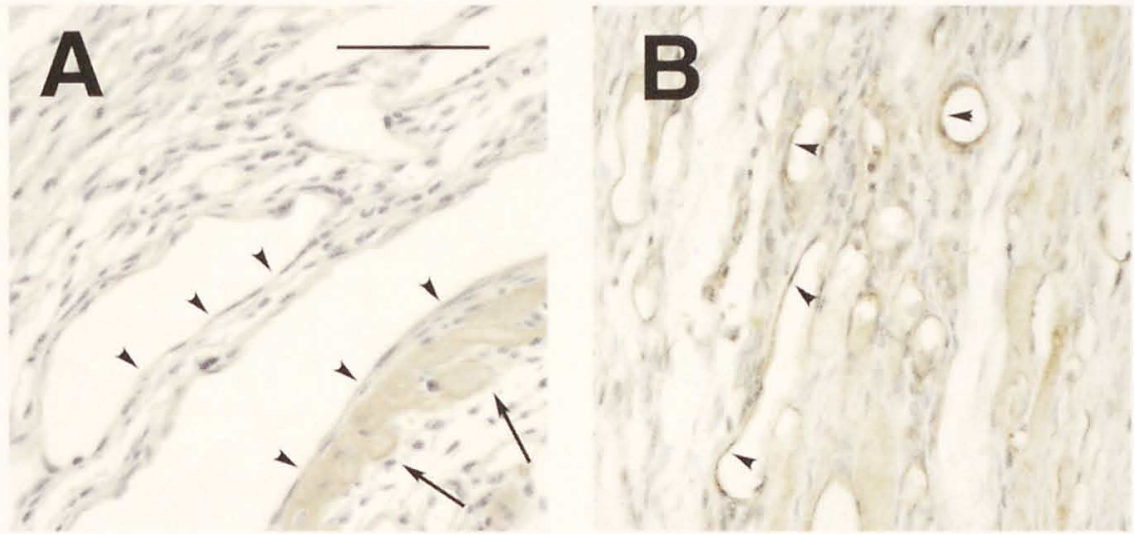

Figure 4. Localization of the APC protein in vascular endothelium during infarct healing in the rat. APC staining was observed in the endothelial cells of newly formed vessels around the infarct area at 7 days after MI (A). In contrast to the $\beta$-catenin staining, APC staining was still observed in these cells 21 days after $M l(B)$.

Figure 5. High power magnification of immunohistochemistry for BrdU and $\beta$-catenin in a small vessel and capillaries in the infarct area of a rat heart, 4 days after Ml. BrdU-positive nuclei of proliferating cells are depicted in red, and $\beta$-catenin is shown in brown. Some of the vascular endothelial cells that contain $\beta$-catenin in their cytoplasm have a BrdU-positive nucleus (arrows). but $\beta$-catenin-positive cells without nuclear BrdU incorporation were also observed (arrowhead).

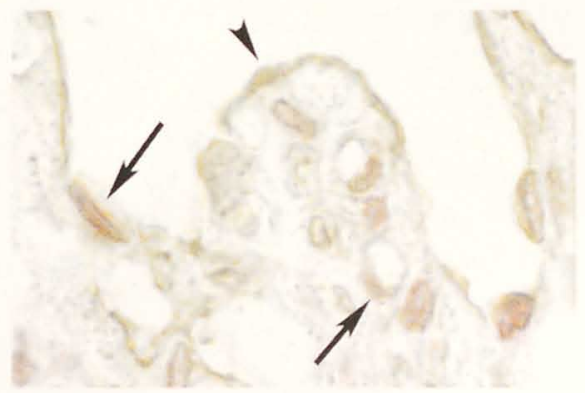


Table I. Primer sets for the $f z$ PCR reactions

\begin{tabular}{lll} 
Gene & Upper primer & Lower primer \\
\hline dvll & CAGGGCACTGACAGCCAC & CAGTAGATGCACTGTCTGGAGG \\
dv12 & AAGAGCGIITGCAGCGG & GACACAAGCCAGGAGACAAC \\
dv13 & CCCCTITCTGTGCTGACAAC & GCTCAATCCGGGAGACCTT
\end{tabular}

\section{Immunobistochemistry}

Immunohistochemistry was performed according to routine procedures. Paraffin sections were mounted on aminopropyltriethoxysilane (APTS) coated slides. A monoclonal antibody for $\beta$-catenin was obtained from Transduction Labs, Lexington KY, USA. After blocking the endogenous peroxidase, sections were boiled twice for $5 \mathrm{~min}$ in $10 \mathrm{mmol} / 1$ citrate buffer ( $\mathrm{pH} \mathrm{6.0)}$ and incubated with the primary antibody in a 1:500 dilution overnight at room temperature. Immunohistochemistry for APC was performed using the $\mathrm{N}-15$ monoclonal antibody obtained from Santa Cruz, Santa Cruz CA, USA in a 1:2000 dilution and incubating for $1 \mathrm{hr}$ at room temperature. Sections were pretreated with $1 \mathrm{mg} / \mathrm{ml}$ pepsin (Boehringer, Mannheim, Germany). Biotinylated multilink Swine-anti-goat, -mouse and -rabbit secondary antibody (dilution 1:100, DAKO, Glostrup, Denmark) and The Vectastain ABC kit (Vector, Burlingame CA, USA) were used according to the manufacturers instructions to visualize the binding of both primary antibodies. Sections were briefly counterstained with hematoxylin and mounted with Entellan (Merck, Darmstad, Germany). The identity of vascular smooth muscle cells and myofibroblasts was determined using an antibody against -smooth muscle actin (dilution 1:500, DAKO, Glostrup, Denmark).

\section{Confocal microscopy}

Confocal microscopy was performed using a BioRad MRC600 confocal scanning laser microscope (BioRad, Hempel Hemstead, UK) as previously described ${ }^{299}$. Immunohistochemistry for $\beta$-catenin was performed as described above with FITC-labeled Rat-anti-Mouse (DAKO, dilution 1:100) as secondary antibody. The nuclei were counterstained using propidium iodide.

\section{BrdU incorporation}

BrdU (Serva, Heidelberg, Germany) was continuously infused using osmotic minipumps (Alzet model 2002, Alza Corp., Palo Alto CA) implanted subcutaneously between the shoulder blades. BrdU was dissolved in $0.9 \% \mathrm{NaCl}$ $(10 \mathrm{mg} / \mathrm{ml})$ and infused at a rate of $240 \mathrm{ng} / \mathrm{kg} / \mathrm{min}$. The pumps were implanted at the time of MI induction; animals were sacrificed 4 and 7 days after MI. The cumulative labeling of $\mathrm{BrdU}$ in the infarct area was determined using a monoclonal antibody directed against BrdU according to previously published methods ${ }^{300}$. 
B-catenin and neovascularization after MII

\section{Results}

\section{Time comse of the $\beta$-catenin expression in nem/y formed vessels around the infart area}

The expression of $\beta$-catenin in the infarcted part of the left ventricle of the rat at different time points after $\mathrm{MI}$ is shown in fig. 1. Two days after infarction, no staining for $\beta$-catenin was observed around the area of infarction (fig. $1 \mathrm{~A}$ ). In this phase of the wound healing no neovascularization or formation of granulation tissue has yet occurred in the infarct area. At 4 days after MI, however, many small blood vessels have emerged in the border zone around the area of infarction. Interestingly, the cytoplasm of the vascular endothelial cells stained positively for $\beta$-catenin (fig. 1B). This staining was not observed in vascular endothelial cells in the non-injured myocardium (fig. $1 \mathrm{E}$ ) and in vascular cndothelial cells of shamoperated animals (not shown). Beta-catenin staining of vascular endothelial cells was also observed 7 days after infarction (fig. 1C). In contrast, the myofibroblasts present in the granulation tissue around the area of infarction did not show any $\beta$-catenin staining, and vascular endothelial cells in non-infarcted parts did not show cytoplasmic $\beta$-catenin staining (fig. 1F). $\lambda t 14$ (not shown), 21 (fig. 1D) and 90 days (not shown) after MI, most of the vascular endothelial cells in the areas of newly formed blood vessels around the infarct did not show $\beta$-catenin staining. Again, the myofibroblasts did not shown any staining for $\beta$-catenin. The intercalated disks between the uninjured cardiomyocytes were positive for $\beta$-catenin (fig. 1D-F) at all time points as previously reported ${ }^{301}$.

\section{$\beta$-catemin expression in langer; muscular arteries in the infarct area}

Cytoplasmic $\beta$-catenin staining of the vascular endothelium was not confined to the newly formed small vessels around the infarct area, but could also be observed in larger arteries in the injured parts of the heart (fig. $2 \mathrm{~A}$ ). These arteries most likely were already present in the area before the infarction, because a fully developed media containing vascular smooth muscle cells (fig. 2B) and a layer of surviving cardiomyocytes around these arteries was observed around them. In contrast, arteries of similar diameter in the uninjured parts of the heart (fig. 2D, E) or in sham-operated animals (not shown) did not show endothelial $\beta$-catenin staining.

Because $\beta$-catenin is known to act as a second messenger in the wnt-fz signal transduction pathway, we performed in situ hybridization for the three known murine dvl (dvl) homologues. As shown in fig. 2C, silver grains were observed over the endothelial cells of the larger arteries in the infarct area when the dvll probe was used. In contrast, neither with the dvl-2 nor the dvl-3 probe a labeling above background levels could be detected in these cells (not shown). Muscular arteries in the uninfarcted parts of the heart did not show signal above background levels with the dvl1 probe (fig. $2 \mathrm{~F}$ ). Abundant labeling with the dvl1 probe was also observed in the granulation tissue around the infarct area, which is rich in (myo) fibroblasts and monocytes (fig. 2C). This abundant labeling obscured the unambiguous detection of dvll signal in endothelial cells of the small, newly formed vessels, 
although in the dvll autoradiograms the density of silver grains in areas with many newly formed blood vessels was above background levcls.

\section{Confocal microscopy' of $\beta$-catenin}

To determine the intracellular localization of $\beta$-catenin in more detail, confocal microscopy was performed on sections of infarcted rat heart, 4 and 7 days after MI. As shown in fig. 3, immunofluorescence was observed in the cytoplasm of the vascular endothelial cells around the infarct area but not in the nuclei, as observed with immunohistochemistry.

\section{Localization of $A P C$ protein in the infarted rat beart}

The expression of the $\triangle \mathrm{PC}$ protein, involved in the degradation of $\beta$-catenin, was studied in infarcted rat tissue after MI. Seven days after MI, some staining for $\triangle P C$ protein was observed in the endothelial cells of the newly formed vessels around the infarct arca (fig. 4A). A similar pattern of staining, though of considerably higher intensity, was observed 21 days after MI (fig. 4B), and positive vascular endothelial cells could still be detected at 90 days after MI (not shown). Surviving cardiomyocytes close to the area of infarction showed a diffuse staining for $\triangle P C$ protein (fig. $4 \AA$ ), which was not observed in cardiomyocytes in the uninjured parts of the heart. $\triangle P C$ staining was also observed in vascular smooth muscle cells at all time points studied.

\section{Dowble staining for $\beta$-catenin and BraU}

Since cytosolic $\beta$-catenin accumulation has been associated with cell proliferation in a number of neoplastic diseases, we performed immunohistochemical double staining for $\beta$-catenin and $\mathrm{BrdU}$, a nucleotide analogue, which is incorporated in the DNA during cell proliferation. $A$ s shown in fig. 5, positive nuclei were obscrved in some, but not all of the vascular cndothelial cells that stained positive for $\beta$-catenin. Because BrdU incorporation was not a generalized phenomenon in $\beta$-catenin-positive vascular endothelial cells, this suggests that the cytoplasmic $\beta$-catenin in these cells is not a direct inducer of cell proliferation.

\section{Discussion}

The aim of the present study was to disclose a potential link between the presence of $\beta$-catenin in the cytoplasm of the vascular endothelial cells and their proliferation and migration during the process of neovascularization in infarct healing. To this end, we have studied the localization of $\beta$-catenin, its regulatory protein $\triangle P C$ and the expression of the dvl genes, located upstream in the wnt- $\mathrm{f} /$ signal transduction pathway, in infarcted rat hearts at different time points. Because the neovascularization which takes place after MI consists of angiogenesis as well as the remodeling of preexisting arteries ${ }^{27}$, processes which are both dependent on endothelial cell proliferation and migration ${ }^{292}$, this model appears to be very 
suitable to study a link between $\beta$-catenin expression and the proliferation and migration of endothelial cells in vivo.

Beta-catenin was observed in the cytoplasm of the endothelial cells of newly formed vessels around the area of infarction, 4 and 7 days after MI. In contrast, vascular endothelial cells in the non-infarcted part of the heart showed no detectable $\beta$-catenin levels in their cytoplasm. Because remodeling of existing capillarics as well de novo gencration of capillaries take place in the first week after $\mathrm{Ml},{ }^{4,}{ }^{22}, 312$, the time frame of the appearance of cytoplasmic $\beta$-catenin matches with that of the neovascularization. Based on in vitro data in which the appearance of $\beta$-catenin in the cytoplasm was observed during HUVEC migration ${ }^{294,215}$, our observations suggest a similar translocation phenomenon in endothelial cell proliferation and migration in vivo. These obscrvations are also in accordance with in vitro studies in which the VE-cadherin-catenin complex was found to be essential for de novo capillary formation ${ }^{3+3}$ and in which VEGF-induced phosphorylation of the cadherin-catenin complex was found to be essential for the loosening of endothelial cell-cell contacts, a first step in angiogenesis ${ }^{30+4}$. Moreover, in a recent study by Cameliet and coworkers $^{305}$ it was shown that the VE-cadherin/ $\beta$-catenin complex is essential for endothelial cell remodeling and maturation during gestation in mice, and that targeted disruption of the intracellular part of the VE-cadherin gene leads to abnormal vascular development, underscoring the importance of these molecules in the formation and remodeling of blood vessels. Moreover, $\beta$-catenin translocation to the cytoplasm was observed in endothelial cells in culture during their remodeling in response to shear stress, suggesting that this is likely to be a normal phenomenon during rearrangement of endothelial cells.

An abundant presence of $A P C$ protein was obscrved in vascular endothelium and myocytes around the infarct area as wcll as in vascular smooth muscle cells. In a recent study by Pollack et al. ${ }^{297}$, a functional interaction between $\beta$-catenin and $\triangle P C$ has been shown to be necessary for tubule formation of MDCK cells in vitro. Moreover, there is increasing evidence that $\triangle P C$ itself is involved in the formation of stable membrane cxtrusions during active cell migration ${ }^{306}$. It is tempting to speculate that the co-expression of $\beta$-catenin and $\triangle P C$ in the area of neovascularization around the infarct area promotes vascular endothelial cell proliferation and migration in both angiogenesis and remodeling of pre-existing vessels. On the other hand, the rise in $A P C$ protein content which coincides with the decrease in $\beta$-catenin content of the vascular endothelial cells may suggest that the APC protein contributes to the $\beta$-catenin degradation in these cells. The role for APC in vascular smooth muscle cells and cardiomyocytes, however, is unclear.

Recently, $\beta$-catenin has been identified as a second messenger in the signal transduction cascade of wnt proteins, which ate involved in control of tissuc polarity $^{1.3 .3}{ }^{17.3}$. In the original description of this signal transduction system in Drosophila, the dvl protein was shown to act directly downstream of frizzled ( $\mathrm{f} z$ ), now recognized as the receptor for proteins from the wht family ${ }^{13 t}$. In the mean 
time, three mammalian dvl homologues have been identified in the mouse $\mathrm{e}^{121-123}$. Using these mouse sequences, we have designed primer sets, which allowed PCRamplification of three fragments from rat DNA. Partial sequencing of these fragments revealed homologies of over $90 \%$ with the published mouse sequences, confirming the identity of these fragments as rat homologues of mouse dvl1-3. The three PCR fragments were subsequently used for in situ hybridization. In sections of infarcted rat hearts, 7 days after MI, expression of dvl1 was detected in vascular endothelial cells of the larger vessels around the infarct area, but not in uninfarcted areas of the heart. Areas rich in newly formed capillaries around the infarct area also showed signal for dvll above background levels, but since the resolution of the radioactive in situ technique is not high enough to allow precise cellular localization, the interpretation of these data is difficult. This problem is further aggravated by the high levels of dvl1 expression in the myofibroblasts, which are abundant around the area of infarction ${ }^{4,38}$. However, from the data obtained with the larger arteries we can conclude that a key upstream component of the wnt- $f$ z cascade is present in the vascular endothelial cells during neovascularization of the infarct area, which may suggest a role for this pathway in the control of proliferation and/or migration of these cells. This concept is supported by a recent study of Duplàa et al. ${ }^{214}$ in which a relation between the level of expression of FrzA, a scavenger for wnt proteins which is structurally related to fz receptors, and endothelial cell proliferation in vitro was demonstrated. Moreover, recently the presence of a wnt- $f z$ signal transduction system which, when activated, increases the cytoplasmic $\beta$-catenin content has been described in vascular endothelial cells in primary culture ${ }^{212}$, providing additional evidence that wnt- $f z$ activation may be involved in the $\beta$-catenin translocation observed in the present study.

In conclusion, the present study shows the presence of cytoplasmic $\beta$-catenin and APC protein in vascular endothelial cells during neovascularization after MI. Since $\beta$-catenin is known to be a key regulator of both cell proliferation and migration, a role for this protein in angiogenesis and vascular remodeling can be anticipated. This is further substantiated by data from in vitro studies in which translocation of $\beta$-catenin to the cytoplasm has been linked to angiogenesis. Moreover, the expression of $\mathrm{dvl} 1$ in these cells suggests an involvement of the wnt-fz cascade in this process. These findings underscore that $\beta$-catenin is not only a crucial factor during development and in neoplastic disease, but can also play a role in the vascular endothelial cell proliferation and migration during neovascularization after MI. 
Chapter 9

\section{ABSENCE OF $\beta$-CATENIN IN INTERCALATED DISKS BETWEEN CARDIOMYOCYTES IS ASSOCIATED WITH INFARCT RUPTURE IN DISHEVELLED-1 KNOCKOUT MICE}

W.M. Blankesteijn, M.E. van Gijn, Y.P.G. Essers-Janssen, N.S. Hamblet, A. Wynshaw-Boris, D.J. Sussman, R.E. Pratt, M.J.A.P. Daemen and J. F.M. Smits

Submitted 


\begin{abstract}
Infarct rupture is a usually fatal complication of MI in humans, for which no molecular mechanism has been defined. In an experimental model of MI, infarct rupture was observed in $75 \%$ of the mice harboring a disrupted dvll gene. In contrast, rupture occurred in only 1 out of 11 wildtype animals. Rupture was associated with latge spaces between the necrotic myocytes in the infarct area of the dv11-/- mice, allowing the leakage of blood cells through the ventricular wall. This suggests that the lack of the dvll gene results in diminished myocyte-myocyte interaction. Dvl proteins are a central component of the signal transduction pathway of polarity genes from the "frizzled"( $(\mathrm{F} z)$ family. Activation of this pathway leads to an increase in the intracellular $\beta$-catenin content, a protein involved in cellcell adhesion present in the intercalated disks between the cardiomyocytes. Immunohistochemical staining showed that $\beta$-catenin was undetectable in the intercalated disks in all ruptured hearts. In contrast, most of the control mice showed high levels of $\beta$-catenin staining. These findings point to a key role for the cadherin-catenin complex in the integrity of the infarct area after infarction.
\end{abstract}

\title{
Introduction
}

MI is one of the most frequent cardiovascular events in the Western world, associated with a high morbidity and mortality ${ }^{317}$. Improvement of the pharmacological treatment of arrhythmias has shifted the major causes of inhospital mortality in the first days after MI to acute pump failure and infarct rupture $^{308}$. Rupture is most frequent when the infarct is located in the ventricular free wall ${ }^{319}$, and nearly always results in sudden death from massive blood loss into the pericardium causing compression of the heart, a phenomenon known as cardiac tamponade ${ }^{307,310}$. Little is known about the cause of infarct rupture, and the diagnostic tools that are available to identify patients prone to rupture after $\mathrm{MI}$ are of poor quality ${ }^{311}$. Although environmental as well as genetic risk factors have been described for MI itself ${ }^{307,312}$, no genetic predisposition for infarct rupture has been identified so far. Identification of genes that are associated with infarct rupture would therefore not only be very helpful for a better understanding of the underlying mechanisms that lead to this complication of MI, but also as a diagnostic tool to identify the patients that are prone to rupture.

In previous work, we have focused on genes that are involved in the control of the architecture of the heart during the adaptation to an increased work load or in response to injury. In these experiments the increased expression of $f z 2$, a mammalian homologue of the Drosophila "frizzled" protein, was observed during cardiac adaptation and repair ${ }^{38,216}$. In Drosophila, this protein is involved in the transduction and translation of cellular polatity signals. In the mean time, the $f \%$ gene product has been identified as a receptor protein with 7 membrane-spanning domains, and multiple mammalian family members have been cloned". Frizzled proteins act as receptors for wnt proteins, homologues of Drosophila "wingless". 
These genes typically are expressed during fetal development and show lower levels of expression after birth ${ }^{58}$. In this report we will focus on a downstream protein of the fz receptors, dvl, which has been shown to play a crucial role in the wnt-fz signal transduction ${ }^{130}$. In the mouse, threc dvl homologues have been identified ${ }^{121-123}$. They act as coupling molecules between the frizzled receptors and their signal transduction cascade. Recently, $\beta$-catenin has been identified as a second messenger molecule for $f z$ receptors ${ }^{26 \%}$. 313 . In this pathway, $d v$ l proteins inhibit GSK $3 \beta$, the enzyme responsible for the phosphorylation of $\beta$-catenin which is the first step in the degradation of this protein. By this mechanism, stimulation of frizzled receptors leads to an increase in intracellular $\beta$-catenin.

In the present paper we report the sudden death of dvl1-/- mice in the first week after $\mathrm{Ml}$, due to infarct rupture. In these micc abnormalities in social interaction and sensorimotor gating have been reported, but they do not display illnesses, histological abnormalities or a reduced life span when compared to wildtype animals with the same genetic background ${ }^{314}$. To investigate the underlying causes for the infarct rupture, we have compared the histology of the infarct area of $\mathrm{dvl} 1-/$ - and wildtype mice. Moreover, we have performed immunohistochemistry for $\beta$-catenin to investigate whether the infarct rupture, observed in these mice, can be linked to a defective wnt- $f z$ pathway.

\section{Methods}

\section{Animals and suryeny}

The male dvl1-/- mice, used in this study, were completely inbred $>10$ generations) into a $129 / \mathrm{SvEv}$ background ${ }^{314}$. Age-matched wildtype $129 / \mathrm{SvEv}$ mice were obtained from Taconic Farms, Germantown NY. They were housed in groups of 3-5 with free access to food and tap water. MI was induced at the age of 10-12 weeks as described previously ${ }^{17}$. Briefly, after intraperitoneal injection of sodium pentobarbital $(100 \mathrm{mg} / \mathrm{kg}$ ) positive pressure respiration was started through an endotracheal tube. The thorax was opened at the left fourth intercostal space, and the left anterior descending (LAD) coronary artery was ligated, just proximal to its main bifurcation, using a 6-0 prolene ligature. After closing of the chest in layers and recovery from anesthesia, the animals were returned to their home-cages. Animals that did not develop infarct rupture were sacrificed at day 9 after $\mathrm{MI}$ and perfusion-fixed according to a previously published protocol ${ }^{17}$.

\section{Immmmobistocbemistiy!}

A previously described immunohistochemistry protocol ${ }^{38}$ was used with the following modifications. Paraffin sections were mounted on 3-aminoproyltriethoxysilane (APTS, Sigma-Aldrich, St. Louis MO, US $\lambda$ ) coated glass slides. After deparaffination and the inhibition of endogenous peroxidase, sections were boiled twice for $5 \mathrm{~min}$ in $10 \mathrm{mmol} / \mathrm{l}$ citrate buffer ( $\mathrm{pH} \mathrm{6.0)}$. Immunohistochemistry for $\beta$-catenin was performed using a monoclonal antibody (Transduction Labs., Lexington $\mathrm{KY}$, USA) in a 1:500 dilution and an overnight incubation at room 
temperature. Immunohistochemistry for cardiac cadherin was performed using a monoclonal antibody (1:100 dilution, Sigma- $A$ ldrich) raised against the C-terminal cadherin sequence which is common in many cadherins including $\mathrm{N}$-cadherin, the main cardiac form. The expcriments were performed as described above. Biotinylated multilink Swine-anti-goat, -mouse and -rabbit secondary antibody (dilution 1:100, DAKO, Glostrup, Denmark) and The Vectastain $\triangle B C$ kit (Vector, Burlingame $C A$, US $A$ ) were used according to the manufacturers instructions to visualize the binding of the primary antibody. Sections were briefly counterstained with hematoxylin and mounted with Entellan (Merck, Darmstadt, Germany).

\section{RT-PCR and in siln byluridization for dufl}

Reverse transcription was performed on RNA, isolated from mouse hearts with the Ultraspec II RN $\Lambda$ isolation system (Biotecx Laboratories, Houston TX) and treated with RQ1 DNase (Promega, Madison WI), using a first strand cDNA synthesis kit (Pharmacia, Uppsala, Sweden) according to the manufacturers instructions. PCR amplification of the dvl-1 fragment was performed using CAGGGCACTGACAGCCAC and CAGTAGATGCACTGTCTGGAGG as upper and lower primers, respectively. The resulting $P C R$ fragment was cloned into the pGEM-T vector (Promega). An RNA transcript of this PCR fragment, generated with $T 7$ RNA polymerase in the presence of radiolabeled ribonucleotides, was used as a probe for the in situ hybridization experiments which were performed as described previously ${ }^{38}$.

\section{Results}

\section{Infarct mpture in do/1-/ - mice}

MI was induced in a total of 8 male dvl1-/- mice and 11 male wildtype mice with the same genetic background. As shown in the survival curve (fig. 1), this resulted in the sudden death of $75 \%$ of the dvl1-/- mice, 3-7 days after the induction of MI. In contrast, only 1 out of 11 control mice died suddenly, 4 days after MI. Autopsy revealed that the thorax of all the mice that had suddenly dicd was filled with blood, suggestive for a rupture of ventricular free wall. Cardiac tamponade was not

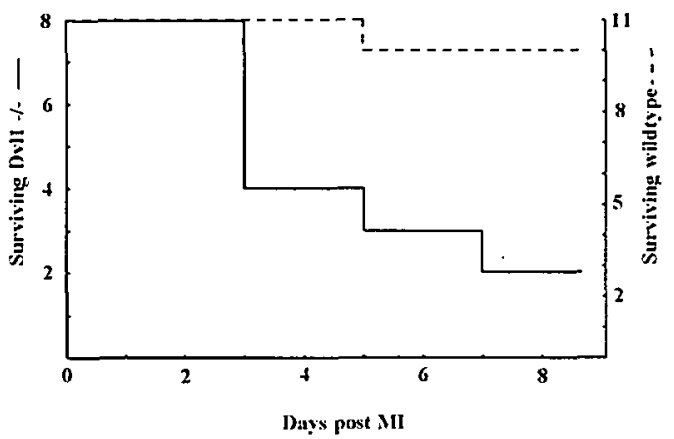

Figure I. Survival curves of the $d v 1$ knockout (Dvil-f-, solid line) and wildtype (dashed line) mice after myocardial infarction (MI). In the Dvll /group. $75 \%$ of the mice died within one week after MI. whereas the mortality in de wildtype group was below $10 \%$. 
observed in these animals because the pericardium had been opened for the induction of MI, resulting in direct bleeding into the thoracic cavity.

\section{Histological examination of the mptured left ventricles}

To investigate the histology of the ruptured ventricles, tissue sections were stained with hematoxylin and eosin ( $\mathrm{HE}$ ) and AZAN. In an overview of the ruptured left ventricle, stained with $\mathrm{HE}$, blood-filled spaces were observed (fig. $2 \mathrm{~A}$ ) through which the blood had flown from the ventricle into the thoracic cavity. Detailed analysis of AZAN-stained sections showed large intercellular spaces between the necrotic myocytes in the infarct area (fig. $2 \mathrm{~B}$ ) which were not observed in wildtype animals. This finding suggests a diminished myocyte-myocyte interaction as the cause for the infarct rupture.

Table I. $\beta$-catenin content of the intercalated disks in section from $\mathrm{dv} / \mathrm{I}-1$ - and wildtype mice.

\begin{tabular}{|c|c|c|c|c|}
\hline \multicolumn{5}{|c|}{$\beta$-catenin staining } \\
\hline & High & Low & Undetectable & Total \\
\hline$d v \mid l-/-$ & 0 & $2^{3}$ & 6 & 8 \\
\hline wildtype & 8 & 1 & $2^{b}$ & 11 \\
\hline
\end{tabular}

\section{Immunobistochemistry for $\beta$-catenin}

Sections of the hearts of all $8 \mathrm{dvl1}-/$ - and 11 wildtype mice, included in this study, were analyzed for their $\beta$-catenin content by immunohistochemistry. In fig. $3 \mathrm{~A}$, a typical example of the absence of $\beta$-catenin staining in the cardiomyocytes of a dvl1-/- mouse that died from infarct rupture is shown. In contrast, strong staining was observed in the intercalated disks in wildtype mice (fig. 3B). The sections were analyzed by two independent observers (WB and MD) in a blind way and included into one of three categories: strong $\beta$-catenin staining in many intercalated disks; few $\beta$-catenin-positive intercalated disks and weak staining; no detectable staining of the intercalated disks (table 1). Interestingly, in all ruptured dvl-/- mice the $\beta$-catenin staining in the intercalated disks of the myocytes in the viable parts of the heart was undetectable, whereas the two dvl1-/- animals that survived showed weak but detectable staining in some of the intercalated disks. In contrast, most of the wildtype mice showed intense staining of the intercalated disks with the $\beta$-catenin antibody whereas 2 showed no detectable staining of the intercalated disks, one of which died from infarct rupture. Unlike $\beta$-catenin, immunohistochemistry for $\mathrm{N}$-cadherin, another component of the cadherin-catenin complex, showed staining in both dvl1-/- and wildtype hearts (not shown), suggesting that the alterations in the cadherin-catenin complex of the dvl1-/- mice is confined to $\beta$-catenin and does not comprise other components of this complex. 

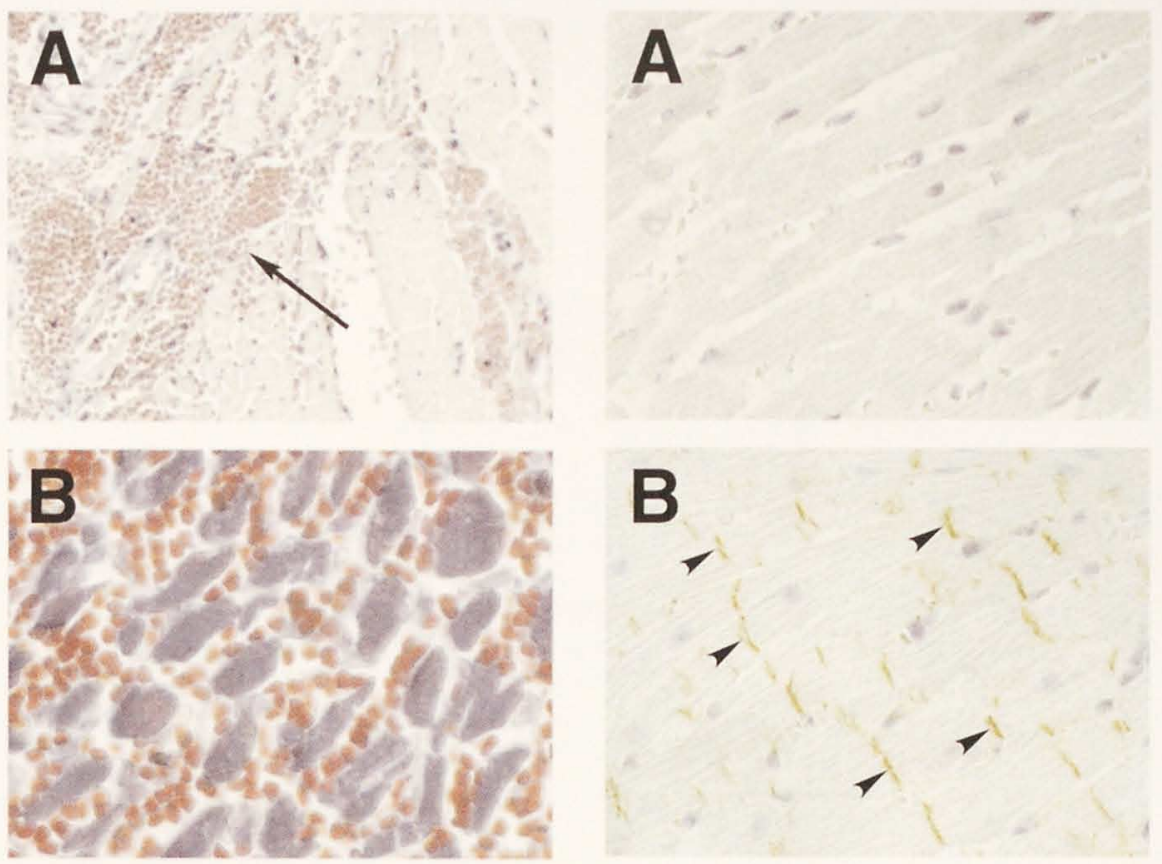

Figure 2. Representative view of the histology of a ruptured infarct area of a dvll-/- mouse. (A) Hematoxylin-eosin stained section at 400x magnification. Note the blood-filled spaces in the tissue (arrow) which allowed the blood to flow from the ventricle into the thoracic cavity. (B) High power (1000x) magnification of the infarct area, stained with AZAN. Large blood-filled spaces (red) can be observed between the myocytes (blue), suggesting an attenuated myocyte-myocyte inter-action as the cause of infarct rupture.

Figure 3. Immunohistochemical staining of sections of hearts obtained from a dvll $/$ - (A) and wildtype (B) animal with anti- $\beta$-catenin antibodies. Magnification: 600x. Abundant staining of intercalated disks between cardiomyocytes was observed in wildtype hearts (arrowheads), whereas this staining was completely absent in hearts obtained from the dvll-/-that died from infarct rupture.

$\beta$-catenin staining in dv/1 - - and wildtype bearts, 48 brs after MI

A trivial explanation for the absence of $\beta$-catenin staining in the ruptured hearts is that these animals died spontaneously whereas the non-ruptured animals were sacrificed. We therefore analyzed the $\beta$-catenin content of the intercalated disks of hearts from 3 dvl1-/- mice and 3 wildtype controls that were sacrificed after 48 hrs, so before infarct rupture had occurred. Again, we observed no detectable $\beta$-catenin staining in all 3 dvl1-/- hearts, whereas all 3 control hearts had high levels of $\beta$-catenin staining in the intercalated disks. This shows that the genotype of the $\mathrm{dvl1}-/-$ mice, rather than the spontaneous death of these animals, is responsible for the lack of $\beta$-catenin staining. 


\section{Dvll expression in normal heart}

To address the question whether the dvl1 gene is expressed in adult, uninfarcted cardiac tissue, we performed a RT-PCR on RNA isolated from wildtype and dvl1-/- hearts. As shown in fig. $4 \mathrm{~A}$, a positive signal was detected when wildtype RNA was used whereas RNA obtained from dv11-/-, as expected, did not yield any PCR product. To establish the cell type(s) that express the dvl1 gene in wildtype heart, we performed in situ hybridization with a dvl1-/- probe. The highest density of photographic grains was detected over the cardiomyocytes. The grain density over blood vessels and other structures that do not contain cardiomyocytes was similar to background levels. This indicates that the dvl1 gene expression is localized in cardiomyocytes (fig. 4B).
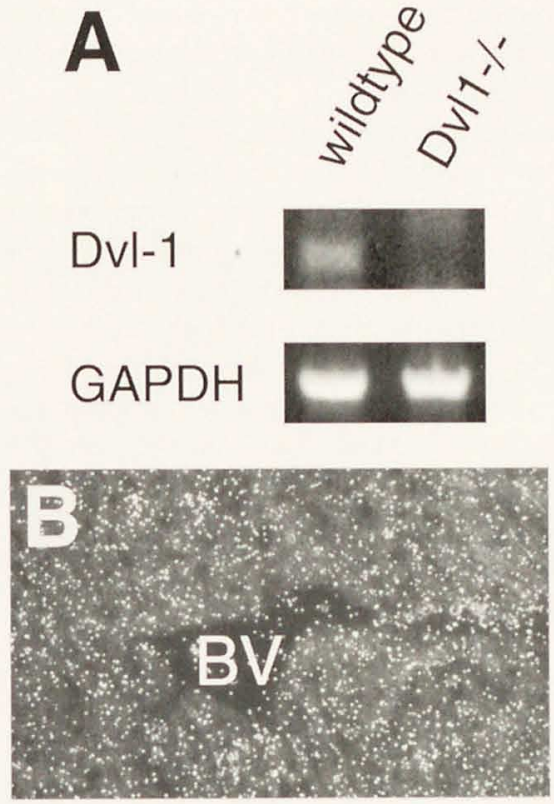

Figure 4. Expression of the dishevelled-I gene in normal mouse heart. (A) Reverse TranscriptasePolymerase Chain Reaction with RNA isolated from a wildtype and a dvll knockout mouse heart. The dvll gene was expressed at a low level in the normal heart but not in the heart obtained from the dvll-1- mouse, whereas the expression of the "house keeping gene" Glyceraldehyde-3-phosphate dehydrogenase (GAPDH) was similar in the two hearts. (B) Dark field image of an in situ hybridization (magnification 400x). The white spots represent the photographic grains, which indicate the sites of dvll expression. Note that the dvil expression is localized over the cardiac myocytes. some of which are indicated by the arrows. The density of photographic grains over the blood vessel (BV) resembles the background level.

\section{Discussion}

In the last decade, early mortality from arrhythmias after MI has decreased due to successful anti-arrhythmatic therapy. Consequently, other early complications of MI, like e.g. infarct rupture, have become increasingly important to further reduce the mortality in the first weeks after MI. However, the mechanism(s) that lead to infarct rupture in humans are unknown which hampers the development of specific diagnostic tools and preventive therapeutic strategies. The present study shows that MI in the dvl1-/- mouse results in rupture of the infarct area with a time course and histological findings that are similar to those observed in humans. Thus, our 
data indicate that infarct rupture can be caused by a defect in a single gene, the dvl1 gene, and that the lack of this gene can induce alterations in the composistion of the cadherin-catenin complex in the intercalated disks of the cardiomyocytes.

The dvl genes form a family consisting of three members in the mouse ${ }^{121 \cdot 123}$ with corresponding human orthologues. The genes are well conserved, with $>95 \%$ homology at the amino acid level between mice and humans ${ }^{315}$. Originally, the dvl gene was identified in Drosophila as a critical component of the wingless signal transduction cascade, involved in the specification of cell fate and polarity in the segmental units of the Drosophila embryo ${ }^{316}$. In the mean time, $f z$ proteins have been identified as receptors for wingless proteins and a direct coupling between $f z$ and $d v l$ has been described ${ }^{133}$. Recently, dvl proteins were shown to be active in two distinct frizzled signal transduction cascades, the armadillo/ $\beta$-catenin pathway and the JNK/SAPK pathway, involved in segmental and planar polarity, respectively ${ }^{131,132}$. These results suggest a central role for the dvl proteins in polarity control in species as diverse as Drosophila and humans.

Dvl1 is expressed at low levels in the myocytes of adult cardiac tissue of wildtype mice, as shown in the present study. In other studies, we have observed a similar low-level expression of members of the $f z$ family in adult mouse hearts (W.M. Blankesteijn, unpublished observation) which may point to a function for the wnt- $\mathrm{f} z$ signal transduction cascade in the normal heart. Moreover, the dvl1 protein appears to play a crucial role in infarct healing after MI, which can not be compensated for by other dvl family members, since a lack of the dvl1 gene leads to infarct rupture in mice. This finding does not support the original idea that the different members of the dishevelled family are redundant, based on the lack of a physiological phenotype of the dvl1-/- mice 58,314 .

The results of the present study point to a link between dvl1 and the cellular $\beta$-catenin content as the cause for the infarct rupture in the dvl1-/- mice. Dvl proteins can inhibit GSK3ß, an enzyme that can phosphorylate $\beta$-catenin, which is the first step in the degradation of this protein ${ }^{167,317}$. $\beta$-Catenin is a protein which can modulate cell-cell adhesion, but also can affect expression of High Mobility Group genes by activating the TCF/LEF family of transcription factors ${ }^{58}$. With respect to the latter function, $\beta$-catenin has received ample attention in cancer research, because it can contribute to the development of different kinds of malignancies ${ }^{286}, 289.291$. However, for the outcomes of the present study the association of $\beta$-catenin with cadherins probably is the most important.

Cadherins constitute a family of transmembranous adhesion proteins, which, in a complex with catenins, link actin filaments of the cytoskeleton to the plasma membrane. In cardiac myocytes, $\beta$-catenin can be found in high concentrations in intercalated disks, where it is associated with cadherins in adherens junctions ${ }^{139,} 283.285$. In dvl1-/- mice the inhibitory action of $d v l$ on GSK-3 $\beta$ is lacking, resulting in an increased degradation of $\beta$-catenin, which can serve as an explanation for the absence of $\beta$-catenin in the intercalated disks of the cardiomyocytes, observed in this study. This most likely results is a weakening of 
the complex between cadherins, catenins and the cytoskeleton, leading to the attenuated myocyte-myocyte interaction observed in this study. This apparently does not cause problems under normal physiological circumstances. However, when the heart is severely challenged, for instance by myocardial infarction, the myocyte-myocyte interactions in the dvl1-/- mice are apparently not sufficiently strong to maintain the integrity of the ventricular wall. This results in infarct rupture as observed in the present study.

An intriguing consequence of the outcomes of the present study is that myocyte-myocyte adhesion seems to be crucial for the integrity of the infarcted venticular wall, despite the fact that the vast majority of these cells is necrotic when infarct rupture occurs. This suggests that in the wildtype animals the necrotic myocytes can still form a barrier against blood cells, thereby preventing the leakage of blood into the pericardial space, a mechanism which is hampered in the dvl1-/mice. At later time points, this function is probably taken over by the granulation tissue, which is beginning to be formed around the necrotic area approximately 5 days after $\mathrm{MI}^{4}$. Therefore this study predicts a functional role for the adhesion of necrotic myocytes during the first weck of infarct healing.

In conclusion, alterations in the cadherin-catenin complex are associated with infarct rupture, suggesting that this complex is a key determinant of the integrity of the ventricular wall after MI. The dvl1-/- mouse is the first animal model in which infarct rupture, with similar time course and histological changes as scen in humans, can be explained by a single molecular defect. Moreover, in preliminary experiments with samples of human cardiac tissue, obtained from MI patients, we have observed an association between alterations in the composition of the cadherin-catenin complex of cardiomyocytes and infarct rupture as well. Therefore these results call for a detailed analysis of the cadherin-catenin complex in cardiomyocytes to better understand, and eventually prevent, this devastating complication of MI. 
Chapter 9 
Chapter 10

\section{GENERAL DISCUSSION}

SUMMARY

SAMENVAT'TING

REFERENCES 


\section{General Discussion}

The architccture of the heart is important for its function. MI has major implications for the architecture of the heart; usually, after MI, infarct thinning and dilatation of the ventricle occur. Genes or signal transduction process involved in the architectural control have hardly been studied in the heart. In Drosophila the tissue polarity genes that are part of the wnt- $f z$ cascade are involved in the architectural control of epithelial structures such as wing hair ${ }^{41}, 4^{2}$ and are required for heart development $t^{197}$.

In this thesis we have investigated the role for the wnt-fz cascade in cardiac development and in the repair process after MI. We have done threc major findings. In chapter 4 we have described that the expression pattern for $\mathrm{fz} 2$ was similar to the pattern of neural crest cells during development of the heart. This suggests an involvement for $\mathrm{f} z 2$ in the migration and patterning of neural crest cells to the heart. Furthermore, the wnt-fz cascade has a role early in the infarct healing by maintaining the structural integrity, as evidenced by the cardiac ruptures after MI in dvl1 knock-out mice (chapter 9). Finally, we have found elevated levels of $\beta$-catenin and dvl1 expression in the vascular endothelial cells after MI suggesting a role of the wnt-fz cascade in neovascularization (chapter 8).

\section{Wnt-fz cascade and development}

In chapter 4 we demonstrated that $\mathrm{fz} 2$ is expressed during the development of the heart. We suggested that $\mathrm{fz}_{2} \mathrm{is}$ involved in the migration and patterning of cardiac neural crest cells. The involvement of the wnt $-\mathrm{fz}$ cascade in neural crest patterning has also been suggested in other studies: wnt 1 and wnt 3 a null mutant mice have neural crest defects and $\mathrm{fz} 4$ is expressed in neural crest-derived

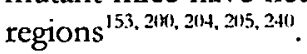

In Drosophila the wnt- $f z$ cascade is involved in initiating cardiac development ${ }^{197}$. Recently, studies in chicken and Xenopus have demonstrated a difference between heart formation in flies and vertebrates ${ }^{318,311}$, as cardiogenesis in vertebrates was induced by inhibiting wnt3a and wnt8c. The role for the wnt-fz cascade in initiating cardiac development in vertebrates, however, temains complex as wnt 11 was expressed in precardiac mesoderm, and was able to induce cardiac differentiation in noncardiac tissue ${ }^{199}$.

Neural crest cells contribute importantly to morphogenesis of the heart. Septation of the pulmonary and systemic outflow tracts depends on the contribution of neural crest cells ${ }^{201}$. 2.37. This suggests that the wnt-fz cascade is functionally involved in the control of cardiac morphology during development.

The neural crest-related syndromes like DiGeorge and Velo Cardio Facial syndrome are associated with a deletion on chromosome $22 q 11^{236,239}$. So far only one member of the wnt-fz cascade, a homologue of $\beta$-catenin, has been localized to that region ${ }^{236}$. In chapter 4 we have suggested that also human dvl2 was located in this region ${ }^{235}$. However, Greco and coworkers ${ }^{320}$ have later shown that human dvl 2 is actually located on chromosome 17 . Human $\mathrm{Ez} 7$ has been localized to the 


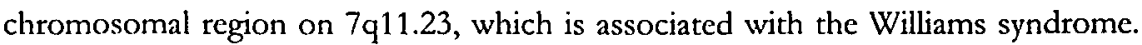
Although not a typical neural crest disorder, the Williams syndrome is associated with a high incidence of stenosis, located predominantly in neural crest derived arteries $^{54}$. These findings are in agreement with the hypothesis that the wnt-fz cascade plays a role in cardiac neural crest patterning during development in the mouse.

Gene knock-out models in mice could be useful tools to study the role of $f z$ receptors in neural crest patterning. $F z$ consists of a family of multiple members with overlapping expression patterns ${ }^{41}$. So far, only for $f z 5$ a knock-out model has been described ${ }^{228}$. The f 55 null mutant mice die in urero around 10.75 days post coitum, due to defects in yolk sac angiogenesis. Cardiac development seemed normal in these mice, but at day 10 of gestational age the neural crest cells have not yet migrated into the heart ${ }^{211 .} 228,237$. Studies in $f 72$ null mutant mice could demonstrate if $f 72$ is essential for cardiac neural crest cell patterning.

In a previous study the f 7.2 expression was linked to the proliferation and migration of myofibroblasts after $\mathrm{MI}^{38}$ In chapter 4 we showed that the $\mathrm{fz} 2$ expression during heart development was also linked to the proliferation and migration of cells. This is in agreement with the finding that genes with a role during the development of the heart can be re-expressed in the heart in pathological conditions ${ }^{194}$.

\section{Wnt-fz cascade in cardiomyocyte cell adhesion}

An important early complication after MI is left ventricular free wall rupture. This complication occurs in $2-4 \%$ of patients with acute myocardial infarction, and accounts for $5-24 \%$ of all in hospital deaths related to acute myocardial infarction ${ }^{321}$.

So far, the molecular mechanism behind infarct rupture has not been clarified. Theoretically infarct rupture could be due to a defect in the extracellular matrix, cell-extracellular matrix interactions and cell-cell interactions. Extracellular matrix degradation has been associated with infarct ruptures as inhibition of plasminogen activators or MMPs has been shown to prevent cardiac rupture ${ }^{35}$.

In chapter 9 we have demonstrated that $\mathrm{MI}$ in dvl1 knockout mice results in cardiac rupture, associated with defects in cell-cell interactions. The cardiac ruptures in the dvil knockout mice were associated with non-detectable $\beta$-catenin in the adherens junctions of the cardiomyocytes. This finding demonstrates that the wnt-fz cascade affects not only cytoplasmic $\beta$-catenin, involved in gene transcription-regulation, but also the $\beta$-catenin in the adherens junctions. In the future, interventions in the wnt-f7. cascade of the dvl1 knock-out mice could be tested to augment $\beta$-catenin levels in the adherens junctions in order to prohibit cardiac ruprure in this model.

Our findings may have implications for cardiac rupture in humans. It would be very helpful to be able to identify the patients at risk for cardiac rupture. If dysfunctional adherens junctions are a cause of human cardiac rupture, mutation analysis for the different components of adherens junctions or the wnt-fz cascade 
could identify patients that are prone to cardiac rupture after MI. Such patients could then get a more aggressive therapy to prevent $\mathrm{MI}$, or, in the future, receive a therapy that enhances the cell-cell adhesion in myocytes possibly by interfering in the wnt-fz cascade.

\section{Frizzled cascade in granulation tissue formation}

\section{Neovascularization}

Restoring the blood supply to the infarct area is an important process in infarct healing. From human and animal data it is known that late reperfusion after MI, even beyond the time of cardiomyocyte salvage, is associated with improved outcome ${ }^{322,323}$. The beneficial effect of late reperfusion can be attributed to several factors, one of which is the acceleration of scar formation, which can attenuate ventricular remodeling. It can be anticipated that neovascularization after MI also contributes to an accelcrated infarct healing.

In chapter 8 we have described $\beta$-catenin expression in vascular endothelial cells after MI, which suggests a role for the wnt- $f$ \% cascade in neovascularization after MI. Neovascularization can be divided in angiogenesis and arteriogenesis (fig. 1) ${ }^{324}$. Angiogenesis involves the formation of new capillaries, which, at a later time point, can be muscularized. Arteriogenesis is the remodeling of pre-existing collaterals after occlusion of a supplying artery ${ }^{324}$. $\beta$-Catenin has been observed in endothelial cells of both newly formed capillaries and pre-existing vessels. Therefore, we propose that $\beta$-catenin in endothelial cells is involved in angiogenesis as well as arteriogenesis.

Our findings have implications for angiogenic therapy after MI and in other ischemic diseases, where neovascularization could be benefecial. Experimentally induced angiogenesis with VEGF can result in non-functional leaking vessels ${ }^{325}$, which could be due to the lack of formation of adherens junctions. Cell culture

\section{Angiogenesis}
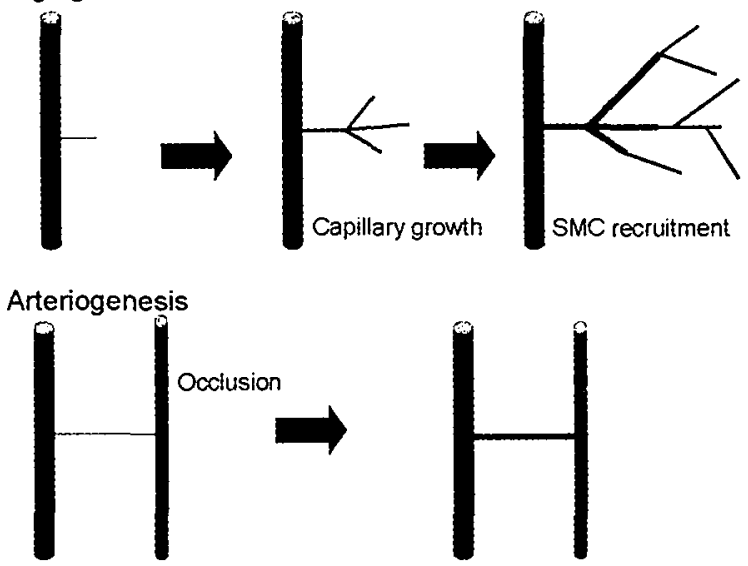

Figure 1. Angiogenesis in adult life describes the process of new formation of capillaries, by recruiting smooth muscle cells the capillaries develop into arterioles and arteries. Arteriogenesis describes the process in which preexisting collaterals develop into arterioles or arteries. 
experiments ${ }^{159}$ and the study described in chapter 9 of this thesis demonstrated that the wnt- $f$ z cascade can stabilize $\beta$-catenin in the adherens junctions. Furthermore, wnt signaling is able to induce endothelial cell proliferation in vitro ${ }^{212}$. Recently, $\mathrm{f} z 5$ has been found to be involved in yolk sac angiogenesis ${ }^{228}$, supporting our hypothesis that the wnt-fz signaling is involved in neovascularization. In $f \geq 5$ null mutant mice, however, it was shown that $f \geq 5$ signaling supports endothelial growth rather than initiating angiogenesis, since the capillary plexus, although formed, was disorganized compared to heterozygous littermates ${ }^{228}$. This suggests that an angiogenic therapy involving the wnt-f7. cascade should include an angiogenic initiator. Furthermore the role for the wnt- $f$ \% cascade in pericytes or smooth muscle cells, which are also important in the formation of arteries, has to be further explored.

\section{Myofibroblasts alignment/migration}

We have tried to characterize the signal transduction route activated by $f 72$ in the myofibroblasts after MI in chapter 5. An association was found between $f 7.2$ and dvl1 expression in the proliferating and migrating myofibroblasts. In chapter 3 we also described an association between $f \not 2$ expression and the migrating intestinal cpithelials cells, which suggests the f $z 2$ expression in migrating cells to be a more generalized phenomenon. Studies with $f z 2$ in other species point to a role for $f z 2$ in planar polarity (cell alignment) rather than in the regulation of $\beta$-catenin induced gene transcripion ${ }^{117.249}$, which is in agreement with our inability to demonstrate cytoplasmatic $\beta$-catenin in the myofibroblasts after MI. Our experiments, however, did not allow us to establish a causal relationship between $f z$ expression and the migration and proliferation of myofibroblasts. Because of the lack of availability of specific agonists and antagonists such causality was difficult to study.

\section{Wnt-fz cascade and apoptosis}

The effect of the wnt-fz cascade and its second messenger $\beta$-catenin on cell growth, as reported in this thesis may seem paradoxial. In chapter $8, \beta$-catenin in the vascular endothelial cells was suggested to be related to the proliferation of these cells, whereas $\beta$-catenin overexpression in the COS7 and 239 cells in chapter 6 was shown to result in apoptosis.

For a long time it was thought that the upregulation of $\beta$-catenin results in cell proliferation, as mutations in APC and $\beta$-catenin that prohibit $\beta$-catenin degradation plays a key role in the development of uncontrolled cell proliferation $^{181.183}$. It was thought that a downregulation of $\beta$-catenin, due to extracellular modulation of the wnt-fz cascade, results in apoptosis ${ }^{114,253}$. Recently, however, two studies have been published in which $\beta$-catenin transfection or upregulation of $\beta$-catenin resulted in apoptosis ${ }^{254,276}$. One could argue that, since these two studies as well as our results in chapter 6 , used overexpression in cultured cell lines, which might not represent a physiological situation. However, also in an in vivo study, GSK-3 $\beta$ inhibition has been associated with apoptosis ${ }^{2(69}$. GSK-3 $\beta$ deficient mice 
die between days 13.5 and 14.5 due to hepatocyte apoptosis and embryonic fibroblasts from these mice are sensitive to TNF- $\alpha$-mediated apoptosis ${ }^{269}$. Apparently, the apoptotic effect of members of the wnt-fz cascade depends on cell type (chapter 6), differentiation state ${ }^{260}$ and the co-expression of other proteins $^{171,254}$.

We suggest that the apoptosis induced by the wnt-fz cascade is a physiologically relevant process, which could also play a role in apoptosis after MI. In the first days after MI, myocytes in the infarct area die due to necrosis and apoptosis $^{3-11}$. Furthermore, apoptosis is involved in the disappearance of monocytes and fibroblasts in the granulation tissue after $\mathrm{MI}^{13}$. In the myofibroblasts after $M I$, the $f z 2$ expression could be observed in a period where apoptosis occurs in these cells. Fourteen days after $\mathrm{MI}$, the number of myofibroblasts has decreased compared to seven days after $\mathrm{MI}^{35}$. However, $\mathrm{f} z 2$ expression was already upregulated 4 days after $\mathrm{MI}^{38}$, a time point at which the myofibroblasts proliferate and migrate rather than undergo apoptosis. Although we can not exclude an active role for $f z 2$ in myofibroblast apoptosis-induction after MI, we suggest that this is unlikely. Further research is necessary to investigate the role of the wnt-fz cascade in apoptosis after MI.

\section{Concluding remarks and outlook}

We have demonstrated the expression of different members of the wnt-frizzled cascade during various processes that contribute to the infarct healing, which suggests a role for this cascade in cardiac wound healing after MI. Furthermore, we

wild-type

A normal heart tissue

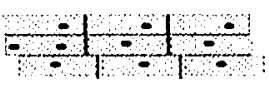

B $12-18$ hours cell death

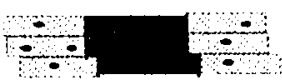

C 1.2 days infiammation

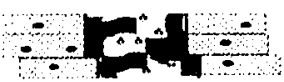

dvit-1-

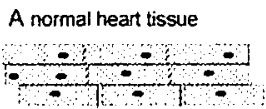

B 12.18 hours cell death

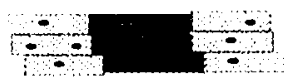

C First week rupture

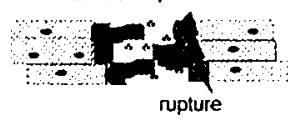

dvi1
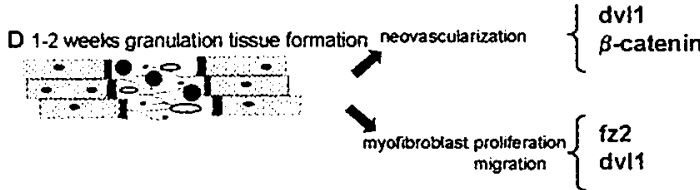

$E>3$ weeks scar maturation

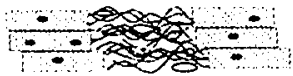

Figure 2. Time course of the wound healing response after myocardial infarction in the rat. (A) normal heart tissue. (B) After 12-18 hours myocytes die due to necrosis or apoptosis. (C) About 24 hours after the onset of the infarct. polymorphonuclear neutrophils infiltrate around the necrotic myocytes. (D) After 1-2 weeks the infarct contains granulation tissue with prominent capillaries, myofibroblasts and macrophages. The necrotic debris has been largely removed and a small amount of collagen has been deposited. In this phase the endothelial cells express dvll and stain positive for $\beta$-catenin. Furthermore the myofibroblasts express $f z 2$ and dvll. (E) After approximately 3 weeks or more the granulation tissue in the infarct region matures into scar tissue. The hearts of dvi-/- mice often rupture in the first week after Ml. 
demonstrated that the wnt- $f z$ cascade is necessary to maintain the structural integrity of the heart. F\% genes encode seven- transmembrane receptors, which makes them potential targets for pharmacological agents to interfere with the signal transduction in vivo, and possibly stimulate the healing process after MI.

This thesis has focussed on the wnt- $f$ z signal transduction pathway after MI, but the wnt- $f$ z cascade also has a potential role in other cardiovascular pathologies. The cascade has been associated with ncointima formation after balloon denudation in rats ${ }^{\hat{2} 26}$. Furthermorc, GSK-3 $\beta$ has been found to be a negative regulator of cardiomyocyte hypertrophy ${ }^{327}$, and in cardiac hypertrophy in the rat, fz2 expression is upregulated ${ }^{218}$. This suggests that the wnt-fz cascade modulates the development of cardiac hypertrophy. Moreover, the expression levels of FRP3 and 4 have been reported to be elevated in hearts of patients with dilated cardiomyopathy and coronary heart disease, compared to non-failing donor hearts "'I. $\beta$-Catenin levels tended to be decreased in myocardial samples with high FRP3 and 4 expression levels, suggesting an active role for the frizzled cascade in failing myocardium ${ }^{110}$.

In conclusion we have found evidence for involvement of the wnt-fz cascade in infarct healing after MI. This cascade has also been implicated in other cardiovascular diseases. Therefore novel intervention strategies could be designed that target components of the wnt-fz cascade, which may lead to new therapeutic interventions in cardiovascular disease. 


\section{Summary}

The wnt-fz cascade is known to be involved in architectural control during development in Drosophila. In mammals the cascade plays an important role in several developmental and pathological processes diverging from organogenesis to cancer and Alzheimer's diseasc. In this thesis we have focussed on the role for the wnt-f7 cascade in cardiac development and wound healing after MI, processes that require architectural control.

In the first chapter the wound healing process after MI was explained and the wnt-f7 cascade was introduced. Furthermore, the role of the cascade in cardiac development and after MI was reviewed.

In a previous study we have demonstrated that $f 72$ expression was upregulated in the myofibroblasts during their migration and proliferation into the infarct area, In chapter 2 we studied the expression of the different members of the fzr receptor and FRP families. We demonstrated the upregulation of the f₹1, 2 and 7 and the FRP1, 2 and 3 gene expression seven days after MI in mice. Furthermore, we demonstrated that, like in rats, the $f z 2$ expression in mice was localized to the borderzone of the infarct area 7 days after MI.

In chapter 3 we studied if the family of frizzled receptors, apart from during the migration and proliferation of myofibroblasts after MI, was also expressed in another highly organized proliferation/migration process, such as the proliferation and migration of epithelial cells in the crypt-villus units of rat and mouse intestine. We demonstrated that in the mouse intestine f $71-7$ were expressed and that the expression of $\mathrm{f} 72$ was predominantly localized in the crypts. Furthermore, an antibody was produced against the third extracellular loop of $f 7.2$ in order to study the receptor at the protein level. The $f \geq 2$ protein was localized at the membrane of the villus epithelial cells. The presence of $f 72$ expression in this highly organized cellular proliferation and migration model suggests that fz.2 expression is not unique for migrating cardiac myofibroblasts, but is a more general phenomenon in proliferating and migrating cells.

Genes that have a role during cardiac development often are re-expressed in the heart after MI. Furthermorc, the wnt-fz cascade has been associated with neural crest cell proliferation and carly migration during devclopment in mammals. To investigate whether $\mathfrak{f} z 2$ can be associated with the process of cardiac morphogenesis, we studied its expression in the thoracic arterial system and heart of mouse embryos of $10,12,14,16$ and 18 days after conception by means of in situ hybridization (chapter 4). $\Lambda$ t day 10 after conception, $f z 2$ was expressed in the pharyngeal arches and arch arteries. The outflow tract, the ascending aorta and the pulmonary trunk were positive for $\mathrm{f} z 2$ from day 12 on. This expression decreased over time and at day 18 only some signal could be detected in the aorta and pulmonary trunk. In contrast, in coronary and pulmonary arterics no expression was observed at any time point. Our results indicate that there is transient expression of $f z 2$ in areas that are invaded by neural crest cells. This cxpression is downregulated upon neural crest cell differentiation. The $f 7.2$ expression supports a role for the wnt-fz pathway in neural crest cell migration. 
In chapter 5 the possible signal transduction pathways for $f z 2$ in the myofibroblasts were investigated. Several signal transduction pathways for these receptors have been described, although the picture is still far from complete. The cxpression of several possible signal transduction molecules for the $f z 2$ receptor, like dvl, $\beta$-catenin, cdc42, and P-JNK were studied by immunohistochemistry and in situ hybridization. We were not able to demonstrate $\beta$-catenin, P-JNK or cde 42 in the myofibroblasts after MI. However, dvl1 expression could be demonstrated in the myofibroblasts. The co-cxpression of $d v 11$ and $f z 2$ in the myofibroblasts during their migration into the infact area suggests that a wnt- $f$ z signal transduction route is activated.

Recently, modulation of the wnt-fz cascade has been related to apoptosis. To clucidate the role of this cascade in apoptosis, we studied the effects of overexpression of $f z 1, f z 2, d v l 1$ and $\beta$-catenin (chapter 6 ). The signal transduction pathway and the involvement of $\beta$-catenin were further investigated by using different inhibitors of the wnt- $f \geq$ pathway. Overexpression of $f \geq 1, f \geq 2$ and $d v 11$ induced apoptosis in $\operatorname{COS} 7$ and 293 cells. $\beta$-Catenin appears to be the mediator for this process since $\beta$-catenin overexpression as well as lithium and valproate, which inhibit $\beta$-catenin degradation, induced apoptosis. In contrast, lithium treatment did not result in apoptosis in PC12 cells. We conclude that different components of the wnt-fz cascade can induce apoptosis, but that this effect is dependent on the cell type.

In chapter 7 we studied a possible model for the involvement of the wnt-f\% cascade in cell alignment. $\mathrm{F}_{z 2}$ is expressed in myofibroblasts during their migration and alignment in the granulation tissuc formed in the infarct area after MI. Myofibroblasts can be found in the granulation tissue aligned in parallel with the epi- and endocardium. This alignment is likely to contribute to the development of a strong scar. So far, little attention has been given to the alignment process. In an in vitro study, where fibroblasts align in a similar way as is observed in the myofibroblasts after MI, the role for the fz signal transduction pathway in the alignment process was investigated. The fzs that are upregulated in the area of infarction after MI were also expressed in the fibroblasts in the alignment assay. By adding several inhibitors it was shown that two of the proposed signal transduction pathways for $f z, G S K-3 \beta$ and $G_{i}$-proteins, werc most likely not involved in the alignment process. The results obtained in this study are not conclusive for an involvement of the wnt- $f$ z cascade in the fibroblast alignment.

Neovascularization is an important process after MI, to restore the blood supply to the infarct area. In chapter 8 , we demonstrated an upregulation of $\beta$-catenin in the vascular endothelial cells at 4 and 7 days after MI, whereas at later time points only few cells were positive. In contrast, vessels in the surviving myocardium did not express $\beta$-catenin at any time point. Dvll was also expressed in endothelial cells of remodeling vessels around the infarct. The $\beta$-catenin and dvl1 co-expression in the endothelial cells suggests that a wnt- $f z$ signal transduction pathway is functional during their migration and proliferation. This observation 
suggests a link between $\beta$-catenin and neovascularization.

In chapter 9 we investigated the role for dvl1 in the wound healing process after MI, by inducing MI in mice lacking the dvll gene. The hearts of most dvl1-/mutant mice ruptured during the first week after MI. There was a negative association between the cardiac ruptures and $\beta$-catenin levels in the intercalated disc between the cardiomyocytes. This finding demonstrated that $\mathrm{MI}$ in the dvl1 knockout mice provides a model for cardiac rupture, associated with defects in cellcell interactions. Furthermore, we demonstrated that the wnt-fz cascade does not only regulate cytoplasmic $\beta$-catenin, involved in gene transcription regulation, but also the $\beta$-catenin in the adherens junctions.

In chapter 10 the experimental chapters are discussed and put into a broader context. We conclude that we have found evidence that the wnt-fz cascade is involved in infarct healing after MI. This cascade has also been implicated in other cardiovascular diseases. Therefore novel intervention strategies could be designed that target components of the wnt-fr. cascade and that lead to new therapeutic agents to treat cardiovascular disease. 


\section{Samenvatting}

Frizzled genen en de wnt-fz cascade hebben in de fruitvlieg een belangrijke rol in de rangschikking van cellen, hetgeen ook wel architectuurcontrole genoemd wordt. Gebleken is dat de wnt- $f z$ cascade in zoogdicren geconserveerd is en een belangrijke rol heeft in de embryonale ontwikkeling en verschillende pathologische processen, zoals kanker en de ziekte van Alzheimer. Architectuur is ook belangrijk voor de functic van het hart. Door een hartinfarct wordt de architectuur van het hart aangetast, wat gevolgen heeft voor de hartfunctic. Als gevolg van een hartinfarct kan namelijk dilatatie van het ventrikel plaatsvinden, hetgeen in veel gevallen leidt tot hartfalen. Er is weinig bekend over genen die betrokken zijn bij de controle van de ventrikelarchitectuur. Het onderzock beschreven in dit proefschrift heeft zich voornamelijk gericht op de rol van de wnt- $f z$ cascade in de ontwikkeling van het hart en in de wondgenezing van het hart na een hartinfarct.

In het eerste hoofdstuk wordt het wondgenezingsproces in het hart na een hartinfarct beschreven. Voorts wordt de wnt-fz cascade geïntroduceerd en wordt beschreven wat tot nu toe bekend is over de rol van deze cascade in hartontwikkeling en hart- en vaatzickten.

In een voorgaande studic in ratten werd reeds een verhoogde expressic van $f z 2$ in de myofibroblasten aangetoond gedurende hun proliferatie en migratie naar het infarctgebied. Nadat de cellen waren aangekomen in het infarctgebied en parallel aan het epi- en endocard gerangschikt waren, nam de fz2 expressic weer af.

In het tweede hoofdstuk van dit proefschrift werd, in de muis, bestudeerd welke frizzleds en aan frizzled gerelateerde eiwitten (FRPs) tot expressie komen in het hart na een hartinfarct. Uit de resultaten bleek dat 7 dagen na het hartinfarct de expressie van $f z 1, f z 2, f z 7, F R P 1, F R P 2$ en FRP3 verhoogd was. Verder werd aangetoond dat de expressie van $f_{z 2}$ in muizen, net als in ratten, was gelokaliseerd in het randgebied van het infarct.

In het onderzoek dat in hoofdstuk 3 beschreven wordt, werd bestudeerd of fz2, behalve bij migrerende myofibroblasten, ook bij andere georganiseerde celmigratie-processen is betrokken. De migratie van epitheelcellen in de dunne darm vanuit de crypten naar de top van de darmvlokken is cen dergelijk georganiseerd proces. Daarom hebben we de expressie van verschillende leden van de frizzled familie bestudeerd in de dunne darm van de muis. Uit deze studie bleek dat $\mathrm{f} z 1$ tot en met $\mathrm{f} z 7$ tot expressie komen in de dunne darm van de muis. De expressie van fz2 was voornamelijk waar te nemen in de epitheelcellen in de crypten van de dunne darm. Vervolgens werd met behulp van een polyclonaal antilichaam, gericht tegen een deel van de $f z 2$ receptor, de lokalisatie van de receptor zelf aangetoond in de epitheelcellen van de darmvlokken. Uit bovenstaande experimenten concludeerden we dat $f z 2$ in twee modellen van georganiseerde celmigratie tot expressie komt. Hieruit blijkt dat de associatie tussen fz2 en celmigratie niet beperkt blijft tot myofibroblasten, maar een meer algemeen fenomeen is voor migterende cellen.

Genen die een rol hebben tijdens de ontwikkeling van het hart komen vaak opnieuw tot expressie in het hart na een hartinfarct. Verder wordt de wnt-fz 
cascade geassocieerd met de migratie en proliferatie van neuraallijstcellen gedurende de embryonale ontwikkeling in zoogdieren. Neuraallijstcellen zijn belangrijk voor de hartontwikkeling. Om te onderzoeken of $\mathrm{fz} 2$ geassocieerd mag worden met de ontwikkeling van het hart is, in hoofdstuk 4, de expressie van fz2 bestudeerd in het hart en het arteriële systeem in de thorax tijdens de embryonale ontwikkcling van de muis met behulp van in situ hybridisatic. Tien dagen na conceptie werd signaal gezien in de kieuwbogen en kieuwboogarteriën. Het uitstroomgebied van het hart, het stijgende gedeelte van de aorta en de stam van de longslagader waren vanaf dag 12 positief voor fz 2 expressie. Deze expressie nam af met de tijd en 18 dagen na de conceptie werd alleen nog signaal in de aorta en de stam van de longslagader waargenomen. Daarentegen werd op geen enkel tijdstip expressie waargenomen in de longslagaders zelf en in de kransslagaders. Deze resultaten geven aan dat er een tijdelijke expressic van $f_{z 2}$ is in gebieden waar neuraallijstcellen voorkomen. Als de neuraallijstcellen differentiëren neemt de $\mathrm{fz} 2$ expressie weer af. Dit expressie-patroon voor $f z 2$ is in overeenstemming met de hypothese dat de wnt- $f z$ cascade een rol speelt in neuraallijstcel migratie en $\mathrm{fz} 2$ betrokken is bij de hartontwikkeling.

Er zijn meerdere signaaltransducrie routes voor $f z 2$ beschreven. Er zijn echter nog steeds veel onduidelijkheden. In hoofdstuk 5 werden een aantal van de mogelijke signaaltransductie routes voor de receptor $\mathrm{fz} 2$ in de myofibroblasten onderzocht. In deze studie werd de expressie van mogelijke signaaltransductie moleculen zoals dvl, $\beta$-catenine, cdc42, en gefosforyleerde JNK (P-jNK) onderzocht met behulp van immunohistochemie en in situ hybridisatie. Er werd in de myofibroblasten geen $\beta$-catenine, P-JNK of cdc42 aangetoond. Daarentegen werd wel expressie van dvl1 gevonden. De co-expressie van dvll en $f z 2$ in myofibroblastrijke gebieden suggereert dat er een wnt-fz toute actief is.

Recentelijk is de wnt-fz cascade gerelateerd aan apoptose (geprogrammeerde celdood). Om dit verband verder op te helderen werden in hoofdstuk 6 de genen die coderen voor $f z 1, f z 2$, dvl1 en $\beta$-catenine getransfecteerd in gekweekte cellen om het effect van expressie op apoptose te onderzoeken. Daarnaast is de betrokkenheid van $\beta$-catenine verder onderzocht met behulp van verschillende farmacologische remmers. In deze studie werd aangetoond dat verhoogde expressie van $\mathrm{fz} 1, \mathrm{fz} 2$ en dvl1 tot apoptose leidde in COS7 en 293 cellen. Vervolgens leck $\beta$-catenine betrokken te zijn bij apoptose omdat zowel expressie van $\beta$-catenine zelf, als het remmen van de afbraak van $\beta$-catenine tot apoptose leidde. Het remmen van de afbraak van $\beta$-catenine had daarentegen geen effect op PC12 cellen. Uit deze experimenten concluderen we dat verschillende leden van de wnt-fz cascade apoptose kunnen bewerkstelligen maar dat het effect afhankelijk is van het type cel.

Vervolgend werd in hoofdstuk 7 een andere mogelijke functie van de wnt-fz cascade bestudeerd. Zoals bovenstaand beschreven komt $\mathrm{fz} 2$ tot expressie in myofibroblasten tijdens hun migratie in het infarctgebied. Als deze cellen parallel liggen met het epi- en endocard neemt de expressie weer af. Gedacht wordt dat de rangschikking van myofibroblasten bijdraagt aan de ontwikkeling van een sterk 
litteken. De mogelijke rol van de wnt-fz cascade in de fibroblast-rangschikking werd bestudeerd in cen celcultuurstudie, waarin fibroblasten zich op een zelfde manier rangschikken als in het litteken na een hartinfarct. In de fibroblasten in celkweek kwamen verschillende frizzleds tot expressie. Remming van twee mogelijke signaal transductie routes van frizzled had echter geen invloed op de rangschikking van de cellen. Uit deze resultaten kunnen we geen conclusies trekken met betrekking tot de betrokkenheid van de wnt- $f$ z cascade in de rangschikking van de fibroblasten.

Neovascularisatie is een belangrijk proces in een helend infarct. Het zorgt ervoor dat de blocdvoorziening naar het weefsel hersteld wordt. In hoofdstuk 8 hebben we aangetoond dat $\beta$-catenine, op 4 en 7 dagen na het hartinfarct, aanwezig is in de vasculaire endotheelcellen in het infarct gebied. In vaatjes in het gezonde hartweefsel werd geen $\beta$-catenine waargenomen. In de vasculaire endotheelcellen in het infarctgebied bleck verder ook dvl1 tot expressie te komen. Deze co-expressie van $\beta$-catenine en dvl1 in endotheelcellen suggereert een rol voor de wnt-fz cascade in de proliferatie en migratie van deze cellen. Verder wijzen deze resultaten op een associatie tussen $\beta$-catenine en neovascularisatie.

In hoofdstuk 9 werd de rol van dv11 in het wondgenezingsproces in het hart na een hartinfarct onderzocht. Daarvoor hebben we muizen gebruikt, die het gen dat codeert voor dvl1 missen. De harten de meeste van deze muizen ruptureerden in de eerste week na het hartinfarct, hetgeen geassociecrd bleek te zijn met de afwezigheid van detectecrbaar $\beta$-catenine in de intercallair schijven tussen de levende hartspiercellen. Deze gegevens tonen aan dat dit hartruptuur model is geassocieerd met een defect in celinteracties. Verder tonen deze gegevens aan dat de wnt- $f z$ cascade niet alleen het $\beta$-catenine in het cytoplasma reguleert, dat betrokken is bij de regulatie van gentranscriptie, maar ook het $\beta$-catenine aan de plasmamembraan.

Tenslotte zijn in hoofdstuk 10 de experimentele data bediscussieerd en in een bredere context geplaatst. We concluderen dat met het onderzoek, beschreven in dit procfschrift, aanwijzingen gevonden zijn voor cen relevante rol van de wnt-fz cascade in de cardiale wondgenezing. In de toekomst zal met behulp van selectieve interventies, die ingrijpen op de wnt-fz cascade, dit mechanisme verder ontrafeld kunnen worden. Aangezien deze cascade ook betrokken is bij andere hart- en vaatziekten zouden interventies gericht op de wnt-fz cascade tot nieuwe therapieën voor hart-en vaatziekten kunnen leiden. 


\section{References}

1. Pfeffer $M I \Lambda$, Braunwald E: Ventricular remodeling after myocardial infarction. Experimental observations and clinical implications. Circulation 1990, 81:1161-1172

2. Packer M: Beta-adrencrgic blockade in chronic heart failure: principles, progress, and practicc. Prog Cardiovasc Dis 1998, 41(1, Suppl 1):39-52

3. Sun Y, Weber KT: Infarct scar: a dynamic tissuc. Cardiovasc Res 2000, 46:250-256

4. Cleutjens JPM, Blankesteijn WM, Daemen MJAP, Smits JFM: The infareted myocardium: simply dead tissue or a lively target for therapeutic interventions. Cardiovasc Res 1999, 44:232241

5. Bardales RH, Hailey LS, Xie SS, Schacfer RF, Hsu SM: In situ apoptosis assay for the detection of early acute myocardial infarction. Am J Pathol 1996, 149:821-829

6. Saraste $\Lambda$, Pulkki K, Kallajoki M, Henriksen K, Parvinen M, Voipio-Pulkki LM: Apoptosis in human acutc myocardial infarction. Circulation 1997, 95:320-323

7. van-Hcerde WI, Robert-Offerman S, Dumont E, Hofstra L, Docvendans PA, Smits JF, Daemen MJ, Reutelingsperger CP: Markers of apoptosis in cardiovascular tissues: focus on Annexin V. Cardiovasc Res 2000, 45:549-559

8. Nio Y, Matsubara H, Murasawa S, Kanasaki M, Inada M: Regulation of gene transcription of angiotensin II receptor subtypes in myocardial infarction. J Clin Invest 1995, 95:46-54

9. Yaoita $\mathrm{H}$, Ogawa $\mathrm{K}$, Machara $\mathrm{K}$, Maruyama $\mathrm{Y}$ : Apoptosis in relcvant clinical situations: contribution of apoptosis in myocardial infarccion. Cardiovasc Res 2000, 45:630-641

10. Majno G, Joris I: $\Lambda$ poptosis, oncosis and necrosis: $\Lambda \mathrm{n}$ overvicw of cell death. $\Lambda \mathrm{m} \mathrm{J}$ Pathol 1995, 146:3-15

11. Anversa $P$, Leri $\Lambda$, Beltrami $C A$, Guerra $S$, Kajstura J: Myocyte death and growth in the failing heart. Lab Invest 1998, 78:767-787

12. Dispersyn GD, Borgers $M$, Flameng $W$ : Apoptosis in chronic hibernating myocardium:sleeping to death? Cardiovasc Res 2000, 45:696-703

13. Takemura G, Ohno M, Hayakawa Y, Misao J, Kanoh M, Ohno A, Uno Y, Minatoguchi S, Fujiwara T, Fujiwara H: Rolc of apoptosis in the disappearance of infiltrated and proliferated interstitial cells after myocardial infarction. Circ Res 1998, 82:1130-1138

14. Anversa P, Loud $\mathrm{AV}$, Levicky V, Guideri G: Ieft ventricular failure induced by myocardial infarction.I. Myocytc hypertrophy. Am J Physiol 1985, 248:H856-H861

15. Capasso JM, Bruno S, Cheng W, Li P, Rodgers R, Darzynkiewicz Z, Anversa P: Ventricular loading is coupled with DNA synthesis in adult cardiac myocytes after acutc and chronic myocardial infarction in rats. Circ Res 1992, 71:1379-1389

16. Kuizinga MC, Smits JFM, Arends JW, Dacmen MJAP: AT2 receptor blockade reduces cardiac interstitial cell DN $\Lambda$ synthesis and cardiac function after rat myocardial infarction. J Mol Cell Cardiol 1998, 30:425-434

17. Lutgens E, Daemen MJAP, De Muinck ED, Debets J, Leenders P, Smits JFM: Chronic myocardial infarction in the mouse: cardiac structural and functional changes. Cardiovasc Res 1999, 41:586-593

18. Cleutjens JPM, Verluyten MJA, Smits JFM, Daemen MJAP: Collagen remodeling after myocardial infarction in the rat heart. Am J Pathol 1995, 147:325-338

19. Willems IEMG, Havenith MG, De Mey JGR, Daemen MJAP: The $\alpha$-smooth muscle actinpositive cells in healing human myocardial scars. Am J Pathol 1994, 145:868-875

20. Gabbiani G: Evolution and clinical implications of the myofibroblast concept. Cardiovase Res 1998, 38:545-548

21. Weisman HF, Bush DE, Mannisi JA, Weisfeldt ML, Healy B: Cellular mechanisms of myocardial infarct expansion. Circulation 1988, 78:186-201

22. Vannan MAA, Taylor DJ: V'cntricular remodelling after myocardial infarction. Br Heart J 1992, 68:257-259 
23. Hammerman H, Kloner RA, Hale S, Schoen FJ, Braunwald E: Dose-dependent effects of short-term methylprednisolone on myocardial infarct extent, scar formation, and ventricular function. Circulation 1983, 68:446-452

24. Jugdutt BI, Musat-Marcu S: Opposite effects of amlodipine and enalapril on infarct collagen and remodelling during healing after reperfused myocardial infarction. Can J Cardiol 2000, 16:617-625

25. Harada K, Grossman W, Friedman M, Edelman ER, Prasad PV, Keighley CS, Manning WJ, Sellke FW, Simons M: Basic fibroblast growth factor improves myocardial function in chronically ischemic porcine hearts. J Clin Invest 1994, 94:623-630

26. Yanagisawa-Miwa $\Lambda$, Uchida Y, Nakamura F, Tomanu T, Kido H, Kamijo T, Sugimoto T, Kaji $\mathrm{K}$, Utsuyama $\mathrm{M}$, Kurashima $\mathrm{C}$, et al.: Salvage of infarcted myocardium by angiogenic action of basic fibroblast growth factor. Science 1992, 257:1401-1403

27. Battegay EJ: Angiogenesis: mechanistic insights, neovascular diseases, and therapeutic prospects. Mol Mcd 1995, 73:333-346

28. Carmeliet P, Collen D: Molecular basis of angiogenesis. Role of VEGF and VE-cadherin. Ann NY Acad Sci 2000, 902:249-262

29. Lec SH, Wolf PL, Escudero R, Deutsch R, Jamicson SW, Thistlethwaite PA: Early expression of angiogenesis factor in acute myocardial ischemia and infarction. N Engl J Med 2000, 342:626-633

30. Kornowski R, Fuchs S, Lcon MB, Epstein SE: Delivery strategies to achieve therapeutic myocardial angiogenesis. Circulation 2000, 101:454-458

31. Weber KT, Sun Y, Tyagi SC, Cleutjens JP: Collagen network of the myocardium: function, structural remodeling and regulatory mechanisms. J Mol Cell Cardiol 1994, 26:279-292

32. Weber KT: Monitoring tissue repair and fibrosis from a distance. Circulation 1997, 96:24882492

33. Tyagi SC, Ratajska A, Weber KT: Myocardial matrix metalloproteinase(s): localization and activation. Mol Cell Biochem 1993, 126:49-59

34. Creemers E, Heymans S, Smits JFM, Moons L, Collen D, Daemen MJAP, Carmeliet P: Disruption of the plasminogen gene in mice abolishes wound healing following myocardial infarction. Am J Pathol 2000, 156:1865-1873

35. Heymans S, Lutrun A, Nuyens D, Theilmeyer G, Creemers E, Moons L, Dyspersin GD, Cleutjens JPM, Shipley M, Angelilo A, Levi M, Nube O, Baker A, Keshet E, Lupu F, Herbert J-M, Smits JFM, Shapiro SD, Beas M, Borgers M, Collen D, Daemen MJAP, Carmeliet P: Inhibition of plasminogen activators or matrix metalloproteinases prevents cardiac rupture but impairs therapeutic angiogenesis and causes cardiac failure. Nature Med 1999, 5:1135-1142

36. Cleutjens JP, Kandala JC, Guarda E, Guntaka RV, Weber KT: Regulation of collagen degradation in the rat myocardium after infarction. J Mol Cell Cardiol 1995, 27:1281-1292

37. Rohde LE, Ducharme A, Arroyo LH, Aikawa M, Sukhova GH, Lopez-Anaya A, McClure KF, Mitchell PG, Libby P, Lee RT: Matrix metalloproteinase inhibition attenuates early left ventricular enlargement after experimental myocardial infarction in mice. Circulation 1999, 99:3063-3070

38. Blankesteijn WM, Essers-Janssen YPG, Verluyten MJA, Daemen MJAP, Smits JFM: $\Lambda$ homologue of Drosophila tissue polarity gene frizzled is expressed in migrating myofibroblasts in the infarcted rat heart. Nature Med 1997, 3:541-544

39. Yang-Snyder J, Miller JR, Brown JD, Lai CJ, Moon RT: A frizzled homolog functions in a vcrtebrate Wnt signalling pathway. Curr Biol 1996, 6:1302-1306

40. Wang Y, Macke JP, Abella BS, Andreasson K, Worley P, Gilbert DJ, Copeland NG, Jenkins NA, Nathans J: A large family of putative transmembrane receptors homologous to the product of the Drosophila tissue polarity gene frizzled. J Biol Chem 1996, 271:4468-4476

41. Vinson $\mathrm{CR}$, Conover $\mathrm{S}$, Adler $\mathrm{PN}$ : $\Lambda$ Drosophila tissue polarity locus encodes a protein containing seven potential transmembrane domains. Nature 1989, 338:263-264 
42. Jones KH, Liu J, Adler PN: Molecular analysis of EMS-induced frizzled mutations in Drosophila melanogaster. Genctics 1996, 142:205-215

43. Park W-J, Liu J, Adler PN: The frizzled gene of Drosophila encodes a membrane protein with an odd number of transmembranc domains. Mcch Dcv 1994, 45:127-137

44. Umbhauer M, Dijane $\Lambda$, Goisset $C$, Penzo-Mendez $\Lambda$, Riou J, Boucaut J, Shi D: The Cterminal cytoplasmic Lys-Thr-X-X-X-Trp motif in frizzled receptors mediates Wnt/betacatenin signalling. EMBO J 2000, 19:4944-4954

45. Sagara N, Toda G, Hirai M, Terada M, Katoh M: Molccular cloning, differential expression, and chromosomal localization of human frizzled-1, frizzled-2, and frizzled-7. Biochem Biophys Rcs Comm 1998, 252:117-122

46. Chan SDH, Karpf DB, Fowlkes ME, Hooks M, Bradley MS, Vuong V, Bambino T, Liu MYC, Arnaud CD, Strewler GJ, Nissenson RA: Two homologs of the Drosophila polarity gene frizzled ( $\mathrm{f} z$ ) are widely expressed in mammalian tissues. J Biol Chem 1992, 267:25202-25207

47. Zhao Z, Lec CC, Baldini $\Lambda$, Caskey CI: A human homologue of the Drosophila polarity gene frizzled has been identified and mapped to $17 \mathrm{q} 21.1$. Genomics 1995, 27:370-373

48. Kirikoshi H, Koike J, Sagara N, Saitoh T, Tokuhara M, Tanaka K, Sckiham H, Hirai M, Katoh M: Molecular cloning and genomic structure of human frizzled-3 at chromosome 8 p21. Biochcm Biophys Res Comm 2000, 271:8-14

49. Bhanot P, Brink M, Harryman Samos C, Hsieh J-C, Wang Y, Macke JP, Andrew D, Nathans J, Nusse R: A new member of the frizzled family from Drosphila functions as a Wingless receptor. Nature 1996, 382:225-230

50. Kirikoshi H, Sagara N, Koike J, Tanaka K, Sekihara H, Hirai M, Katoh M: Molecular cloning and characterization of human Frizzled-4 on chromosome 11q14-q21. Biochem Biophys Res Comm 1999, 264:955-961

51. He X, Saint-Jeannet J-P, Wang Y, Nathans J, Dawid I, Varmus $H: A$ member of the frizzled protein family mediating axis induction by wnt-5a. Science 1997, 275:1652-1654

52. Tokuhara M, Hirai M, Atomi Y, Terada M, Katoh M: Molecular cloning of human Frizzled-6. Biochem Biophys Res Comm 1998, 243:622-627

53. Medina $A$, Reintsch $W$, Steinbeisser $H$ : Xenopus frizzled 7 can act in canonical and noncanonical Wnt signaling pathways: implications on early patterning and morphogenesis. Mech Dev 2000, 92:227-237

54. Wang Y-K, Samos CH, Peoples R, Perez-Jurado LA, Nuss R, Francke U: A novel human homologue of Drosophila frizzled wnt receptor gene binds wingless protein and is in the Williams syndrome deletion at 7q11.23. Hum Mol Genet 1997, 6:465-472

55. Malik TH, Shivdasani RA: Structure and expression of a novel frizzled gene isolated from the developing mouse gut. Biochem J 2000, 349:829-834

56. Koike J, Takagi A, Miwa T, Hirai M, Terada M, Katoh M: Molecular cloning of Frizzled-10, a novel member of the Frizzled gene family. Biochem Biophys Res Comm 1999, 262:39-43

57. Nusse R, Varmus HE: Wnt genes. Cell 1992, 69:1073-1087

58. Dale TC: Signal transduction by the Wnt family of ligands. Biochem J 1998, 329:209-223

59. Smolich BD, McMahon JA, McMahon AP, Papkoff J: Wnt family proteins are secreted and associated with the cell surface. Mol Biol Cell 1993, 4:1267-1275

60. Moon R'T, Campbell RM, Christian JL, McGrew LL, Shih J, Fraser S: Xwnt-5A: a maternal Wht that affects morphogenetic movements after overexpression in embryos of Xenopus lacvis. Development 1993, 119:97-111

61. Du SJ, Purcell SM, Christian JL, McGrcw LL, Moon RT: Identification of distinct classes and functional domains of Wnt throughe expression of wild-type and chimeric proteins in Xenopus embryos. Mol Cell Biol 1995, 15:2625-2634

62. Moon RT, Brown JD, Torres M: WNTs modulate cell fate and behaviour during vertebrate development. Trends Gen 1997, 13:157-162 
63. Torres MA, Yang-Snyder JA, Purcell SM, DeMarais AA, McGrew LL, Moon RT: Activitics of the Wnt-1 class of scereted signaling factors are antagonized by the Wnt-5A class and by a dominant negative cadherin in carly Xenopus development. J Cell Biol 1996, 133:1123-1137

64. Nusse R, Theunissen H, Wagenaar E, Rijsewijk F, Gennissen A, Otte A, Schuuring E, vanOoyen $A$ : The Wnt-1 (int-1) oncogene promoter and its mechanism of activation by insertion of proviral DNA of the mouse mammary tumor virus. Mol Cell Biol 1990, 10:4170-4179

65. Shimizu H, Julius MA, Giarre M, Zheng Z, Brown AM, Kitajewski J: Transformation by Wnt family protcins correlates with regulation of beta-catenin. Cell Growth Differ 1997, 8:13491358

66. Thomas KR, Capecchi MR: Target disruption of the murine int-1 proto-oncogene results in scverc abnormalities in midbrain and cerebellar development. Nature 1990, 346:847-850

67. Roclink H, Wang J, Black DM, Solomon E, Nussc R: Molccular cloning and chromosomal localization to $17 \mathrm{q} 21$ of the human WNT3 genc. Genomics 1993, 17:790-792

68. Huguet EL, McMahon JA, McMahon AP, Bicknell R, Harris AL: Differential expression of human Wnt genes 2, 3, 4, and $7 B$ in human breast cell lines and normal and disease states of human breast tissuc. Canc Res 1994, 54:2615-2621

69. Jandesman Y, Sokol SY: Xwnt-2b is a novel axis-inducing Xenopus Wnt, which is expressed in embryonic brain. Mech Dev 1997, 63:199-209

70. Monkley SJ, Delancy SJ, Pennisi DJ, Christiansen JH, Wainwright BJ: Targeted disruption of the Wnt2 gene results in placentation defects. Development 1996, 122:3343-3353

71. Grove EA, Tole S, Limon J, Yip L., Ragsdalc CW: The hem of the embryonic cerebral cortex is defined by the expression of multiple Wnt genes and is compromised in Gli3-deficient mice. Development 1998, 125:2315-2325

72. Katoh M, Hirai M, Sugimura T, Terada M: Cloning, expression and chromosomal localization of Wnt-13, a novel member of the Wnt gene family. Oncogene 1996, 13 (4):873-876

73. Zakin LD, Mazan S, Maury M, Maruin N, Guenet JL, Brulet P: Structure and expression of Wnt13, a novel mouse Wnt2 related gene. Mech Dev 1998, 73:107-116

74. Roclink H, Wagenaar E, Lopes-da-Silva S, Nusse R: Wnt-3, a gene activated by proviral insertion in mousc mammary tumors, is homologous to int- $1 / \mathrm{Wnt}-1$ and is normally cxpressed in mouse embryos and adult brain. Proc Natl $\Lambda$ cad Sci U S A 1990, 87:4519-4523

75. Wong GT, Gavin BJ, McMahon AP: Differential transformation of mammary cpithelial cells by Wnt genes. Mol Cell Biol 1994, 14:6278-6286

76. Liu P, Wakamiya M, Shea MJ, Albrecht U, Behringer RR, Bradley A: Requirement for Wne 3 in vertebrate axis formation. Nature Genet 1999, 22:361-365

77. Greco TL, Takada S, Newhouse MM, McMahon JA, MciMahon AP, Camper SA: Analysis of the vestigial tail mutation demonstrates that $W_{n t-3 a}$ gene dosage regulates mousc axial development. Gencs Dcv 1996, 10:313-324

78. Wolda SL, Moody CJ, Moon RT: Overlapping expression of Xivnt-3A and Xivnt-1 in neural tissuc of Xenopus hevis embryos. Dev Biol 1993, 155:46-57

79. Gavin BJ, McMahon JA, McMahon AP: Expression of multiple novel Wnt-1/int-1-related gencs during fetal and adult mouse development. Genes Dev 1990, 4:2319-2332

80. Stark K, Vainio S, V'assileva G, McMahon $\Lambda$ P: Epithelial transformation of metanephric mesenchyme in the developing kidney regulated by Wnt-4. Nature 1994, 372:679-683

81. Clark CC, Cohen I, Eichsetter I, Cannizzaro LA, McPherson JD, Wasmuth JJ, Iozzo RV': Molccular cloning of the human proto-oncogene Wnt-5A and mapping of the gene (WNT5A) to chromosome 3p14-p21. Genomics 1993, 18:249-260

82. Yamaguchi TP, Bradlcy $A$, McMahon $A P$, Jones $S: A W n t 5 a$ pathway underlics outgrowth of multiple structures in the vertebrate cmbryo. Development 1999, 126:1211-1223

83. Rankin J, Strachan T, Lako M, Lindsay S: Partial cloning and assignment of WNTo to human chromosome band $2 q 35$ by in situ hybridization. Cytogenet Cell Genet 1999, 84:50-52 
84. Ikegawa S, Kumano Y, Okui K, Fujiwara $\Gamma$, Takahashi E, Nakamura Y: Isolation, characterization and chromosomal assignment of the human WNT7A gene. Cytogenet Cell Genet 1996, 74:149-152

85. Parr $B \Lambda$, McMahon $\Lambda P$ : Dorsalizing signal Wnt-7a required for normal polarity of D-V and $A$ $P$ axes of mouse limb. Nature 1995, 374:350-353

86. Bouillet $\mathrm{P}$, Oulad-Abdelghani $\mathrm{M}$, Ward SJ, Bronner $\mathrm{S}$, Chambon $\mathrm{P}$, Dolle $\mathrm{P}: \mathrm{A}$ new mouse member of the Wnt gene family, mWnt-8, is expressed during early embryogenesis and is cctopically induced by retinoic acid. Mech Dev 1996, 58:141-152

87. Christian JL, McMahon JA, McMahon AP, Moon RT: Xwnt-8, a Xenopus Wnt-1/int-1-related gene responsive to mesoderm-inducing growth factors, may play a role in ventral mesodermal patterning during embryogenesis. Development 1991, 111:1045-1055

88. Lako M, Strachan T, Curtis $A R J$, Lindsay S: Isolation and characterization of WNT8B, a nove] human Wnt gene that maps to $10 \mathrm{q} 24$. Genomics 1996, 35:386-388

89. Cui Y, Brown JD, Moon RT, Christian JL: Xwnt-8b: a maternally expressed Xenopus Wnt gene with a potential role in establishing the dorsoventral axis. Development 1995, 121:21772186

90. Wang J, Shackleford GM: Murine Wnt10a and Wnt10b: cloning and expression in developing limbs, face and skin of embryos and in adults. Oncogene 1996, 13:1537-1544

91. Bui TD, Rankin J, Smith K, Huguet EL, Ruben S, Strachan T, Harris AL, Lindsay S: A novel human Wnt gene, WNT10B, maps to $12 q 13$ and is expressed in human breast carcinomas. Oncogene $1997,14: 1249-1253$

92. Adamson MC, Dennis C, Delaney S, Christiansen J, Monkley S, Kozak CA, Wainwright B: Isolation and genetic mapping of two novel members of the murine Wnt gene family, Wnt11 and Wnt12, and the mapping of Wnt5a and Wnt 7a. Genomics 1994, 24:9-13

93. Lako M, Strachan T, Bullen P, Wilson DI, Robson SC, Lindsay S: Isolation, characterisation and embryonic expression of WNT11, a gene which maps to $11 \mathrm{q} 13.5$ and has possible roles in the development of skeleton, kidncy and lung. Gene 1998, 219:101-110

94. Ku M, Melton DA: Xwnt-11: a maternally expressed Xenopus wnt gene. Development 1993, 119:1161-1173

95. Christiansen JH, Monkley SJ, Wainwright BJ: Murine WNT11 is a secreted glycoprotein that morphologically transforms mammary epithelial cells. Oncogene 1996, 12:2705-2711

96. Bergstein I, Eiscnberg LM, Bhalerao J, Jenkins NA, Copeland NG, Osborne MP, Bowcock $A M$, Brown AM: Isolation of two novel WNT genes, WNT14 and WNT15, one of which (WNT15) is closely linked to WNT3 on human chromosome 17q21. Genomics 1997, 46:450458

97. McWhirter JR, Neuteboom ST, Wancewicz, EV, Monia BP, Downing JR, Murre C: Oncogenic homeodomain transcription factor $\mathrm{E} 2 \Lambda$-Pbx1 activates a novel WNT gene in pre-B acute lymphoblastoid lcukemia. Proc Natl Acad Sci U S A 1999, 96:11464-11469

98. Finch PW, He X, Kelley MI, Uren $\Lambda$, Schaudics RP, Popescu NC, Rudikoff S, Aaronson SA, Varmus HE, Rubin JS: Purification and molecular cloning of a secreted, Frizzled-related antagonist of Wnt action. Proc Natl Acad Sci U S A 1997, 94:6770-6775

99. Hoang B, Moos M, Vukicevic S, Luyten FP: Primary structure and tissue distribution of FRZB, a novel protein related to Drosophila frizzled, suggest a role in skeletal morphogenesis. J Biol Chem 1996, 271:26131-26137

100.Leyns L, Bouwmeester T, Kim S-H, Piccolo S, De Robertis EM: Frzb-1 is a secreted antagonist of wnt signaling expressed in the Spcmann organizer. Cell 1997, 88:747-756

101. Mayr T, Deutsch U, Kuhl M, Drexler HCA, Lottspeich F, Deutzmann R, Weblich D, Risau W: Fritz: a sccreted frizzled-related protein that inhibits wnt activity. Mech Dev 1997, 63:109-125

102. Rattner A, Hsieh J-C, Smallwood PM, Gilbert DJ, Copeland NG, Jenkins NA, Nathans J: $A$ family of secreted proteins contains homology to the cystein-rich ligand-binding domain of frizzled receptors. Proc Natl $\Lambda$ cad Sci 1997, 94:2859-2863 
103. Leimeister $C$, Bach $\Lambda$, Gessler M: Developmental expression patterns of mouse sFRP genes encoding members of the secreted frizzled related protein family. Mech Dev 1998, 75:29-42

104. Melkonyan H S, Chang W C, Shapiro J P, Mahadevappa M, Fitzpatrick P A, Kiefer M C, Tomei L D, Umansky S R: SARPs:a family of secreted apoptosis-related proteins. Proc Natl Acad Sci 1997, 94:13636-13641

105.Xu Q, D'Amore PA, Sokol SY: Functional and biochemical interactions of Wnts with FrzA, a scereted Wnt antagonist. Development 1998, 125:4767-4776

106. Hu E, Zhu Y, Fredrickson T, Barnes M, Kelsell D, Becley L, Brooks D: Tissuc restricted expression of two human Frzbs in preadipocytes and pancreas. Biochem Biophys Res Comm $1998,247: 287-293$

107.Shirozu M, Tada H, Tashiro K, Nakamura T, Lopez ND, Nazarea M, Hamada T, Sato T, Nakano T, Honjo T: Characterization of novel secreted and membrane proteins isolated by the signal sequence trap method. Genomics 1996, 37:273-280

108.Lin K, Wang S, Julius MA, Kitajewski J, Moos M Jr, Luyten FP: The cystcinc-rich frizzled domain of Frzb-1 is required and sufficient for modulation of Wht signaling. Proc Natl $A$ cad Sci U S A 1997, 94:11196-11200

109. Ugolini F, Adelaide J, Charafe-Jauffret E, Nguyen C, Jacquemier J, Jordan B, Birnbaum D, Pebusque MJ: Differential expression assay of chromosome arm 8p genes identifics Frizzledrelated (FRP1/FRZB) and Fibroblast Growth Factor Receptor 1 (FGFR1) as candidate breast cancer genes. Oncogene 1999, 18:1903-1910

110.Schumann H, Holtz J, Zerkowski HR, Hatzfeld M: Expression of secreted frizzled related proteins 3 and 4 in human ventricular myocardium correlates with apoptosis related gene expression. Cardiovase Res 2000, 45:720-728

111.Chang JT, Esumi N, Moore K, Li Y, Zhang S, Chew C, Goodman B, Rattner $A$, Moody S, Stetten G, Campochiaro PA, Zack DJ: Cloning and characterization of a secteted frizzledrelated protein that is expressed by the retinal pigment epithelium. Hum Mol Genet 1999, 8:575-583

112. Salic AN, Kroll KL, Evans LM, Kirschner MW: Sizzled: a secreted Xiwnt8 antagonist expressed in the ventral marginal zone of Xenopus embryos. Development 1997, 124:47394748

113.Zhou Z, Wang J, Han X, Zhou J, Linders S: Up-regulation of human secreted frizzled homolog in apoptosis and its down-regulation in breast tumors. Int J Cancer 1998, 78(1, 25 Sep): $95-99$

114. Binari RC, Staveley BE, Johnson WA, Godavarti R, Sasisekharan R, Manoukian AS: Generic evidence that heparin-like glycosaminoglycans are involved in wingless signaling. Devclopment 1997, 124:2623-2632

115. Baeg GH, Lin X, Khare N, Baumgartner S, Perrimon N: Heparan sulfate proteoglycans are critical for the organization of extracellular distribution of Wingless. Development 2001, 128:87-94

116. Boutros M, Mihaly J, Bouwmeester T, Mlodzik M: Signaling specificity by Frizzled receptors in Drosophila. Science 2000, 288:1825-1828

117. Kuhl M, Sheldahl LC, Park M, Miller JR, Moon RT: The Wnt/Ca2+ pathway: a new vertebrate Wnt signaling pathway takes shape. Trends Gen 2000, 16:279-283

118.Slusarski DC, Corces VG, Moon RT: Interaction of Wnt and a Frizzled homologue triggers Gprotcin-linked phosphatidylinositol signalling. Nature 1997, 390:410-413

119.Liu T, Liu X, Wang H, Moon RT, Malbon CC: Activation of rat frizzled-1 promotes Wht signaling and differentiation of mouse F9 teratocarcinoma cells via pathways that require $G$ alpha-q and G-alpha-o function. J Biol Chem 1999, 274, 47:33539-33544

120.Wu C, Zeng Q, Blumer KJ, Muslin AJ: RGS proteins inhibit Xwnt-8 signaling in Xenopus embryonic development. Development 2000, 127(13):2773-2784 
121. Klingensmith J, Yang Y, Axelrod JD, Beier DR, Perrimon N, Sussman DJ: Conservation of dishevelled structure and function between flies and mice: isolation and characterization of Dvl2. Mech Dev 1996, 58:15-26

122. Sussman DJ, Klingensmith J, Salinas P, Adams PS, Nusse R, Perrimon N: Isolation and characterization of a mouse homolog of the Drosophila segment polarity gene Dishevelled. Dev Biol 1994, 166:73-86

123. Tsang M, Lijam N, Bcircr DR, Wynshaw-Boris A, Sussman DJ: Isolation and characterization of mouse Dishevelled-3. Dev Dynam 1996, 207:253-262

124. Lijam N, Paylor R, McDDonald MP, Crawley JN, Deng C, Herrup K, Stevens KE, Maccaferri G, McBain CJ, Sussman DJ, Wynshaw-Boris $A$ : Social interaction and sensorimotor gating abnormalities in mice lacking dvl1. Cell 1997, 90:895-905

125. Yanagawa S, Van Lecuwen F, Wodarz A, Klingensmith J, Nusse R: The dishevelled protein is modified by wingless signalling in Drosophila. Genes Dev 1995, 9:1087-1097

126. Willert K, Brink M, Wodarz $\Lambda$, Varmus $H$, Nusse R: Cascin kinase 2 associates with and phosphorylates dishevelled. EMBO J 1997, 16:3089-3096

127.Zeng L, Fagotto F, Zhang T, Hsu W, Vasicek TJ, Perry WL 3rd, Lec JJ, Tilghman SM, Gumbiner BM, Costantini F: The mouse Fused locus cncodes $\Lambda$ xin, an inhibitor of the Wnt signaling pathway that regulates embryonic axis formation. Cell 1997, 90:181-192

128. Doyle DA, Lec $\Lambda$, Lewis J, Kim E, Sheng M, MacKinnon R: Crystal structures of a complexed and peptide-free membrane protein-binding domain: molecular basis of peptide recognition by PDZ. Cell 1996, 85:1067-1076

129. Ponting CP, Bork P: Pleckstrin's repeat performance: a novel domain in G-protein signaling? TIBS 1996, 21:245-246

130. Krasnow RE, Wong LL, Adler PN: Dishevelled is a component of the frizzled signaling pathway in Drosophila. Development 1995, 121:4095-4102

131. Boutros M, Paricio N, Strutt DI, Mlodzik M: Dishevelled activates JNK and discriminates between JNK pathways in planar polarity and wingless signaling. Cell 1998, 94:109-118

132. Li L, Yuan H, Xie W, Mao J, Caruso AM, McMahon A, Sussman DJ, Wu D: Dishevelled proteins lead to two signaling pathways. ] Biol Chem 1999, 274:129-134

133. Miller JR, Moon RT: Signal transduction through $\beta$-catenin and specification of cell fate during embryogenesis. Genes Dev 1996, 10:2527-2539

134. Fagotto F, Gumbiner BM: Beta-catenin localization during Xenopus embryogenesis: accumulation at tissue and somite boundaries. Development 1994, 120:3667-3679

135.Schneider S, Steinbeisser H, Warga RM, Hausen P: Beta-catenin translocation into nuclei demarcates the dorsalizing centers in frog and fish embryos. Mech Dev 1996, 57:191-198

136. Yost C, Torres M, Miller JR, Huang E, Kimelman D, Moon RT: The axis-inducing activity, stability, and subcellular distribution of beta-catenin is regulated in Xenopus embryos by glycogen synthase kinase 3. Genes Dcv 1996, 10:1443-1454

137. Behrens J, von-Kries JP, Kuhl M, Bruhn L, Wedlich D, Grosschedl R, Birchmeier W: Functional interaction of beta-catenin with the transcription factor LEF-1. Nature 1996, 382:638-642

138. Molenaar M, van-de-Wetering M, Oosterwegel M, Peterson-Maduro J, Godsave S, Korinek V, Roose ], Destree O, Clevers $\mathrm{H}$ : XTcf-3 transcription factor mediates beta-catenin-induced axis formation in Xenopus embryos. Cell 1996, 86:391-399

139. Takeichi M: Cadherin cell adhesion receptors as a morphogenetic regulator. Science 1991, 251:1451-1455

140.Ilan N, Mahooti S, Rimm DL, Madri J $\Lambda$ : PECAM-1 (CD31) functions as a reservoir for and a modulator of tyrosine-phosphorylated beta-catenin. J Cell Sci 1999, 112 Pt 18:3005-3014

141.Ilan N, Cheung L, Pinter E, Madri J $\Lambda$ : Platelet-endothelial cell adhesion molecule-1 (CD31), a scaffolding moleculc for selected catenin family members whose binding is mediated by different tyrosine and serine/threonine phosphorylation. J Biol Chem 2000, 275(28):2143521443 
142.He TC, Sparks AB, Rago C, Hermeking H, Zawel L, da-Costa LT, Morin PJ, Vogelstein B, Kinzler KW: Identification of c-MYC as a target of the APC pathway. Science 1998, 281:15091512

143. Tetsu O, McCormick F: Beta-catenin regulates expression of cyclin D1 in colon carcinoma cclls. Nature $1999,398: 422-426$

144. Roose J, Huls G, van-Beest M, Mocrer P, van-der-Horn K, Goldschmeding R, Logtenberg T, Clevers H: Synergy between tumor suppressor $A P C$ and the beta-catenin-Tef4 target Tcf1. Science 1999, 285:1923-1926

145. Mann B, Gelos M, Siedow A, Hanski ML, Gratchev A, Ilyas M, Bodmer WE, Moyer MP, Riecken EO, Buhr $\mathrm{HJ}$, Hanski C: Target genes of beta-catenin-T cell-factor/lymphoidenhancer-factor signaling in human colorectal carcinomas. Proc Natl Acad Sci U S A 1999, 96:1603-1608

146. Crawford HC, Fingleton BM, Rudolph-Owen LA, Goss KJ, Rubinfeld B, Polakis P, Matrisian I.M: The metalloproteinase matrilysin is a target of beta-catenin transactivation in intestinal tumors. Oncogene 1999, 18:2883-2891

147. Wiclenga VJ, Smits R, Korinek V, Smit L, Kielman M, Fodde R, Clevers H, Pals ST: Expression of CD44 in Apc and Tef mutant mice implies regulation by the WNT pathway. Am J Pathol 1999, 154:515-523

148.Gradl D, Kuhl M, Wedlich D: The $\mathrm{W} n / / \mathrm{W} / \mathrm{g}$ signal transducer beta-catenin controls fibroncctin expression. Mol Cell Biol 1999, 19:5576-5587

149. Baker JC, Beddington RS, Harland RM: Wnt signaling in Xenopus cmbryos inhibits bmp4 expression and activates neural development. Genes Dev 1999, 13:3149-3159

150.van-der-Heyden MA, Rook MB, Hermans MM, Rijksen G, Boonstra J, Defize LH, Destree $\mathrm{OH}$ : Identification of connexin43 as a functional target for Wht signalling. J Cell Sci 1998, 111:1741-1749

151.Ai Z, Fischer $A$, Spray DC, Brown AM, Fishman GI: Wnt-1 regulation of connexin43 in cardiac myocytes. J Clin Invest 2000, 105:161-171

152.McGrew LL, Takemaru K, Bates R, Moon RT: Direct regulation of the Xenopus engrailed-2 promoter by the Wht signaling pathway, and a molecular screen for Wnt-responsive genes, confirm a role for Wnt signaling during neural patterning in Xenopus. Mech Dev 1999, 87:2132

153.Dorsky RI, Moon RT, Raible DW: Control of neural crest cell fate by the Wnt signalling pathway. Nature 1998, 396:370-373

154. Xu L, Corcoran RB, Welsh JW, Pennica D, Levine AJ: WISP-1 is a Wnt-1- and beta-cateninresponsive oncogene. Genes Dev 2000, 14:585-595

155. Howe LR, Subbaramaiah K, Chung WJ, Dannenberg AJ, Brown AM: Transcriptional activation of cyclooxygenase-2 in Wnt-1-transformed mouse mammary cpithelial cells. Cane Res 1999, 59:1572-1577

156.Lescher $B$, Haenig $B$, Kispert $A$ : sFRP-2 is a target of the Wnt-4 signaling pathway in the developing metanephric kidney. Dev Dynam 1998, 213:440-451

157. Fagotto F, Funayama N, Gluck U, Gumbiner BM: Binding to cadherins antagonizes the signaling activity of beta-catenin during axis formation in Xenopus. J Cell Biol 1996, 132:11051114

158. Orsulic S, Peifer $\mathrm{M}$ : $\mathrm{An}$ in vivo structure-function study of armadillo, the beta-catenin homologue, reveals both separate and overlapping regions of the protein required for cell adhesion and for wingless signaling. J Cell Biol 1996, 134:1283-1300

159. Toyofuku $\mathrm{T}$, Hong $\mathrm{Z}$, Kuzuya $\mathrm{T}$, Tada M, Hori $\mathrm{M}$ : Wnt/Frizzlcd-2 signaling induces aggregation and adhesion among cardiac myocytes by increased cadherin-beta-catenin complex. J Cell Biol 2000, 150 (1):225-241

160. Pai LM, Orsulic S, Bejsovec $\Lambda$, Peifer M: Negative regulation of Armadillo, a Wingless effector in Drosophila. Development 1997, 124:2255-2266 
161.Ikeda S, Kishida S, Yamamoto $H$, Murai $H$, Koyama S, Kikuchi $\Lambda$ : $\Lambda$ xin, a negative regulator of the Wnt signaling pathway, forms a complex with GSK-3 and -catenin and promotes GSK3 dependent phosphorylation of -catanin. EMBBO J 1998, 17:1371-1384

162. Hart MJ, de-los-Santos R, Albert IN, Rubinfeld B, Polakis P: Downregulation of beta-catenin by human $\Lambda$ xin and its association with the $\Lambda \mathrm{PC}$ tumor suppressor, beta-catenin and GSK3 beta. Curr Biol 1998, 8:573-581

163. Salic A, Lee E, Mayer L, Kirschner MW: Control of beta-catenin stability: reconstitution of the cytoplasmic steps of the wht pathway in Xenopus egg extracts. Mol Cell 2000, 5:523-532

164. Kishida S, Yamamoto H, Ikeda S, Kishida M, Sakamoto I, Koyama S, Kikuchi A: Axin, a negative regulator of the wnt signaling pathway, directly interacts with adenomatous polyposis coli and regulates the stabilization of beta-catenin. J Biol Chem 1998, 273:10823-10826

165.Stambolic V, Ruel L, Woodgett JR: Lithium inhibits glycogen synthase kinase-3 activity and mimics wingless signalling in intact cells. Curr Biol 1996, 6:1664-1668

166.Satomon D, Sacco PA, Roy SG, Simcha I, Johnson KR, Wheclock MJ, Ben-Zc'cv A: Regulation of $\beta$-catenin levels and localization by overexpression of plakoglobin and inhibition of the ubiquitin-proteasome system. J Cell Biol 1997, 139:1325-1335

167.Aberle H, Bauer A, Stappert J, Kispert A, Kemler R: $\beta$-catenin is a target for the ubiquitinprotcasome pathway. EMBO J 1997, 16:3793-3804

168.Ikeda S, Kishida M, Matsuura Y, Usui H, Kikuchi A: GSK-3beta-dependent phosphorylation of adenomatous polyposis coli gene product can be modulated by beta-catenin and protein phosphatase $2 A$ complexed with Axin. Oncogene 2000, 19:537-545

169.Sceling JM, Miller JR, Gil R, Moon RT, White R, Virshup DM: Regulation of beta-catenin signaling by the B56 subunit of protcin phosphatase $2 A$. Science 1999, 283:2089-2091

170.Strovel ET, Wu D, Sussman DJ: Protein phosphatase 2Calpha dephosphorylates axin and activates LEF-1-dependent transcription. J Biol Chem 2000, 275:2399-2403

171.Neo SY, Zhang Y, Yaw LP, Li P, Lin SC: $A$ xin-induced apoptosis depends on the extent of its JNK activation and its ability to down-regulate beta-catenin levels. Biochem Biophys Res Comm 2000, 272:144-150

172. Munemitsu S, Albert I, Souza B, Rubinfeld B, Polakis P: Regulation of intracellular betacatenin levels by the adenomatous polyposis coli (APC) tumor-suppressor protein. Proe Natl Acad Sci U S A 1995, 92:3046-3050

173. Willert K, Nusse R: Beta-catenin: a key mediator of Wnt signaling. Curr Opin Genet Dev 1998, 8:95-102

174. Cavallo R, Rubenstein D, Peifer M: Armadillo and dTCF: a marriage made in the nucleus. Curr Opin Genet Dev 1997, 7:459-466

175.McCartney BM, Dicrick HA, Kirkpatrick C, Moline MM, Baas $A$, Peifer M, Bejsovec $\Lambda$ : Drosophila $A P C 2$ is a cytoskeletally-associated protein that regulates wingless signaling in the embryonic epidermis. J Cell Biol 1999, 146:1303-1318

176. Bell SM, Lam WK, Carr IM, Cartwright E], Pinchin K, Wedgwood S, Markham AF, Coletta PL: Assignment of the murine adenomatous polyposis coli 2 (Apc2) gene to mouse chromosome band 10B5-C2 by in situ hybridisation. Cytogenet Cell Genet 1999, 86:81-82

177.van-Es JH, Kirkpatrick C, van-de-Wetering M, Molenaar M, Miles A, Kuipers J, Destrec O, Peifer M, Clevers H: Identification of APC2, a homologue of the adenomatous polyposis coli tumour suppressor. Curr Biol 1999, 9:105-108

178. Pyles RB, Santoro IM, Groden J, Parysek LM: Novel protein isoforms of the APC tumor suppressor in neural tissue. Oncogene 1998, 16:77-82

179. Vleminckx K, Wong E, Guger K, Rubinfeld B, Polakis P, Gumbiner BM: Adenomatous polyposis coli tumor suppressor protein has signaling activity in Xenopus laevis embryos resulting in the induction of an ectopic dorsoanterior axis. J Cell Biol 1997, 136:411-420

180. Kinzler KW, Vogelstein B: Lessons from hereditary colorectal cancer. Cell 1996, 87(2):159-170 
181. Korinek V, Barker N, Morin PJ, Van Wichen D, De Weger R, Kinzler KW, Vogelstein B, Clevers H: Constitutive transcriptional activation by a $\beta$-catenin-Tef complex in APC-/- colon carcinoma. Science 1997, 275:1784-1787

182. Morin PJ, Sparks AB, Korinck V, Barker N, Clever H, Vogelstein B, Kinzler KW: Activation of $\beta$-catenin- $T$ cf signaling in colon cancer by mutations in $\beta$-catenin or APC. Science 1997, 275:1787-1790

183.Rubinfeld B, Robbins P, El-Gamil M, Albert I, Porfiri E, Polakis P: Stabilization of $\beta$-catenin by genctic defects in melanoma cell lines. Science 1997, 275:1790-1792

184. Bradley RS, Cowin P, Brown AM: Expression of Wnt-1 in PC12 cells results in modulation of plakoglobin and E-cadherin and increased cellular adhesion. J Cell Biol 1993, 123:1857-1865

185. Karnovsky $A$, Klymkowsky MW: Anterior axis duplication in Xenopus induced by the overexpression of the cadherin-binding protein plakoglobin. Proc Natl Acad Sci U S $\Lambda$ 1995, 92:4522-4526

186.Zhurinsky J, Shtutman M, Ben-Zc'ev $\Lambda$ : Differential mechanisms of I.EF/TCF familydependent transcriptional activation by beta-catenin and plakoglobin. Mol Cell Biol 2000, 20:4238-4252

187. Axclrod JD, Matsuno K, Artavanis-Tsakonas S, Perrimon N: Interaction between Wingless and Notch signaling pathways mediated by dishevelled. Scicnce 1996, 271:1826-1832

188. Blair SS: Notch and Wingless signals collide. Science 1996, 271:1822-1823

189. Anderton BH, Dayanandan R, Killick R, Lovestone S: Does dysregulation of the Notch and wingless/Wnt pathways underlic the pathogenesis of Alzheimer's disease? Mol Med Today 2000, 6:54-59

190.Anderton BH: Alzheimer's disease: clues from flies and worms. Curr Biol 1999, 9:R106-R109

191.Nishimura M, Yu G, Levesque G, Zhang DM, Rucl L, Chen F, Milman P, Holmes E, Liang Y, Kawarai T, Jo E, Supala $\Lambda$, Rogacva E, Xu DM, Janus C, Levesque L, Bi Q, Duthic M, Rozmahel R, Mattila K, Lannfelt L, Westaway D, Mount HT, Woodgett J, St-George-Hyslop $P$, et al.: Presenilin mutations associated with Alzheimer disease cause defective intracellular trafficking of beta-catenin, a component of the presenilin protein complex. Nature Med 1999, 5:164-169

192. Hoschuetzky H, Aberle H, Kemler R: Beta-catenin mediates the interaction of the cadherincatenin complex with epidermal growth factor receptor. J Cell Biol 1994, 127:1375-1380

193. Andre F, Rigot V, Thimonier J, Montixi C, Parat F, Pommier G, Marvaldi J, Luis J: Integrins and E-cadherin cooperatc with IGF-I to induce migration of cpithelial colonic cells. Int J Cancer 1999, 83:497-505

194. Boheler KR, Schwartz K: Gene expression in cardiac hypertrophy. Trends Cardiovasc Med 1992, 2:176-182

195.Smalley MJ, Dalc TC: Wnt signalling in mammalian development and cancer. Cancer Metastasis Rev 1999, 18:215-230

196. Wodarz A, Nusse R: Mechanisms of Wht signaling in development. Annu Rev Cell Dev Biol 1998, 14:59-88

197.Park M, Wu X, Golden K, Axclrod JD, Bodmer R: The wingless signalling pathway is directely involved in Drosohila heart development. Dev Biol 1996, 177:104-116

198. Jaspard B, Couffinhal T, Dufourcq P, Moreau C, Duplaa C: Expression pattern of mouse sFRP-1 and mWnt-8 gene during heart morphogenesis. Mech Dev 2000, 90:263-267

199. Eisenberg CA, Eisenberg LM: WNT11 promotes cardiac tissue formation of early mesoderm. Dev Dynam 1999, 216:45-58

200. Wheeler GN, Hoppler S: Two novel Xenopus frizzled genes expressed in developing heart and brain. Mech Dev 1999, 86:203-207

201. Kirby ML, Waldo KL: Neural crest and cardiovascular patterning. Circ Res 1995, 77:211-215

202. Waldo KL, Kumiski D, Kirby ML: Cardiac neural crest is essential for the persistence rather than the formation of an arch artery. Dev Dynam 1996, 205:281-292 
203. Bergwerff M, Verberne ME, DeRuiter MC, Poelmann RE, Gittenberger-de Groot AC: Neural crest cell contribution to the developing circulatory system, Implications for Vascular Morphology? Circ Res 1998, 82:221-231

204. Augustine K, Liu ET, Sadler TW: Antisense attenuation of Wnt-1 and Wnt-3a expression in whole embryo culture reveals roles for these genes in craniofacial, spinal cord, and cardiac morphogenesis. Dev Genet 1993, 14:500-520

205.DeRossi C, Laiosa MD, Silverstone AE, Holdencr BC: Mouse fæd4 maps within a region of chromosome 7 important for thymus and cardiac development. Genesis 2000, 27:64-75

206. Huang GY, Wessels A, Smich BR, Linask KK, Ewart JL, Lo CW: Alteration in conncxin 43 gap junction gene dosage impairs conotruncal heart devclopment. Dev Biol 1998, 198:32-44

207. Waldo KL, Lo CW, Kirby ML: Conncxin 43 cxpression reflects ncural crest patterns during cardiovascular development. Dev Biol 1999, 208:307-323

208.Linask KK, Knudsen KA, Gui YH: N-cadherin-catenin interaction: Necessary component of cardiac cell compartmentalization during early vertebrate heart development. Dev Biol 1997, 185:148-164

209.Ruiz P, Brinkmann V, Lcdermann B, Behrend M, Grund C, Thalhammer C, Vogel F, Birchmeier C, Gunthert U, Franke WW, Birchmeier W: Targeted mutation of plakoglobin in mice reveals essential functions of desmosomes in the embryonic heart. J Cell Biol 1996, 135:215-225

210. Bicrkamp C, McLaughlin KJ, Schwart. H, Huber O, Kemler R: Embryonic heart and skin defects in mice lacking plakoglobin. Dev Biol 1996, 180:780-785

211. Hacgel H, Larue L, Ohsugi M, Fedorov L, Herrenknecht K, Kemler R: Lack of beta-catenin affects mouse development at gastrulation. Development 1995, 121:3529-3537

212. Wright M, Aikawa M, S7cto W, Papkoff J: Idcntification of a Wnt-responsive signal transduction pathway in primary endothelial cells. Biochem Biophys Res Comm 1999, 263:384 388

213. Cohen AW, Carbajal JM, Schaeffer RC Jr: VEGF stimulates tyrosinc phosphorylation of betacatenin and small-pore endothelial barricr dysfunction. Am J Physiol 1999, 277:H2038-H2049

214. Duplaa C, Jaspard B, Moreau C, D'Amore PA: Identification and cloning of a secreted protein related to the cystein-rich domain of frizaled; Evidence for a role in endothelial cell growth control. Circ Res 1999, 84:1433-1445

215. Carmelict P, Lampugnani MG, Moons L, Breviario F, Compernolle V, Bono F, Balconi G, Spagnuolo R, Oostuyse B, Dewerchin M, Zanetti A, Angellilo A, Mattot V, Nuyens D, Lutgens E, Clotman F, de-Ruiter MC, Gittenberger-de-Groot $\Lambda$, Poclmann R, Lupu F, Hcrbcrt JM, Collen D, Dejana E: Targeted deficiency or cytosolic truncation of the VE-cadherin gene in mice impairs VEGF-mediated endothelial survival and angiogenesis. Cell 1999, 98:147-157

216. Roura S, Miravet S, Piedra J, Garcia-de-Herreros A, Dunach M: Regulation of Ecadherin/Catenin association by tyrosine phosphorylation. J Biol Chcm 1999, 274:36734-36740

217. Wang $\mathrm{X}$, Gerdes $A \mathrm{M}$ : Chronic pressurc overload cardiac hypertrophy and failure in guinca pigs: III. Intercalated disc remodeling. J Mol Cell Cardiol 1999, 31:333-343

218. Blankesteijn WM, Essers-Janssen YPG, Ulrich MMW, Smits JFM: Increased expression of a homologue of Drosophila tissue polarity gene 'frizzled' in left ventricular hypertrophy in the rat, as detcrmined by subtractive hybridization. J Mol Cell Cardiol 1996, 28:1187-1191

219. Auffray C, Rougeon F: Purification of mouse immunoglobulin heavy-chain messenger RN $\Lambda$ s from total myeloma tumor RNA. Eur J Biochem 1980, 107:303-314

220. Kuhl M, Wedlich D: Wnt signalling goes nuclear. BioEssays 1997, 19:101-104

221. Wong MH, Rubinfeld B, Gordon JI: Effects of Forced Expression of an NH2-terminal Truncated beta-catenin on Mousc Intestinal Epithelial Homeostasis. J Cell Biol 1998, 141 (3):765-777

222. Wong MH, Hermiston ML, Syder $\mathrm{AJ}$, Gordon JI: Forced expression of the tumor suppressor adcnomatosis polyposis coli protein induces disordered cell migration in the intestinal epithclium. Proc Natl Acad Sci 1996, 93:9588-9593 
223. Hermiston MIL, Wong MH, Gordon JI: Forced cxpression of E-cadherin in the mouse intestinal cpihclium slows cell migration and provides evidence for nonautonomous regulation of cell fate in a self-renewing system. Genes Dev 1996, 10:985-996

224.Alman BA, Li C, Pajerski ME, Diaz-Cano S, Wolfe HJ: Increased $\beta$-catenin protein and somatic APC mutations in sporadic aggressivc fibromatoses (Desmoid Tumors). $\mathrm{Am}$ J Pathol $1997,151: 329-334$

225. Kitacva MN, Grogan L, Williams JP, Dimond E, Nakahara K, Hausner P, DeNobile JW, Soballe PW, Kirsch IR: Mutations in $\beta$-catenin are uncommon in colorectal cancer occurring in occasional replication error-positive tumors. Canc Res 1997, 57:4478-4481

226. De Block M, Debrouwer D: RNA-RNA in situ hybridization using digoxigenin-labeled probes: the use of high-molecular-weight polyvinyl alcohol in the alkaline phosphatase indoxylnitroblue tertazoliuym reaction. Anal Biochem 1993, 215:86-89

227. Guillet JG, Hocbeke J, Lengagne R, Tate K, Borras-Herrera F, Strosberg AD, Borrcs-Cuesta F: Haplotype specific homology scanning algorithm to predict $T$-cell epitopes from protein scquences. J Mol Recognit 1991, 4:17-25

228. Ishikawa T, Tamai Y, Zorn AM, Yoshida H, Scldin MF, Nishikawa T, Takcto MME: Mouse wnt receptor gene Fzd5 is essential for yolk sac and placental angiogenesis. Development 2001, 128:25-33

229. Vider BZ, Zimber $\Lambda$, Chastre E, Prevot S, Gespach C, Estlein D, Wo Y, Tronick SR, Gazit $\Lambda$, Yaniv A: Evidence for the involvement of the Wht 2 gene in human colorectal cancer. Oncogene 1996, 12 (1): 153-158

230.Smith K, Bui TD, Poulsom R, Kaklamanis L, Williams G, Harris AL: Up-rcgulation of macrophage wnt gene expression in adenoma- carcinoma progression of human colorectal canccr. Br J Canccr 1999, 81:496-502

231. Wong LL, Adler PN: Tissuc polarity genes of Drosophila regulate the subcellular location for prehair initiation in pupal wing cells. J Cell Biol 1993, 123:209-221

232. Dickinson M E, Sclleck M $A$, McMahon $A$ P, Bronner-Fraser M: Dorsalization of the neural rube by the non-ncural ectoderm. Development 1995, 121:2099-2106

233. Echelard Y, Vassileva G, McMahon AP: Cis-acring regulatory sequences governing Wnt-1 expression in the developingmouse CNS. Development 1994, 120:2213-2224

234. Jiang $\mathrm{X}$, Rowitch DH, McMahon AP, Sucov HM: Fate of the mammalian cardiac neural crest. Development 2000, 127:1607-1616

235.Pizzudi A, Novelli G, Mari $A$, Rati $A$, Colosimo A, Amati F, Penso D, Sangiuolo F, Calabrese G, Palka G, Silani V', Gennarelli M, Mingarelli R, Scarlatto G, Scambler P, Dallapiccola B: Human homologue sequences to the Drosophila dishevelled segment-polarity gene are deleted in the DiGcorge syndrome. Am J Hum Genet 1996, 58:722-729

236. Sirotkin H, O'Donnell H, DasGupta R, Halford S, St. Jore B, Pucch A, Parimoo S, Morrow B, Skoultchi $\Lambda$, Wissman SM, Scambler $P$, Kucherlapati $R$ : Identification of a new human catenin family member (ARVCF) from the region deleted in Velo-Cardio-Facial syndrome. Genomics 1997, 41:75-83

237.Poclmann RE, Mikawa T, Gittenberger-De Groot AC: Neural crest cells in outflow tract septation of the embryonic chicken heart: differentiation and apoptosis. Dev Dynam 1998, 212:373-384

238. Wang YK, Sporle R, Papcrna T, Schughart K, Francke U: Characterization and expression pattern of the frizzled gene F\%d9, the mouse homolog of the FZD9 which is deleted in the Williams-Beuren syndrome. Genomics 1999, 57:235-248

239. Momma K, Matsuoka R, Takao A: Aortic Arch Anomalics Associated with Chromosome 22q11 Deletion (CATCH 22). Pediatr Cardiol 1999, 20(2):97-102

240.Ikeya M, Lee SMK, Johnson JE, McMlahon AP, Takada S: Wnt signalling required for expansion of neural crest and CNS progenitors. Nature 1997, 389:966-970 
241. Dettman RW, Denetclaw W Jr, Ordahl CP, Bristow J: Common epicardial origin of coronary vascular smooth muscle, perivascular fibroblasts, and intermyocardial fibroblasts in the avian heart. Dev Biol 1998, 193:169-181

242.Gittenberger-de Groot A C, Vrancken Peeters MP, Mentink MM, Gourdic RG, Poclmann RE: Epicardium-derived cells contribute a novel population to the myocardial wall and the atrioventricular cushions. Circ Res 1998, 82:1043-1052

243. Vrancken Pecters MPFM, Gittenberger-de Groot AC, Mentink MMT, Poclmann RE: Smooth muscle cells and fibroblasts of the coronary arteries derive from epithelial-mescnchymal transformation of the cpicardium. Anat Embryol 1999, 199:367-378

244.Schiaffino S, Dallapiccola B, Di Lisi R: Molccular Genetics of congenital heart discase: a problem of faulty septation. Circ Res 1999, 84:247-249

245. Peifer M, Polakis P: Wnt signaling in oncogenesis and embryogenesis- a look outside the nucleus. Science 2000, 287:1606-1609

246. Coso OA, Chiaricllo M, Yu JC, Teramoto H, Crespo P, Xu N, Miki T, Gutkind JS: The small GIP-Binding protcins Racl and Cde42 regulate the activity of the JNK/S $\Lambda$ PK signaling pathway. Cell 1995, 81:1137-1146

247.Li S, Chen BPC, $A$ zuma N, Hu Y-J, Wu SZ, Sumpio BE, Shyy JY-J, Chien S: Distinct roles for the samll GTPases Cde42 and Rho in endothclial responses to shear stress. J Clin Invest 1999, 103:1141-1150

248. Minden A, Lin A, Claret F-X, Abo $A$, Karin M: Selective activation of the JNK signaling cascade and c-jun transcriptional activity by the small GTP-ases Rac and Cdc42Hs. Cell 1995, 81:1147-1157

249.Sheldahl LC, Park M, Malbon CC, Moon RT: Protein kinase C is differentially stimulated by Wnt and Frizzled homologs in a G-protein-dependent manner. Curr Biol 1999, 9:695-698

250. Park WJ, Liu J, Adler PN: Frizzled gene expression and development of tissue polarity in the Drosophila wing. Dev Genet 1994, 15:383-389

251. Bradley RS, Brown AMC: A soluble form of Wnt-1 protcin with mitogenic activity on mammary epithelial cells. Mol Cell Biol 1995, 15:4616-4622

252. Fagotto.F, Jho.E, Zeng.L, Kurth.T, Joos.T, Kaufmann.C, Costantini.F; Domains of Axin Involved in Protcin-Protcin Intcractions, Wht Pathway Inhibition, and Intracellular Localization. J Cell Biol 1999, 145:741-756

253.Zhou Z, Wang J, Han X, Zhou J, Linder S: Up-regulacion of human secreted frizzled homolog in apoptosis and its down-rcgulation in breast tumors. Int J Cancer 1998, 78:95-99

254.Strovel.E, Sussman.D: Transient Overcxpression of Murinc Dishevelled Genes results in Apoptotic Ccll Deach. Exp Cell Res 1999, 253:627-648

255.Zhoo Z, Rivkees SA: Programmed cell death in the developing heart: regulation by BMP4 and FGF2. Dev Dynam 2000, 217:388-400

250. Evan G, Harrington E, Fanidi A, Jand H, Amati B, Bennet M: Integrated control of cell proliferation and cell death by the c-myc oncogen. Phil Trans R Soc Lond B 1994, 345:269-275

257. Depre C, Taegtmeyer H: Metabolic aspects of programmed cell survival and cell death in the heart. Cardiovasc Res 2000, 45:538-548

258. Bcllamy CO, Malcomson RD, Harrison DJ, Wyllic $A \mathrm{H}$ : Cell deaath in health and disease: the biology and regulation of apoptosis. Scm Cancer Biol 1995, 6:3-16

259.van Gijn ME, Blankesteijn WM, Smits JFM, Hierck B, Gittenberger-de Groot AC: Frizzled 2 is transicntly expressed in neural crest containing areas during development of the heare and grcat arterics in the mousc. Anat Embryol 2001, 203(3):185-192

260. D'Mcllo SR, Anclli R, Calissano P: Lithium induccs apoptosis in immaturc cerebellar granulc cells but promotes survival of mature neurons. Exp Cell Res 1994, 211:332-338

261. Madiche AM, Mampuru LJ, Tyobeka EM: Induction of apoptosis in HL-60 cells by lithium. Biochem Biophys Res Comm 1995, 209:768-774

262. Elsasser A, Suzuki K, Schaper J: Unresolved issues regarding the role of apoptosis in the pathogenesis of ischemic injury and heart failure. J Mol Cell Cardiol 2000, 32:711-724 
263.Yuan P, Chen G, Manji HK: Lithium activates the c-Jun NH2-terminal kinases in vitro and in the CNS in vivo. J Ncurochem 1999, 73 (6):2299-2309

264.Sakamoto I, Kishida S, Fukui A, Kishida M, Yamamoto H, Hino S, Michiuc T, Takada S, Asashima $M$, Kikuchi $A: A$ novel beta-catenin binding protein inhibits beta-catenin dependent Tcf activation and axis formation. J Biol Chem 2000, july31:1-1

265. Tago K, Nakamura T, Nishita M, Hyodo J, Nagai S, Murata Y, Adachi s, Ohwada S, Morishita $\mathrm{Y}$, Shibuya $\mathrm{H}$, Akiyama $\mathrm{T}$ : Inhibition of wnt signaling by ICAT, a novel beta-catenininteracting protein. Genes Dev 2000, 14(14):1741-1749

266.Liu.x, Liu.T, Slusarski.C, Tang-Snyder.J, Malbon.C, Moon.R, Wang.H: Activation of a frizzled2/beta-adrenergic receptor chimern promotes $W$ nt signaling and differentation of mouse F9 tcratocarcinoma cells via G-alfa-O and G-alfa-t. Proc Natl Acad Sci 1999, 96:14383-14388

267.Datta SA, Brunet A, Greenberg ME: Cellular survival: a play in threc $\Lambda$ kts. Genes Dev 1999, 13:2905-2927

268. Kandel ES, Hay N: The regulation and activitics of the multifunctional scrine/threonine kinase $\Lambda \mathrm{kt} / \mathrm{PKB}$. Exp Cell Res 1999, 253(1):210-229

269. Hocflich KP, Luo J, Rubie EA, Tsao MS, Jin O, Woodgett JR: Requirement for glycogen synthase kinasc-3beta in cell survival and NF-kappaB activation. Naturc 2000, 406(6791):86-90

270.Lce.J, Ishimoto.A, Yanagawa.S: Characterization of Mousc Dishcvelled (Dvl) Proteins in Wnt/wingless Signaling Pathway. J Biol Chem 1999, 274,10:21464-21470

271. Strovel ET, Wu D, Sussman DJ: Protein phosphatasc 2Calpha dephosphorylates Axin and activates LEF 1 -1 dependent transcription. J Biol Chem 1999, 275:2399-2403

272. Takekawa M, Maeda T, Saito H: Protein phosphatase 2Calpha inhibits the human surcssrcsponsive $\mathrm{p} 38$ and JNK MAPK pathways. EMBO J 1998, 17:4744-4752

273. Sakanaka C, Weiss JB, Williams LT: Bridging of beta-catenin and glycogen synthase kinase3 beta by axin and inhibition of beta-catenin-mediated transcripion. Proc Natl Acad Sci 1998, 95(6):3020-3023

274. $\Lambda$ hmed Y, Hayashi S, Levine $A$, Wiehaus E: Regulation of armadillo by a drosophila $A P C$ inhibits neuronal apoptosis during retinal development. Cell 1998, 93(7):1171-1182

275. Bordonaro M, Mariadason JM, Aslam F, Hecrdt BG, Augenlicht L: Butyratc-induced apoptotic cascade in colonic carcinoma cells: modulation of the beta-catenin-Tcf pathway and concordance with effects of sulindac and trichostatin $\Lambda$ but not curcumin. Cell Growth \& Differentation 1999, 10(10):713-720

276. Kim K, Ming Pang K, Evans M, Hay ED: Overexpression of beta-catenin induces apoptosis independent of its transactivation function with LEF-1 or the involvement of major G1 cell cycle rcgulators. Mol Biol Cell 2000, 11:3509-3523

277. Nakano A, Baines CP, Kim SO, Pelech SL, Downey JM, Cohen MV, Critz SD: Ischemic preconditioning activates MAPKAPK2 in the isolated rabbit heart: evidence for involvement of p38 MAPK. Circ Res 2000, 86:144-151

278.Trindadc MC, Schurman DJ, Maloney WJ, Goodman SB, Smith RJ: G-protein activity requirement for polymethylmethacrylate titanium particle-induced fibroblast interleukin- 6 and mono chemoattractant protein-1 release in vitro. J Biomed Mater Res 2000, 51:360-368

279. Elattar TM, Virji $\Lambda \mathrm{S}$ : The inhibitory effect of crcumin, genistein, quercetin and cisplatin on the growth of omal cancer cells in vitro. anticancer res 2000, 20:1733-1738

280. Hermans JJR, Fischer MAJ, Schiffers PM, Struijker-Boudier HAJ: High dictary potassium chloride intake augments rat renal mincralocorticoid receptor sclectivity via 11 betahydroysteroid dehydrogenase. BBA 1999, 1472:537-549

281.Saldanha J, Singh J, Mahadevan D: Identification of a Frizzled-like cystein rich domain in the extracellular region of developmental receptor kinases. Protein Sci 1998, 7:1632-1635

282. Kim L, Liu J, Kimmel $A R$ : The novel tyrosine kinase ZAK1 activates GSK3 to dircet cell fatc specification. Cell 1999, 99(4):399-408

283.Takeichi M: Cadherins: a molecular family important in selective cell-cell adhesion. Ann Rev Biochem 1990, 59:237-252 
284.Geiger B, Ayalon O: Cadherins. Ann Rev Cell Biol 1992, 8:307-332

285. Gumbiner BM: Cell adhesion: The molecular basis of tissue architecture and morphogenesis. Cell 1996, 84:345-357

286.Shapiro L: The multi-talented $\beta$-catenin makes its first appearancc. Structure 1997, 5:1265-1268

287. Morin PJ, Sparks AB, Korinck V, Barker N, Clevers H, Vogelstein B, Kinzler KW: Activation of $\beta$-catenin- $-\mathrm{ccf}$ signaling in colon cancer by mutations in $\beta$-catenin or $A P C$, Science 1997, 275:1787-1790

288. Peifer M: $\beta$-Catenin as oncogene: The smoking gun. Science 1997, 275:1752-1753

289. Gumbiner BM: Carcinogenesis: $A$ balance between $\beta$-catenin and $A P C$. Curr Biol 1997, 7:R443-R446

290. Haegel H, Larue L, Ohsugi M, Fedorov L, Herrenknecht K, Kemler R: Lack of $\beta$-catenin affects mousc development at gastrulation. Development 1995, 121:3529-3537

291.Resnik E: B-Catenin - onc player, two games. Naturc Genct 1997, 16:9-11

292. Fan T-PD, Jaggar R, Bickncll R: Controlling the vasculature: angiogenesis, anti-angiogenesis and vascular targeting of gene therapy. Trends Pharmacol Sci 1995, 16:57-66

293. Schnittler H-J: Structural and functional aspects of intercellular junctions in vascular endothelium. Basic Res Cardiol 1998, 93:30-39

294.Lampugnani MG, Corada M, Caveda L, Breviario F, Ayalon O, Geiger B, Dejana E: The molccular organization of endothelial cell to cell junctions: diffferential association of plakoglobin, $\beta$-catenin, and $\alpha$-catenin with vascular endothelial cadherin (VE-cadherin). J Cell Biol 1995, 129:203-217

295. McMahon GA, Garfinkel S, Prudovsky I, Hu X, Maciag T: Intracellular precursor Interleukin (II) $-1 \alpha$, but not maturc IL- $1 \alpha$, is able to regulate human endothelial cell migration in vitro. $J$ Biol Chem 1997, 272:28202-28205

296. Muller T, Choidas $A$, Reichmann $E$, Ullrich $A$ : Phosphorylation and free pool of $\beta$-catenin are regulated by tyrosine kinases and tyrosine phosphatases during epithelial cell migration. J Biol Chem 1999, 274:10173-10183

297. Pollack AL, Barth AIM, Altschuler Y, Nclson WJ, Mostov KE: Dynamics of $\beta$-catenin interactions with APC protein regulate epithelial tubulogenesis. J Cell Biol 1997, 137:1651-1662

298. Passier RCJJ, Smits JFM, Verluyten MJA, Studer R, Drexler H, Dacmen MJAP: Activation of angiotensin-converting-enzyme in the infaret zone following myocardial infarction. Am $\mathrm{J}$ Physiol 1995, 269:H1268-H1276

299. Broers JLV, Machiels BM, Van Eys GJJM, Kuijpers HJH, Manders EMM, Van Dricl R, Ramaekers FCS: Dynamics of the nuclear lamina as monitored by GFP-tagged A-type lamins. J Cell Sci 1999, 112:3463-3475

300.Van Klecf EM, Smits JF, Schwart. SM, Daemen MJ: Doxazosin blocks the angiotensin IIinduced smooth muscle cell DNA synthesis in the media, but not in the ncointima of the rat carotid artery after balloon injury. Cardiovasc Res 1996, 31:324-330

301. Kurth T, Scwhartz. H, Schneider S, Hausen P: Fine structural immunohistochemistry of catcnins in amphibian and mammalian muscle. Cell Tissue Res 1996, 286:1-12

302. Nelissen-Vrancken HJMG, Debets JJM, Snoeckx LHEH, Dacmen MJAP, Smits JFM: Timerelated normalization of maximal coronary flow in isolated perfused hearts of rats with myocardial infarction. Circulation 1996, 93:349-355

303. Cai J, Jiang WG, Mansel RE: Inhibition of the expression of VE-cadhcrin-catenin complex by gamma linolenic acid in human vascular endothelial cells, and its impact on angiogenesis. Biochem Biophys Res Comm 1999, 258:113-118

304. Esser S, Lampugnani MG, Corada M, Dejana E, Risau W: Vascular endothelial growth factor induces VE-cadherin tyrosine phosphorylation in endothelial cells. J Cell Sci 1998, 111:18531865

305. Carmeliet P, Lampugnani M-G, Moons L, Breviario F, Compernolle V, Bono F, Balconi G, Spagnuolo R, Oosthuyse B, Dewerchin M, Zanetti $A$, Angellillo. $\Lambda$, Mattot $V$, Nuyens $D$, 
Lutgens E, Clotman F, De Ruiter M, Gittenberger-de Groot AC, Poclmann R, Lupu F, Herbert J-M, Collen D, Dejana E: Targeted deficiency of cytosolic truncation of the VEcadherin gene in micc impairs VEGF-mediated endothelial survival and angiogenesis. Cell 1999, 98:147-157

306. Barth AIM, Nathke IS, Nelson WJ: Cadherins, catenins and APC protein: interplay between cytoskcletal complexes and signaling pathways. Curr Opin Cell Biol 1997, 9:683-690

307. Antman EM, Brauntvald E (1997): Acute myocardial infarction. In: Heart discase, a textbook of cardiovascular medicine. 5th ed. WB Saunders \& Co, Philadelphia, 1184-1288.

308. Reeder GS: Identification and treatment of complications of myocardial infarction. Mayo Clin Proc 1995, 70:880-884

309.Julian DG: Why do patients die after myocardial infarction? J Cardiovase Pharmacol 1991, 18:S80-S82

310.Stout B, Ferell L, Wray T, Mayes C: Myocardial rupture, your patient's survival may depend on you. Postgrad Mcd 1991, 90:115-122

311. Buda $\mathrm{AJ}$ : The role of celhocardiography in the evaluation of mechanical complications of acute myocardial infarction. Circulation 1991, 84:1109-1121

312. Marian AJ: Genetic risk factors for myocardial infarction. Curr Opin Cardiol 1998, 13:171-178

313.Cook D, Fry MJ, Hughes K, Sumathipala R, Woodgett JR, Dale TC: Wingless inactivates glycogen synthase kinase- 3 via an intracellular signalling pathway which involves a protein kinase C. EMBO J 1996, 15:4526-4536

314.Lijam N, Paylor R, McDonald MP, Crawley JN, Deng C-X, Herrup K, Stevens KE, Maccaferri G, McBain CJ, Sussman DJ, Wynshaw-Boris $A$ : Social interaction and sensorimotor gating abnormalities in mice lacking Dull. Cell 1997, 90:895-905

315.Semënov $M N$, Snyder M: Human dishevelled genes constitute a DHR-containing multigene family. Genomics 1997, 42:302-310

316.Sicgfricd E, Wilder EL, Perrimon N: Components of Wingless signalling in Drosophila. Nature 1994, 367:76-80

317. Orford K, Crockett C, Jensen JP, Weissman AM, Byers SW: Scrinc phosphorylation-regulated ubiquitination and degradation of $\beta$-catenin. J Biol Chem 1997, 272:24735-24738

318. Marvin MJ, Di Rocco G, Gardiner A, Bush sm, Lassar AB: Inhibition of wne accivity induces heart formation from posterior mesoderm. Genes Dev 2001, 15:316-317

319.Schneider $V$, Mercola M: Wnt antagonism initiates cardiogenesis in Xenopus lacvis. Genes Dev 2001, 15:305-315

320.Greco TL, Sussman DJ, Camper SA: Dishevelled-2 maps to human chromososme 17 and distal to wnt3a and vestigial tail (vt) on mouse chromosome 11. Mamm Genome 1996, 7:475476

321. Figueras J, Cortadellas J, Soler-Solcr J: Left ventricular frec wall rupturc: clinical presentation and management. Heart 2000, 83:499-504

322. Marroquin OC, Lamas GA: Beneficial effects of an open artery on left ventricular remodeling after myocardial infarction. Prog Cardiovasc Dis 2000, 42:471-483

323.Sadanandan S, Hochman JS: Early reperfusion, late reperfusion, and the open artery hypothesis: an overvicw. Prog Cardiovasc Dis 2000, 42:397-404

324. Carmeliet P: Mechanisms of angiogenesis and arteriogenesis. Nature Med 2000, 6:389-395

325. Jee RJ, Springer MU, Blanco-Bose WE, Shaw R, Ursell PC, Blau HM: VEGF gene delivery to myocardium; delcterious effects of unregulated cxpression. Circulation 2000, 102:898-901

326. Mao C, Malek O, Pucyo M, Steg G, Soubrier F: Differential Expression of Rat FrizzledRelated frzb-1 and Frizzled receptor $£ \neq 1$ and $£ \neq 2$ Genes in the Rat Aorta After Balloon Injury. $\Lambda$ rterioscler Thromb Vasc Biol 2000, 20:43-51

327. Haq S, Choukroun G, Kang ZB, Ranu H, Matsui T, Rosenzweig A, Molentin JD, Alessandrini $\Lambda$, Woodgett J, Hajjar $\mathrm{R}$, Michacl $A$, Force T: Glycogen synthase kinase-3beta is a negative regulator of cardiomyocyte hypertrophy. J Cell Biol 2000, 151:117-129 


\section{Dankwoord}

Toen ik vier en een half jaar geleden aan dit onderzoek begon, wist ik niets van frizzled, nu een aantal jaren verder, na een breed scala van experimenten en de hulp van heel veel mensen, een beetje meer. I $\mathrm{k}$ wil bij deze iedereen die in meer of mindere mate aan de inhoud van dit procfschrift heeft bijgedragen bedanken!!! Enkele mensen wil ik er toch even uitlichten...

Allereerst natuurlijk mijn promotor en copromotor. Jos, bedankt voor alle adviezen, discussies en hulp bij het schrijven van dit proefschrift. $\Lambda \mathrm{l}$ had je het vaak druk, als ik je nodig had, was je er. Matthijs, in de vier jaar dat ik een kamer met je heb gedeeld, heb ik gemerkt dat achter de toch wat luide persoonlijkheid iemand zit met een groot gevoel voor humor, dic de gave heeft goed te kunnen uitleggen en overtuigen. Op wetenschappelijk en op schrijfgebied heb ik heel wat van je kunnen leren, bedankt. Yvonne, jij hebt me vooral in het begin aardig wat technieken bijgebracht.Veel immuno's en in situ's in dit proefschrift zijn van jouw hand. Christel, jij kwam pas toen ik eigenlijk al aan het schrijven was, maar het was gewoon leuk jou het cén en ander op het lab te leren. Bedankt voor die laatste proeven die toch altijd nog gedaan moeten worden. Ook dank aan alle studenten die het lab gepasseerd zijn, maar vooral Frans voor alle TUNELs en Bart, de eerste student, die ook het meeste indruk achterliet. Rob, dank voor je altijd goede raad bij het eiwitwerk. Jacque, Peter en Nicole van het dierenlab, het respect dat jullie voor dieren tonen, zou iedereen moeten hebben die met proefdieren werkt, bedankt voor alle operaties. Gregorio, ondanks het feit dat je niet echt bij mijn onderzoek betrokken was, werd je als collega erg gewaardeerd, al mijn onzinverhalen die ik altijd aan je kwijt kon, je bercidwilligheid mij te helpen als ik weer eens ruzic had met de computer of aanverwante apparatuur, maar het meest zal ik toch je danscapriolen missen. Verder wil ik Ewald, Jos, Susanne, Wendy, Marijke, Liesje en alle andere AIO's en postdocs bedanken voor de prof-analyses, steun in slechte tijden maar vooral voor de gezelligheid. Alle andere collega's binnen de vakgroep farmacologic, bedankt voor de plezicrige werksfeer.

De cardio's van pathologie onder leiding van Mat kunnen in dit dankwoord natuurlijk niet ontbreken, de nauwe samenwerking die er tussen de pathologie en farmacologie bestaat levert nict alleen goede experimentele resultaten op, tevens houdt het je op een plezicrige manier geinformeerd over zaken die slechts indirect met werk te maken hebben.

Uiteraard wil ik ook diegenen met wie ik buiten Maastricht heb samengewerkt bedanken. Ik heb goede herinneringen aan mijn verblijf in Leiden bij de groep van Prof. Dr. Gittenberger de Groot. Adri, bedankt voor de lecrzame discussies, jouw enthousiasme voor het onderzoek werkt heel motiverend! Verder natuurlijk dank aan alle medewerkers die me daar met de experimenten geholpen hebben. I would like to thank Dr. Eftekhari and Prof. Dr. Hoebeke from Strasbourg for their work on the frizzled 2 antibody and thcir hospitality during our short stay in France (still missing the room service). 
Tevens wil ik de diegenen bedanken dic ervoor gezorgd hebben dat het procfschrift eruit ziet zoals het hicr ligt, Ine bedankt voor de lay-out en oma bedankt voor zoveel meer dan het ontwerp van de kaft.

Mijn paranimfen, niet voor niets uitgekozen: Esther, zonder jou had ik niet eens over het bestaan van deze AIO baan geweten, een vriendin die inhoudelijk ook nog weet waar ik mee bezig ben en de mensen op het werk kent, is heel handig, maar je bent en blijft een vriendin omdat je de dingen op z'n Esthers doet en zegt. Karin, mijn andere paranimf, het aantal keren dat ik de afgelopen jaren op jou kon terugvallen, is ontelbaar. Ik ben blij dat je terug naar Maastricht bent gekomen, toen ik hicr AIO werd! Gijs, jou wilde ik toch ook nog even apart noemen, als je an het promoveren bent is het heel verhelderend iemand in je naaste omgeving te hebben die niets met onderzoek te maken heeft en de dingen met een nuchtere blik kan bekijken. Bedankt dat jullie deur altijd open staat!! Catalina, admiration for the warm and strong person you are, thanks for your support!!!

Tenslotte wil ik mijn ouders bedanken voor de vanzelfsprekendheid waarmee ze altijd weer klaar staan en hun onvoorwaardelijke steun bij alles wat ik doe.

Marielle 


\section{Curriculum Vitae}

$\begin{array}{ll}\text { Born } & 21 \text { februari } 1970 \\ \text { Place of Birth } & \text { Dordrecht }\end{array}$

\section{Education}

$1982-1988 \quad$ Atheneum, Titus Brandsmacollege, Dordrecht.

1988 - 1991 Propedeuse degree in Human Nutrition, Agricultural University of Wageningen, Wageningen.

1991 - 1994 MSc in Health Sciences, Maastricht University, Maastricht.

\section{Research Positions}

October 1994 - Research fellow in population genetics.

November 1995 Laboratory of Human Genetics, University of Pavia, Italy. (head: Prof. Dr. A. S. Santachiara-Benerecetti)

January 1996 - Research fellow on the screening for mutations in the January 1997 Neurofibromatosis I gene.

Service de Biochimie, Hôpital Henri Mondor, Créteil Cedex, France. (head: Prof. Dr. M. Goossens)

January 1997 - PhD student.

May 2001 Department of Pharmacology and Toxicology, Maastricht. University, Maastricht

(head: Prof. Dr. J.F.M. Smits)

present Postdoctoral research fellow.

Department of Immunology, University of Utrecht, Utrecht. (head: Prof. Dr. H. Clevers)

\section{Publications}

van Gijn ME, Snel F, Cleutjens JPM, Smits JFM, Blankesteijn WM. Overexpression of components of the wnt-frizzled cascade results in apoptotic cell death, mediated by $\beta$-catenin. Exp Cell Res 2001 265:46-53. 
Marielle. E. van Gijn, W. Matthijs Blankesteijn, Jos F.M. Smits, Beerend Hierck and Adriana C. Gittenberger-de Groot. Frizzled 2 is transiently expressed in Neural Crest containing Areas during Development of the Heart and Great Arteries in the Mouse. Anat Embryol. 2001 203:185-192

W. Matthijs Blankesteijn, Marielle E. van Gijn, Yvonne P.G. Essers-Janssen, Mat J.A.P. Daemen and Jos F.M. Smits. Beta-Catenin, an inducer of uncontrolled cell proliferation and migration in malignancies, is localized in the cytoplasm of vascular endothelium during neovascularization after myocardial infarction. $\mathrm{Am} J$ Patbol. 2000 Sep;157(3):877-83.

Boulandet EG, Pantel J, Cazeneuve C, van Gijn ME, Vidaud D, Lemay S, Martin J, Zeller J, Revuz J, Goossens M, Amselem S, Wolkenstein P. NF1 gene analysis focused on $\mathrm{CpG}$-rich exons in a cohort of 93 patients with neurofibromatosis type 1. Hum Mutat. 2000 Sep;16(3):274-5

Quintana-Murci L, Semino O, Poloni ES, Liu A, van Gijn M, Passarino G, Brega A, Nasidze IS, Maccioni L, Cossu G, al-Zahery N, Kidd JR, Kidd KK, SantachiaraBenereceti AS.Y-chromosome specific YCAII, DYS19 and YAP polymorphisms in human populations: a comparative study. Ann Hmm Genet. 1999 Mar;63 (Pt 2):153-66

\section{Abstracts}

Marielle E. van Gijn, Frans Snel, Jos F.M. Smits, W. Matthijs Blankesteijn. Induction of apoptosis by components of the Wnt-frizzled cascade in vitro. Hypertension 2000; Vol 34, No 4: 677

Marielle E. van Gijn, W. Matthijs Blankesteijn, Yvonne P.G. Essers-Janssen, Mat J.A.P. Daemen, Jos F.M. Smits. $\beta$-Catenin and Dishevelled 1 are expressed in Endothelial Cells in the Border Zone of the Infarcted Area after Myocardial Infarction. Hypertension 1999; Vol 34, No 4: 702

Marielle E. van Gijn, W. Matthijs Blankesteijn, Jos F.M. Smits, Adriana C. Gittenberger-de Groot. Frizzled 2 Expression during the Development of the Thoracic Arterial System and the Heart in the Mouse. Circulation 1998; Vol 98, No 17: 1-604

Marielle E. van Gijn, W. Matthijs Blankesteijn, Yvonne P.G. Essers-Janssen, Mat J.A.P. Daemen, Jos F.M. Smits. Expression of Homologues of the Dishevelled Tissue Polarity Gene in the Infarct Area after Myocardial Infarction. Hypertension 1997; Vol 30, No 4:1002 